\title{
An Independent Assessment of Air Force Compliance with Headquarters Reduction Goals
}

John A. Ausink, Kristin F. Lynch, James A. Leftwich, H. G. Massey, David W. George, JJ Roomsburg, Robert G. DeFeo, Robert S. Tripp 
Library of Congress Cataloging-in-Publication Data is available for this publication.

ISBN: 978-0-8330-9428-5

Published by the RAND Corporation, Santa Monica, Calif.

(C) Copyright 2016 RAND Corporation

RAND $^{\circledR}$ is a registered trademark.

\section{Limited Print and Electronic Distribution Rights}

This document and trademark(s) contained herein are protected by law. This representation of RAND intellectual property is provided for noncommercial use only. Unauthorized posting of this publication online is prohibited. Permission is given to duplicate this document for personal use only, as long as it is unaltered and complete. Permission is required from RAND to reproduce, or reuse in another form, any of its research documents for commercial use. For information on reprint and linking permissions, please visit www.rand.org/pubs/permissions.html.

The RAND Corporation is a research organization that develops solutions to public policy challenges to help make communities throughout the world safer and more secure, healthier and more prosperous. RAND is nonprofit, nonpartisan, and committed to the public interest.

RAND's publications do not necessarily reflect the opinions of its research clients and sponsors.

\section{Support RAND}

Make a tax-deductible charitable contribution at www.rand.org/giving/contribute

www.rand.org 


\section{Preface}

Congress has expressed concerns about the size and growth of staff elements in U.S. Department of Defense and military headquarters. In the fiscal year 2014 National Defense Authorization Act, Congress instructed the Secretary of Defense to develop a plan for streamlining those headquarters. In both anticipation of and response to that, the Secretary directed two separate reductions, one in 2013 and one in 2015. The first called for a 20-percent cut in the budgets of management headquarters by 2019, and the second called for a 25-percent reduction by 2020. The Air Force asked the RAND Corporation to assess the Air Force's effort in reducing its major headquarters by independently verifying the headquarters reductions taken, comparing the Air Force's methodology and approach with best practices, and identifying the degree to which opportunities exist for future reductions. This report, conducted within the Manpower, Personnel, and Training Program of RAND Project AIR FORCE, responds to those requests.

\section{RAND Project AIR FORCE}

RAND Project AIR FORCE (PAF), a division of the RAND Corporation, is the U.S. Air Force's federally funded research and development center for studies and analyses. PAF provides the Air Force with independent analyses of policy alternatives affecting the development, employment, combat readiness, and support of current and future air, space, and cyber forces. Research is conducted in four programs: Force Modernization and Employment; Manpower, Personnel, and Training; Resource Management; and Strategy and Doctrine. The research reported here was prepared under contract FA7014-06-C-0001.

Additional information about PAF is available on our website:

http://www.rand.org/paf/

This report documents work originally shared with the U.S. Air Force in February 2016. The draft report, issued on January 19, 2016, was reviewed by formal peer reviewers and U.S. Air Force subject-matter experts. 



\section{Table of Contents}

Preface

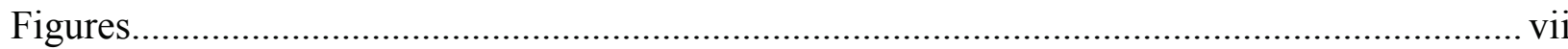

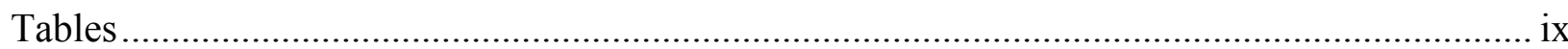

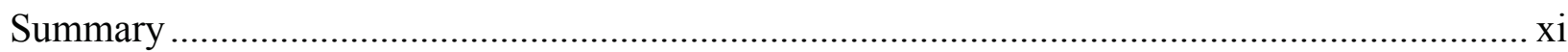

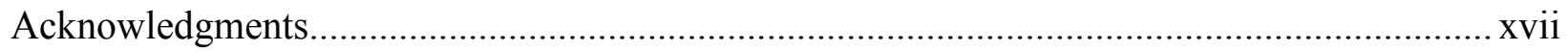

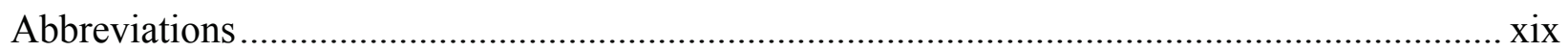

Chapter One: Background, Purpose, and Analytic Approach ................................................ 1

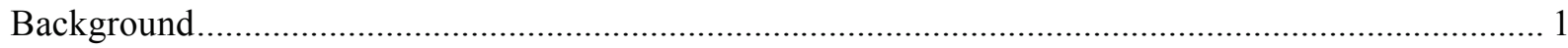

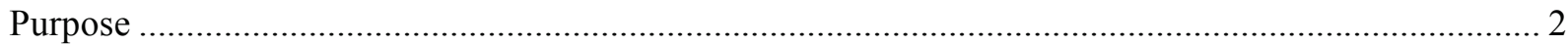

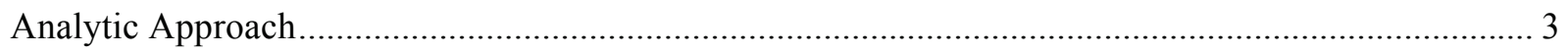

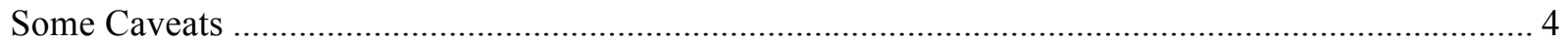

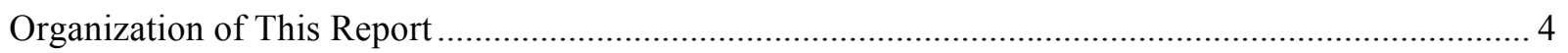

Chapter Two: Assessment of Air Force Headquarters Reductions …...................................... 5

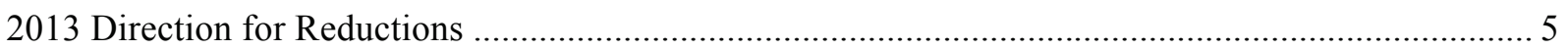

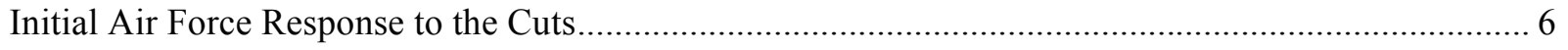

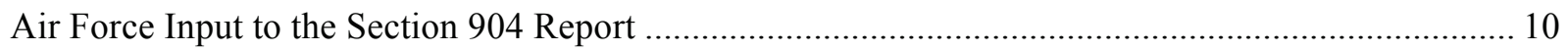

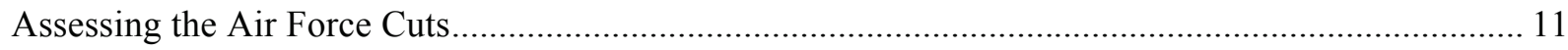

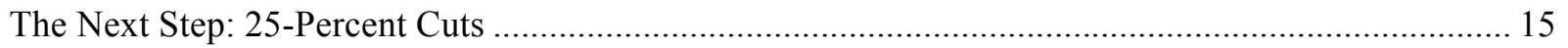

Chapter Three: Comparing Practices from Literature and Industry with the Services'

Approach to Streamlining and Delayering .................................................................... 17

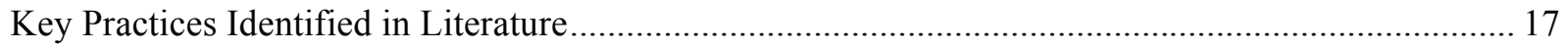

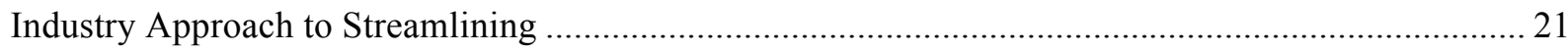

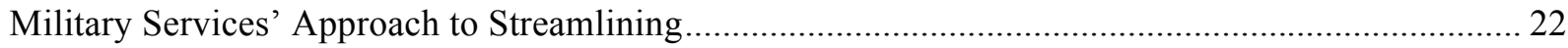

Summary Findings from Comparing the Air Force's Approach with Sound Practices ....................... 25

Chapter Four: Opportunities for Additional Savings and Staff Reductions ............................. 29

Chapter Five: Conclusions and Recommendations .......................................................... 33

Appendix A: Detailed Discussion of Reductions and Data ................................................... 35

Appendix B: Delayering in the Air Staff and Secretariat .................................................. 47

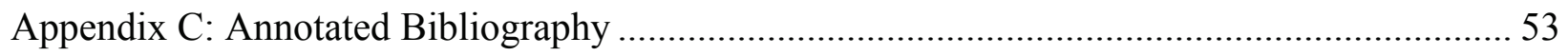

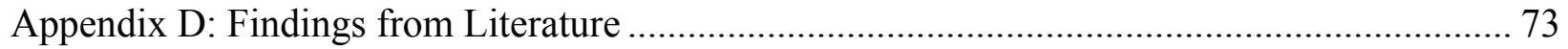

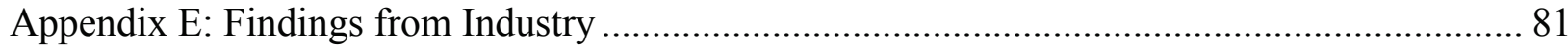

Appendix F: Navy and Army Approaches to Reductions ................................................ 87

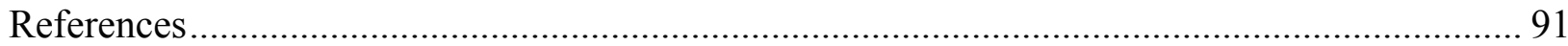





\section{Figures}

Figure B.1. Span of Control, by Number of Subordinate Organizational Elements

Figure B.2. Span of Control, by Number of Personnel in the Lowest-Level Organizational

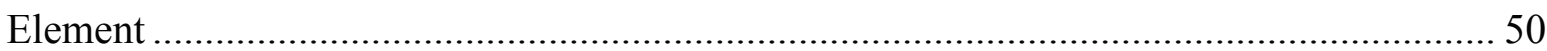

Figure B.3. Span of Control, by Number of Personnel and Organizations ............................... 51

Figure D.1. Mintzberg's Elements of an Organization.......................................................... 74

Figure D.2. A Divisionalized Form Comprising Different Types of Subordinate Divisions ....... 76 



\section{Tables}

Table S.1. Air Force Reductions in End Strength and Funding.............................................. xii

Table S.2. Key Focuses from Theory and Practice Literature...............................................xiii

Table 1.1. Reduction Initiatives and Purposes ................................................................... 2

Table 2.1. Air Force Reductions in End Strength and Funding.............................................. 11

Table 2.2. Net Change in Air Force Management Headquarters Authorizations ....................... 12

Table 3.1. Key Focuses from Theory and Practice Literature ............................................... 18

Table A.1. Timeline of Headquarters Reduction Documentation .......................................... 36

Table A.2. Status of Reductions in July 2014 .................................................................... 38

Table A.3. Detailed Changes in PEC 98-Coded Authorizations.............................................. 40

Table A.4. Civilian and Military Breakdown of End-Strength and Funding Reductions............ 44

Table E.1. Interviewee Lessons Learned ................................................................................. 84

Table E.2. Interviewee Common Practices .......................................................................... 84 



\section{Summary}

In recent years, Congress has voiced concerns over the size and growth of staff elements in U.S. Department of Defense (DoD) and military headquarters. The fiscal year (FY) 2014 National Defense Authorization Act instructed the Secretary of Defense to develop a plan for streamlining those headquarters. In anticipation of such an order in 2013, Secretary of Defense Chuck Hagel directed a 20-percent reduction in headquarters spending across DoD, and in 2015, Deputy Secretary of Defense Robert O. Work directed a 25-percent reduction across all appropriations funding for major DoD headquarters activities. Although the direction pertained to funding, all agencies were encouraged to reduce personnel authorizations. Any reductions taken to achieve the initial 20-percent cut could apply to the subsequently directed cut.

The Air Force asked RAND Project AIR FORCE to analyze several issues related to the headquarters reductions. Specifically, it asked RAND researchers to

- determine whether the 20-percent reduction in management headquarters planned for FY 2015 had been achieved

- compare the Air Force's methodology and approach with government and industry best practices

- identify opportunities for additional savings and staff reduction

- evaluate reductions already taken in management headquarters against the new baseline consistent with the FY 2016 National Defense Authorization Act's definition of major headquarters activities (MHA).

Our analysis addressed each of these tasks, except the last one. We could not evaluate the reductions against the new baseline because, as of January 2016, DoD had not yet settled on the organizations that should be included in the new baseline for MHA.

\section{What We Found}

\section{0-Percent Reductions in Air Force Management Headquarters}

The Air Force based its reduction target on the FY 2018 management headquarters end strength as stated in the FY 2014 President's budget. Analyzing those authorizations, the Air Force determined that it needed to reduce headquarters authorizations by about 3,000. It achieved those reductions by identifying efficiencies, consolidations, and transfers. These changes were made with an eye to achieving net reductions in personnel and funding. Table S.1 charts those changes as originally presented by the Air Force. It shows that, compared with the FY 2018 authorized end strength of 13,847, the FY 2016 end strength of 10,869 represented a 
management headquarters reduction of 21.5 percent. ${ }^{1}$ Compared with the FY 2018 baseline, the FY 2016 budget for management headquarters authorized end strength was lower by $\$ 176$ million, or 21 percent. ${ }^{2}$ These reductions came from full-time government positions in the activeduty Air Force and the Air Reserve Component that had a program element code ending in 98, which designates management headquarters and headquarters support positions. RAND analysis indicates that the Air Force did comply with direction and reduced its headquarters by 20 percent, both in personnel end strength and in funding.

Table S.1. Air Force Reductions in End Strength and Funding

\begin{tabular}{|c|c|c|c|c|}
\hline & \multicolumn{3}{|c|}{ End Strength } & \multirow[b]{2}{*}{ Funding } \\
\hline & Civilian & Military & Total & \\
\hline $\begin{array}{l}\text { Baseline } \\
\text { (FY } 2018 \text { column of FY } 2014 \\
\text { President's budget) }\end{array}$ & 6,253 & 7,594 & 13,847 & \$854 million \\
\hline $\begin{array}{l}\text { Air Force position in the FY } 2015 \\
\text { President's budget }\end{array}$ & 5,463 & 5,406 & 10,869 & $\$ 678$ million \\
\hline Reduction & $\begin{array}{r}790 \\
(13 \%)\end{array}$ & $\begin{array}{l}2,188 \\
(29 \%)\end{array}$ & $\begin{array}{r}2,978 \\
(21.5 \%)\end{array}$ & $\begin{array}{c}\$ 176 \text { million } \\
(21 \%)\end{array}$ \\
\hline
\end{tabular}

SOURCE: DoD, Plan for Streamlining DoD Management Headquarters: Section 904 Initial and Status Report to Congress, Washington, D.C., May 14, 2015.

\section{Air Force Approach Compared with Sound Practices}

The literature describing organizational design and the methods for restructuring is vast, so we began our analysis by reviewing literature on topics that relate to the fundamentals of organizational design, as well as to delayering and streamlining organizations. We view organizational design, business process reengineering, consulting practices used to delayer organizations, and management best practices as particularly important to the topic of streamlining organizations, so we call out lessons from the literature in these areas. ${ }^{3}$ Theory and practice offer different perspectives on streamlining and organizational design. The theory tends to provide a good perspective on the elements of organizations, their purpose, and factors to consider when structuring an organization to most effectively and efficiently deliver the work product. The practice literature focuses on methods and approaches for conducting organizational change or restructuring. Neither theory nor practice provides a solution for the

\footnotetext{
1 RAND's independent analysis showed a slightly higher FY 2016 end strength of 10,878, which still represents a 21-percent reduction.

2 RAND's independent analysis showed the FY 2016 budget was $\$ 177$ million lower. As new ceilings, the FY 2016 authorization and funding levels remain through FY 2018.

${ }^{3}$ See Appendix $\mathrm{C}$ for an annotated bibliography of the literature reviewed during the course of this analysis.
} 
"correct" organizational design; instead, both illuminate the many factors that must be considered in the design and implementation of a structure. Table S.2 summarizes the key focuses from each genre of our review.

Table S.2. Key Focuses from Theory and Practice Literature

\begin{tabular}{ll}
\hline Genre & \multicolumn{1}{c}{ Key Focuses } \\
\hline $\begin{array}{l}\text { Academic organizational } \\
\text { design }\end{array}$ & $\begin{array}{l}\text { Organization function; importance of headquarters in shaping } \\
\text { business units; importance of developing work regulations to } \\
\text { harmonize mission accomplishment }\end{array}$ \\
$\begin{array}{l}\text { Business process } \\
\text { reengineering }\end{array}$ & $\begin{array}{l}\text { Organizations' need to focus work processes on goal achievement } \\
\text { and reduce work that is not value added }\end{array}$ \\
Management practice & $\begin{array}{l}\text { Examples of how various businesses are organized and } \\
\text { differences among industry groups; rationale for differences }\end{array}$ \\
Consulting literature & Methods for approaching reorganizations \\
Military literature & Approaches for process or organizational design \\
\hline
\end{tabular}

Several key points emerge from this review. One is the need to focus on strategic goals. This focus is a prerequisite to ensure that organizational, process, or other changes do not lead to an inefficient or ineffective organizational structure or to broken or inefficient processes. Key factors requiring consideration include the division of labor, the design of formal reporting relationships, and the design of coordinating mechanisms.

As part of our analysis, we interviewed personnel from six companies regarding their recent reorganization experience to gain industry insights into reorganization, streamlining, and process reengineering. We found that company reorganization approaches varied, and different objectives guided headquarters reshaping. But even for those firms that did not undertake specific targeted management headquarters analyses, all reorganizations changed headquarters function and size based on the process changes and the reduction and realignment of staff made in the other parts of the organization. Common responses to questions we posed about sound practices used by their company included references to the following: ${ }^{4}$

- a clear strategy and active executive leadership

- effective communication plans and change management programs

- an inclusive reorganization strategy team to lead the effort

- substantial upfront strategy planning.

${ }^{4}$ One of the goals of this research was to compare Air Force practices with industry best practices. However, through the course of this analysis, we discovered that there are no best practices that apply to all organizations or types of industry. Therefore, we identify sound practices, which can be applied across business goals and organizational structures. 
Companies also placed special emphasis on specific targets, such as analyzing span of control and organizational layers; reducing redundancies; identifying best practices of each merged entity; and realigning into a combined entity.

Armed with the information from the literature, we then reviewed recent changes undertaken by the military services, specifically the Army, Navy, and Air Force. What we found was that, although each service employed different approaches to restructuring its organization, all embodied some of the sound practices we had identified in the literature and our interviews. With respect to the Air Force effort to achieve its targeted reductions, we found that the approach used aligned with those practices identified in literature as fundamentally sound. Some of those practices included combining like functions and centralizing decision rights, such as through the formation of the Air Force Installation and Mission Support Center, 25th Air Force, and Air Force Personnel Center reorganization. Acquisition process improvements and organizational realignment strengthened ties between strategic planning and Program Objective Memorandum activities, tightened lateral linkages, reduced redundancies, and improved process coordination. The Air Force adjusted its hierarchy, incorporating appropriate span of control practices by consolidating the Air Force Civil Engineer Center, Air Force Security Forces Center, Air Force Installation Contracting Agency, Air Force Financial Services Center, Air Force Personnel Center services, and Financial Management Center of Expertise under the Air Force Installation and Mission Support Center. The organizational design principles and process reengineering that the Air Force used yielded approximately 60 percent of the required reductions. Task analyses were used in targeted apportionments to the major commands (MAJCOMs) for the additional approximately 40 percent of the required reductions. MAJCOMs focused on eliminating lowvalue tasks, and some included risk assessment in their analyses.

\section{Opportunities for Additional Savings and Staff Reductions}

The Air Force has undergone multiple force reductions in recent years, including the ones described in this report. In 2005, the active-duty end strength was lowered by about 40,000; a 2011 resource management decision effectively eliminated some 16,500 civilian authorizations, about 25 percent of which were taken from management positions at headquarters, field operating agencies, and installations; and, most recently, the 20-percent cut that was directed in 2013. The cuts have been deep and have affected all headquarters and operations. Process changes, realignments, and major structural changes have all been implemented to achieve these cuts.

The Air Force is currently analyzing headquarters processes and staffing distributions made as a result of the reductions taken to date. As part of the initial cuts taken to meet the targeted apportionment, MAJCOMs reviewed, by each organizational element, those activities they would no longer be performing and identified the risks associated with not performing those activities. Since taking the cuts, they have been conducting in-depth resource allocation reviews

to determine where resources need to be reallocated among or within directorates. The Air Force 
is also reviewing workloads to determine the effects cuts may have on the mission. It may need to reverse some of the cuts or realign personnel to meet its strategic goals.

The upshot is that the low-hanging fruit appears to have been harvested, and there do not appear to be obvious targets in major headquarters for additional reductions. The cuts thus far have had some negative effects, which the MAJCOMs and headquarters are analyzing. However, they have also had some positive effects, such as improved processes and consolidations of like functions.

Looking to the future, organizational design principles may identify targets of opportunity for future Air Force reductions. Consolidating like missions and using a matrix management approach to achieve economies of scale may warrant further evaluation. For example, combining the Space and Missile Center and Air Force Life Cycle Management Center, consolidating support functions across headquarters organizations (e.g., having a single public affairs office service Headquarters Air Force and all MAJCOMs), and combining Secretary of the Air Force and Headquarters Air Force staffs (such as personnel and logistics) may all hold potential for manpower savings while still hewing to sound organizational and management practices.

Whatever the Air Force does in the future should follow the principles identified here for any further reductions. Headquarters Air Force needs to specify the strategic direction and approach to be used in the process. The Headquarters Air Force and MAJCOM continuous process groups could facilitate the implementation of the desired approach. Whatever the approach may be, detailed process reengineering and analysis of options take time. A senior leadership governance council should oversee the process, and the process needs to be transparent and communicated widely.

\section{Conclusions and Recommendations}

A key part of this analysis was determining whether the Air Force had indeed taken reductions meeting the intent of the 2013 Secretary of Defense management headquarters reductions mandate. As indicated in Table S.1, the Air Force did achieve the 20-percent reduction in funding and authorizations, as was reported in the Section 904 Report, when a technical count of program element code 98 positions is made. Furthermore, all MAJCOMs contributed to the reductions.

Additional analysis focused on sound practices, methodologies used to achieve headquarters management function reductions, and opportunities for future reductions. Industry practices emphasize several key considerations that should be included in any future MHA reduction initiatives. These considerations include early and regular engagement of a broad cross-section of stakeholders, consistency of approach and methods for long-term accountability and traceability, and simple messaging to aid the acceptability of reductions.

The Air Force's approach to reducing its headquarters management functions included many sound practices, such as identifying improved business processes that streamline information 
flow and eliminate work, eliminating or combining redundant organizations, and ensuring that work is done at an appropriate organizational level.

Our reviews and interviews produced many factors to consider; however, those factors all hinge on maintaining focus on the organization's strategic goals to ensure that organizational, process, or other changes do not lead to an inefficient or ineffective process or organizational structure. Although sound practices were employed in meeting the management headquarters reductions in the Air Force, they were not applied consistently. Different MAJCOMs employed different strategies with differing results.

While additional opportunities to reduce MHA may exist, no areas stand out as immediate targets. Process reengineering and other efficiencies identified during previous reduction efforts can provide targets for future MHA reductions. However, it will take strategic direction, time, and analyses from the Air Force to accomplish them. 


\section{Acknowledgments}

Numerous people both within and outside the Air Force provided valuable assistance to and support of our work. They are listed here with their rank and position as of the time of this research. We thank Marilyn Thomas, Deputy Under Secretary of the Air Force for Management (SAF/MG), for sponsoring this work. We also thank Brig Gen Richard Murphy, AF/A1M; Paul Dunbar, SAF/MG; Anne Graham, SAF/AAR; Darryl Hickman, AF/A9; and their staffs for their time and support during this research. Specifically, we would like to thank William Booth, Col Jill Higgins, Eric Halmon, James Johnson, Lt Col Patrick Miller, and Michael O'Keefe, all from AF/A1, as well as Col James Peccia, SAF/FM.

At Air Combat Command (ACC), we would like to thank Maj Gen Jerry Harris, ACC/CV; Matthew Cornell; Norma Inabinet; and Chari Wilhelm, all from ACC/A1. At Air Force Materiel Command (AFMC), we thank Maj Gen Warren Berry, AFMC/CV; Michael Gill, AFMC/CA; Lynn Eviston, AFMC AFLCMC/XP; and Donna McMannes, AFMC/A1M. At Air Mobility Command (AMC), we thank Maj Gen Rowayne Schatz, AMC/CV; and Gregg Clark and Gregory Mondloh, AMC/A1. At Pacific Air Forces (PACAF), we thank Maj Gen Mark Dillon, PACAF/CV; Timothy Cashdollar, PACAF/CS; and David Crabtree, PACAF/A1M. At U.S. Air Forces in Europe (USAFE), we thank Maj Gen Timothy Zadalis, USAFE/CV; Vincent Gasaway, USAFE/A1; and Col William Lewis, USAFE/AFAFRICA/CS. And finally, we thank the Army Office of the Deputy Chief of Staff for Personnel (G-1) and the Office of Naval Operations, Programming division (N-80) for sharing their recent staffing reduction efforts with us.

We are grateful to Jordan Wescott, SAF/MG; Andrew Bartosovsky, SAF/AARM; and Charlene Xander, AFMC/A1M for their exceptional assistance in providing important background documents for our research.

At the RAND Corporation, we are grateful for the support given by Ted Harshberger and Raymond Conley in shaping the analysis. We thank Nancy Moore and Katherine Pfrommer for

their help with industry interviews and Anita Szafran for her in-depth literature review. We also thank John Drew for his comments and review of this work. We would especially like to thank Natalie Crawford, Al Robbert, and Cynthia Cook for their thorough reviews of this analysis. Their reviews helped shape it into its final, improved form.

Responsibility for the content of the document, analyses, and conclusions lies solely with the authors. 



\section{Abbreviations}

ABIDES

ACS

AF

AFIMSC

AFLC

AFLCMC

AFMC

AFPC

DoD

DOTMLPF

FOA

FY

FYDP

HAF

ISR

MAJCOM

MHA

NAF

NDAA

PB

PEC

RMD

SAF

UMD

VCSAF
Automated Budget Interactive Data Environment System

agile combat support

Air Staff

Air Force Installation and Mission Support Center

Air Force Logistics Command

Air Force Life Cycle Management Center

Air Force Materiel Command

Air Force Personnel Center

U.S. Department of Defense

doctrine, organization, training, materiel, leadership and education, personnel, and facilities

field operating agency

fiscal year

Future Years Defense Program

Headquarters Air Force

intelligence, surveillance, and reconnaissance

major command

major headquarters activities

numbered Air Force

National Defense Authorization Act

President's budget

program element code

Resource Management Decision

Secretary of the Air Force

unit manpower document

Vice Chief of Staff of the Air Force 



\section{Chapter One: Background, Purpose, and Analytic Approach}

\section{Background}

The U.S. Department of Defense (DoD) is one of the world's largest employers, with more than 1 million men and women on active duty and hundreds of thousands of civilian personnel. To control costs, the government has implemented several initiatives to adjust personnel levels in $\mathrm{DoD}$, to reduce spending outright, to use personnel cost savings to finance other DoD purposes, and to streamline management.

For example, the Air Force issued Program Budget Directive 720 to reduce tens of thousands of personnel authorizations in order to recapitalize aircraft and pay for other modernization programs. In 2009, assuming that it could decrease costs while still maintaining capability by shifting work from contractors to government civilians, DoD decreased funding for support service contracts and increased funding for new civilian authorizations across DoD components. According to the U.S. Government Accountability Office, DoD

assumed a 40 percent savings from the in-sourcing actions, so that roughly 60 percent of the original funding for contracted services went toward new civilian authorizations, while the remainder was retained by the Comptroller as savings available for other purposes. Thus, DOD components were required to either find savings under in-sourcing or reduce the functions they performed, or both. ${ }^{1}$

This approach was effectively undone by the Budget Control Act of 2011 and the resulting DoD Resource Management Decision (RMD) 703A2, which froze, through 2018, civilian hiring levels to those of fiscal year (FY) 2010. In effect, this cut manpower by reducing funding for contractors, yet at the same time restricting the hiring of government civilians to perform the work.

Recent actions related to DoD personnel have focused on funding for headquarters activities. ${ }^{2}$ In 2013, Secretary of Defense Chuck Hagel directed a 20-percent cut in headquarters spending across DoD. Later that year, Section 904 of the FY 2014 National Defense Authorization Act (NDAA) directed the Secretary of Defense to develop a plan for streamlining DoD management headquarters (to include changing or reducing staff sizes). And in 2015, Deputy Secretary of Defense Robert O. Work directed a 25-percent reduction across all

\footnotetext{
${ }^{1}$ U.S. Government Accountability Office, DoD Needs to Better Oversee In-Sourcing Data and Align In-Sourcing Efforts with Strategic Workforce Plans, Washington, D.C., GAO-12-319, February 2012.

${ }^{2}$ As discussed in Chapter Two, which organizations and positions should be included when determining the funding and personnel involved in headquarters activities can be a matter of dispute and is the reason the DoD Deputy Chief Management Officer worked with staffs in 2015 to develop a comprehensive definition of major DoD headquarters activities.
} 
appropriations funding for major DoD headquarters activities. These decisions have led to discussions about which organizations and personnel should be included when accounting for major headquarters activities (MHA), which baseline budgets and personnel counts should be used when determining which cuts are required, how the reductions should be calculated, and how cuts made to satisfy the 2013-directed 20-percent reductions should be accounted for when determining how the new 25-percent cuts will be made.

Table 1.1 lists several of the government's spending reduction initiatives since 2005.

Table 1.1. Reduction Initiatives and Purposes

\begin{tabular}{lll}
\hline Year & \multicolumn{1}{c}{ Initiative } & \multicolumn{1}{c}{ Purpose } \\
\hline 2005 & $\begin{array}{l}\text { Program Budget Directive 720 (Air } \\
\text { Force) }\end{array}$ & $\begin{array}{l}\text { Reduced total active Air Force by approximately 40,000 personnel } \\
\text { to finance aircraft recapitalization and modernization programs. }\end{array}$ \\
2009 & $\begin{array}{l}\text { RMD } 802 \text { (Office of the Secretary of } \\
\text { Defense) }\end{array}$ & $\begin{array}{l}\text { Reduced contractor funding by insourcing or converting contractor } \\
\text { workforce to the federal civilian workforce. The goal was to reduce } \\
\text { the contractor workforce to FY 2000 levels by FY 2010. }\end{array}$ \\
2011 & $\begin{array}{l}\text { Budget Control Act (Public Law 112- } \\
\text { 25) and RMD 703A2 }\end{array}$ & $\begin{array}{l}\text { Directed components to freeze civilian full-time equivalents for FY } \\
\text { 2011 through FY 2013 (and later extended through FY 2018) to } \\
\text { the levels budgeted in FY 2010. }\end{array}$ \\
2013 & Deputy Secretary of Defense Memo & $\begin{array}{l}\text { Required a 20-percent cut in management headquarters spending } \\
\text { throughout DoD. } \\
\text { Required the Secretary of Defense to develop a plan for } \\
\text { streamlining DoD management headquarters by changing or } \\
\text { reducing staff sizes, eliminating tiers of management, cutting } \\
\text { functions, and consolidating duplicative programs and offices. }\end{array}$ \\
& Section 904 of the FY 2014 NDAA & $\begin{array}{l}\text { Required a 25-percent reduction across all appropriations for DoD } \\
\text { MHA. }\end{array}$ \\
\hline
\end{tabular}

\section{Purpose}

While the 20-percent headquarters spending cuts directed by Secretary Hagel in 2013 could occur over a five-year period, the Air Force elected to make several major organizational changes that, by its estimation, achieved the goal by the end of FY 2015. Concern about the effect of new cuts on headquarters organizations led the Deputy Chief Management Officer of the Secretary of the Air Force (also the Director of Business Transformation) to ask RAND Project AIR FORCE to analyze several issues related to mandated headquarters reductions. ${ }^{3}$ Specifically, RAND researchers were asked to accomplish the following tasks:

\footnotetext{
${ }^{3}$ The Office of Business Transformation and Air Force Deputy Chief Management Officer function, Office of the Under Secretary of the Air Force was redesignated as the Deputy Under Secretary of the Air Force, Management, effective November 1, 2015 (Hailey Haux, "SAF/US(M) Becomes SAF/MG," Secretary of the Air Force Public Affairs Command Information, December 4, 2015).
} 
- Determine whether the 20-percent reduction in management headquarters planned for FY 2015 was achieved.

- Identify opportunities for additional savings and staff reduction. Given the data and information gleaned from the first task, assess whether opportunities for additional staff reductions or savings exist by looking for the following:

- Organizational redundancies: Consider whether duplication of functions occurs within Air Force management organizations.

- Process inefficiencies: Review and assess opportunities for streamlining processes.

- Duplication of work or processes: Review whether there is duplication of work or unnecessary work being done in Air Force management organizations.

- Excessive overhead: Perform comparative analysis of servicing or supervisor ratios to identify areas that need improvement while ensuring mission accomplishment and smart organizational constructs.

- Compare the methodology and approach used by the Air Force with government and industry best practices.

- Based on existing research, identify government and industry best practices that will assist the Air Force in reducing the size of and streamlining its management and operational headquarters.

- Evaluate reductions already taken in management headquarters against the new baseline consistent with the FY 2016 NDAA management headquarters definition of MHA.

\section{Analytic Approach}

Research for this project required various analytical approaches. To assess whether the Air Force had achieved its planned FY 2015 management headquarters reductions, we analyzed force and financial plan data in the Automated Budget Interactive Data Environment System (ABIDES) and unit manpower document (UMD) data in the Manpower Programming and Execution System. To learn about the methodology that the Air Force used for making cuts in headquarters authorizations, we reviewed Air Force and DoD instructions, read numerous background briefings and memoranda produced when the 20-percent cuts were being developed, and discussed with senior officials who participated in the process what actions the Air Force took.

To compare Air Force approaches with industry best practices, we reviewed academic literature on organizational structure and business literature on organizational change. We gave special emphasis to organizational design, process improvement, consulting practices, and sound management practices. We also discussed with several business leaders their experiences with changing headquarters structures.

To explore opportunities for additional headquarters savings and changes in staff sizes, we met with subject-matter experts to discuss objective measures of the effect of previous changes and how these measures could be used to determine whether process or personnel changes could lead to more-efficient operations. We also took advantage of earlier RAND research that 
proposed organizational changes that might still be useful in helping the Air Force consider how to deal with additional headquarters cuts that may be required.

\section{Some Caveats}

Several relevant issues fall outside the scope of this report because of the relatively short time available to complete our assessment. First, we did not conduct a comprehensive evaluation of the effects of the implemented reductions on the effectiveness and efficiency of the organizations involved. We could not compare the effects against the new FY 2016 NDAA baseline because, as of January 2016, DoD had not yet settled on the organizations that should be included in the new baseline for MHA. Nor were we able to assess the effects of the promising reengineering actions that were initiated. Finally, we were unable to develop a comprehensive set of streamlining recommendations. All these issues merit attention, and the Air Force should undertake them in the future.

\section{Organization of This Report}

In Chapter Two, we present our analysis and verification of the management headquarters reductions taken in response to the 2013 mandate. In Chapter Three, we identify sound practices from literature and industry and compare those practices with how the services approached their headquarters reductions. In Chapter Four, we evaluate opportunities for additional reductions, and in Chapter Five, we offer some conclusions and recommendations.

There are six appendixes to this document:

- A: Detailed Discussion of the Reductions and the Supporting Data

- B: Delayering in the Air Staff and Secretariat

- C: Annotated Bibliography

- D: Findings from Literature

- E: Findings from Industry

- F: Army and Navy Approaches to the Reductions. 


\section{Chapter Two: Assessment of Air Force Headquarters Reductions}

This chapter provides more background for the headquarters reductions directed by Secretary Hagel, describes Air Force efforts to streamline processes and organizations in ways that led to cost and personnel savings, and outlines how RAND researchers independently assessed reductions that were made by the Air Force by FY 2015. It also briefly addresses how the next round of MHA cuts will be accomplished.

The assessment is complicated because there are different contexts for discussing how the Air Force managed changes in headquarters and how these changes were reported. In particular, some organizational changes were not directly related to the headquarters reductions, and early reports of the effects of those changes included counts of positions that might not be considered technically in management headquarters activities. Later, in the initial report to Congress describing progress made in streamlining DoD, ${ }^{1}$ the Air Force used a technical definition of management headquarters positions (those designated by a specific funding code) to count the manpower and funding reductions it achieved by the end of FY 2015. While this approach showed that the Air Force had satisfied the 20-percent reduction goals in both funding and authorizations, the numbers reported differed from what had appeared in other documents.

Such differences are not unusual, but they could affect how much credit the Air Force receives for cuts it has already made. The details related to how reduction goals were determined and why different reporting requirements can lead to different numbers are presented in Appendix A. This chapter has fewer details, but it describes the background necessary to show how the Air Force achieved its 20-percent reduction goal.

\section{Direction for Reductions}

In a July 2013 memorandum, Deputy Secretary of Defense Ashton Carter announced that Secretary Hagel had directed a 20-percent cut in management headquarters spending throughout DoD. These cuts were to be made regardless of budget levels approved by Congress and were “designed to streamline DoD's management through efficiencies and elimination of lowerpriority activities." 2

The 20-percent cut applied to budgets, including salaries for government civilian personnel and costs associated with contract services, facilities, information technology, and other spending that supports headquarters functions. While the cut applied specifically to budgets, organizations

\footnotetext{
${ }^{1}$ DoD, Plan for Streamlining DoD Management Headquarters: Section 904 Initial and Status Report to Congress, Washington, D.C., May 14, 2015.

2 Ashton B. Carter, Deputy Secretary of Defense, “20\% Headquarters Reductions,” memorandum, July 31, 2013.
} 
were directed to strive to reduce authorized government civilian personnel on headquarters staffs by 20 percent as well. In addition, they were to seek to reduce headquarters military billets, even though military personnel are not considered part of headquarters budgets. The military reductions would not contribute to the dollar savings for the purpose of the 20-percent reductions.

Carter's memo specified that the cuts would be based on budgets specified in the Future Years Defense Program (FYDP) supporting the FY 2014 President's budget (PB) submission (which pertains to FY 2014 through FY 2018), extended to FY 2019 accounting for inflation. That is, the 20-percent cut would be based on the projected FY 2018 budget for management headquarters inflated by one year. Senior managers were directed to make cuts as soon as possible, but were expected to make them proportional - one-fifth of the cuts in FY 2015, onefifth in FY 2016, and so forth.

\section{Initial Air Force Response to the Cuts}

\section{Future Air Force Organization}

The Air Force, which had already been preparing for reductions based on Secretary Hagel's 2013 Strategic Choices and Management Review, ${ }^{3}$ used the direction for reductions as motivation to develop a streamlined management framework for the service. The idea was to restructure important business processes to improve efficiency and effectiveness, which would lead to organizational structure changes that would reduce personnel requirements. ${ }^{4}$

As outlined in a memo from the Acting Secretary and the Chief of Staff of the Air Force, ${ }^{5}$ the Future Air Force Organization initiative had three primary objectives:

\footnotetext{
3 According to Hagel, the Strategic Choices and Management Review was meant to help DoD "understand the impact of further budget reductions on the Department, and develop options to deal with these additional cuts" (Chuck Hagel, Secretary of Defense, "Statement on Strategic Choices and Management Review," July 31, 2013). The review had three objectives: to help DoD deal with sequestration if it continued into 2014; to inform fiscal guidance for the services for DoD's FY 2015 through FY 2019 budget plans; and to provide a fiscal basis for the upcoming Quadrennial Defense Review.

${ }^{4}$ Two documents are important here. The first is a memorandum from the Under Secretary of the Air Force Eric K. Fanning to the Deputy Secretary of Defense saying that in support of the Strategic Choices and Management Review, the Air Force believed it could absorb a 33-percent personnel reduction in Air Force-wide headquarters staffs "over the BCA [budget control act] period" (Eric K. Fanning, Under Secretary of the Air Force, "Staff Reduction, your Apr 23, 2013 Memo," memorandum for the Deputy Secretary of Defense, May 3, 2013). The second document is a memo from the Acting Secretary and Chief of Staff of the Air Force to the Vice Chief of Staff of the Air Force directing the development of a streamlined management framework (Eric K. Fanning, Acting Secretary of the Air Force, and Mark Welsh, Chief of Staff of the Air Force, "Future Air Force Organization," memorandum to Larry O. Spencer, Vice Chief of Staff of the Air Force, July 23, 2013).

${ }^{5}$ See Fanning and Welsh, 2013.
} 
1. Rebaseline Headquarters Air Force (HAF), major command (MAJCOM), and numbered Air Force (NAF) responsibilities in order to ensure that functions were not duplicated within or between management levels. MAJCOMs and NAFs should focus on operational mission execution, and field operating agencies (FOAs) that have operational functions should be realigned to MAJCOMs.

2. In accordance with the direction from the Secretary of Defense, reduce costs of headquarters management operations by 20 percent by $2019 .^{6}$

3. Promote closer integration of the active, reserve, and Air National Guard components by consolidating policy and supporting activities.

In preparing a plan to meet these objectives, the Vice Chief of Staff of the Air Force (VCSAF) was to focus on four areas: streamlining the programming, planning, budgeting, and execution process; streamlining the acquisition process; "rationalizing" the management of operations in cyber and intelligence, surveillance, and reconnaissance (ISR); and continuing the centralization of installation services using the process that began with the establishment of the Air Force Civil Engineering Center. The "guiding principles" for this plan were to

- identify improved business processes that streamline information flow and eliminate work

- eliminate or combine redundant organizations

- ensure work is done at an appropriate organizational level, and, where appropriate, realign execution tasks to line organizations, not overhead staff

- take reductions as early as possible

- maintain or improve remaining functions while reducing costs of management headquarters by at least 20 percent. $^{7}$

\section{Air Force Planning for Changes Associated with Reductions}

In the last six months of 2013, the Air Force made a concerted effort to develop proposals in accordance with the Future Air Force Organization guidance and the 20-percent reductions directed by the Secretary of Defense. At a December 2013 presentation to the Secretary of the Air Force, the Air Force Deputy Chief Management Officer noted that, among other things, several changes to headquarters organizations (such as those associated with personnel) had been designed; refinements to the programming, planning, budgeting, and execution process were being developed that would reduce staff requirements; eight study teams were examining approaches to streamlining acquisition; and a proposal for an installation support command was

\footnotetext{
${ }^{6}$ While the Future Air Force Organization memorandum is dated July 23, 2013 (Fanning and Welsh, 2013) —eight days before the 20 Percent Headquarters Reduction memorandum from Deputy Secretary Carter (Carter, 2013) - it is plain that the Air Force was aware that the latter memorandum was about to be released.

${ }^{7}$ U.S. Air Force, Future Air Force Organization: Headquarters Air Force (HAF), background paper prepared for a leadership forum with the Office of the Under Secretary of the Air Force, Management, April 10, 2014a.
} 
almost ready for review. ${ }^{8}$ These changes were expected to lead to a reduction of 3,361 headquarters authorizations and reduce costs in FY 2015 by more than $\$ 170$ million. ${ }^{9}$

Efforts to restructure processes to improve efficiency and effectiveness are evident in some of the documentation related to changes that were proposed. For example, a cross-functional team of representatives from various HAF offices, including the Air Staff (AF) and Secretary of the Air Force (SAF), as well as from MAJCOMs, produced a detailed white paper on change proposals to the programming, planning, budgeting, and execution process, ${ }^{10}$ and the Office of the Administrative Assistant to the Secretary of the Air Force (SAF/AA) managed analyses of headquarters processes and the manpower required to accomplish them. ${ }^{11}$

By May 2014, the Air Force Deputy Chief Management Officer was able to report that significant organizational changes had been made in several areas: ${ }^{12}$

- Installation management. A new Air Force Installation and Mission Support Center (AFIMSC) would be established under Air Force Materiel Command (AFMC) to eliminate redundant MAJCOM base support staffs. In addition to improving efficiency and effectiveness, this step would contribute to the desired 20-percent cost savings. This new organization would require 350 personnel authorizations for a new AFIMSC headquarters. ${ }^{13}$

- HAF. Numerous adjustments and reductions to the staff were made. The plans, policy, strategy, and requirements divisions within the Office of Operations, Plans, and Requirements (AF/A3/5) were moved into the A8 to create a new Office of Strategic Plans and Programs (A5/8), which will integrate strategic inputs and guidance. Overlapping human resource management functions between the Secretariat (the Office of Manpower and Reserve Affairs, SAF/MR) and the Air Staff (the Office of Manpower,

\footnotetext{
${ }^{8}$ David Tillotson, Future Air Force Organizational Structure Status Update, briefing slides, Air Force Deputy Chief Management Officer, December 2, 2013.

${ }^{9}$ Tillotson, 2013, slide 3. According to this presentation, the FY 2014 PB forecast for FY 2018 (which was the baseline for the 20-percent cuts directed by Secretary Hagel) showed 15,741 authorizations in major headquarters positions. Hence, the reduction of 3,361 authorizations represents a 21-percent cut. The briefing does not describe exactly how these authorizations were counted, but a November 6, 2015, email to the authors from Air Force staff notes that this "wedge" was the target the Air Force programmed into the FY 2015 Program Objective Memorandum as a result of the Strategic Choices and Management Review (U.S. Air Force AF/A1 staff, email correspondence with the authors, November 6, 2015). The \$170 million figure comes from a July 2014 memo (Larry O. Spencer, Vice Chief of Staff of the Air Force, "MAJCOM FY 2015 PB Headquarters Staff Billet Reduction," memorandum, July 9, 2014).

${ }^{10}$ U.S. Air Force, Planning, Programming, Budgeting and Execution: Process and Organization Whitepaper, draft, May 6, 2014b, not available to the general public.

${ }^{11}$ These analyses were similar to those done in response to RMD 703 cuts. RAND obtained examples of documents related to RMD 703 cuts at HAF, which showed that the approach used statistical analyses of relations between the size of a staff and the population it supports, existing manpower standards, reviews of workloads, and interviews to determine redundancies and possibilities for improved efficiency.

12 This is a partial list of changes made, based on U.S. Air Force, 2014b.

${ }^{13}$ All manpower for AFIMSC was to come from other MAJCOM staffs, which would be reduced by 1,273 . Of these, 350 authorizations would be transferred to AFIMSC headquarters, with a net reduction of 923 authorizations.
} 
Personnel, and Services, SAF/A1) were eliminated. Redundant acquisition functions between HAF and AFMC were eliminated.

- ISR. The Air Force Intelligence, Surveillance, and Reconnaissance Agency and other ISR activities would be consolidated in a new organization, the 25th Air Force, which would be aligned under Air Combat Command.

- FOAs. The Air Force redesignated the Air Force Weather Agency as a global weather wing tentatively assigned to Air Combat Command to better support the operational weather mission while eliminating a management layer.

Details of the formal implementation of the many organizational changes that resulted from the Future Air Force Organization initiative are described in a memorandum released by Under Secretary of the Air Force Fanning on October 3, 2014. ${ }^{14}$

\section{Reduction Status in July 2014 and Congressional Notification}

The modifications to headquarters, the creation of the AFIMSC, and realignments related to ISR and FOAs did result in reductions to positions in Air Force headquarters, but in July 2014 Air Force leadership realized that they were still 1,190 positions short of the goal of 3,361 reductions. Because the Air Force wanted to complete the changes by the end of FY $2015,{ }^{15}$ MAJCOMs were directed to make "targeted" reductions to make up the difference. ${ }^{16}$

Anticipating congressional interest in changes that might lead to the loss of jobs in states where headquarters were located, the Air Force prepared an official congressional notification about what was now called its "Management Headquarters Review." This notification, which was released July 11, 2014, showed reductions that totaled 2,725-3,459 for MAJCOMs and 734 for HAF and FOAs. ${ }^{17}$ A July 14, 2014, press release from the Air Force provided an overview of the changes made to reduce costs and manning, and also noted that the total reductions in

\footnotetext{
${ }^{14}$ Eric K. Fanning, Under Secretary of the Air Force, "Future Air Force Organization: Implementation of HAF Decisions," memorandum to all MAJCOMs, FOAs, and DRUs, October 3, 2014.

15 Author discussions with AF/A1 staff indicate that the 3,361 "wedge" was developed as part of the Strategic Choices and Management Review, and because the Air Force faced cuts related to the Budget Control Act of 2011, it "front-loaded" these reductions related to the Future Air Force Organization initiative (which included both management headquarters and non-management headquarters activities) in order to spare further reductions in weapon systems and personnel (U.S. Air Force AF/A1 staff, email correspondence with the authors, November 6, 2015). Thus, when initial Future Air Force Organization efforts fell short of the total reductions that were already programmed, remaining reductions had to be distributed among the MAJCOMs.

${ }^{16}$ Spencer, 2014. The memo lays out only the MAJCOM reductions specifically (totaling 2,725); it appears to assume that 636 cuts were made in other organizations to reach the original goal of 3,361 reductions. All of these numbers should be considered approximate.

${ }^{17}$ U.S. Air Force Office of Legislative Liaison, "Management Headquarters Review Congressional Notification," memorandum, July 11, 2014, not available to the general public. This notification referred to the 20-percent cuts required by Secretary Hagel, but it does not refer to the Future Air Force Organization memo. Instead, it ascribes cuts to a Management Headquarters Review, the establishment of the AFIMSC, and "other" cuts. Interestingly, the number of reductions described in the notification $(3,459)$ appears, as the potential effect of establishing the AFIMSC, in the same December 2013 briefing that notes the reduction goal of 3,361 (see Tillotson, 2013, slide 4).
} 
headquarters authorizations would be $3,459 .{ }^{18}$ The headquarters reduction count of 734 is also described in two Air Force memoranda. ${ }^{19}$

\section{Air Force Input to the Section 904 Report}

Section 904 of the FY 2014 NDAA directed DoD to develop a plan for "streamlining management headquarters by changing or reducing the size of staffs, eliminating tiers of management, cutting functions that provide little or no added value, and consolidating overlapping and duplicative programs and offices." ${ }^{20}$ It also required the submission of an initial status report (referred to as the Section 904 Report) for the plan within 180 days of the passage of the act. In developing its input for the Section 904 Report, the Air Force counted reductions in authorizations in a way that leads to a different number from what was provided in the congressional notification related to the Management Headquarters Review.

According to one Air Force instruction,

Air Force Management Headquarters and Headquarters Support includes those functions and the direct support integral to their performance that are required to manage the programs and operations of the DoD and its major military organizations. $^{21}$

Management functions provide oversight, direction, and control by developing and issuing policies, providing policy guidance, reviewing and evaluating program performance, allocating and distributing resources, and conducting activities related to the programming, planning, budgeting, and execution process. Direct support includes staff support for policy or program analysis and operating support, such as secretarial or data-processing services. Air Force Instruction 38-202 directs that management headquarters and headquarters support positions will be identified using program element codes (PECs) that end in the number 98, and that this coding will not be used for other positions. An example of functions that are not counted as headquarters support (and therefore not to be identified with a PEC ending in 98) are base operating support functions (e.g., civil engineering, human resource management) provided by a host operational unit to all units, including tenant organizations. ${ }^{22}$

\footnotetext{
18 DoD, “Air Force Changes Headquarters Manning, Organization,” DoD News, July 14, 2014.

19 The first memo described 325 cuts (Eric K. Fanning, Under Secretary of the Air Force, and Larry O. Spencer, Vice Chief of Staff of the Air Force, "Future Air Force Organization: Headquarters Air Force (HAF)," memorandum, April 11, 2014a), and the second memo described 409 cuts (Eric K. Fanning, Under Secretary of the Air Force, and Larry O. Spencer, Vice Chief of Staff of the Air Force, "Future Air Force Organization: Headquarters Air Force (HAF) Round 2," memorandum, July 16, 2014b).

${ }^{20}$ Public Law 116-33, National Defense Authorization Act for Fiscal Year 2014, Section 904, paragraph a.

${ }^{21}$ U.S. Air Force, Air Force Management Headquarters and Headquarters Support Activities, Washington, D.C., Air Force Instruction 38-202, March 1, 1995, p. 1.

${ }^{22}$ U.S. Air Force, 1995.
} 
Some of the reductions that resulted from the Future Air Force Organization initiative included positions that were above wing level but that did not satisfy the technical definition of management headquarters functions - and that may or may not have been identified with PECs ending in 98. The Air Force decided that for its contribution to the Section 904 Report, it would strictly adhere to the formal definition, and so, for determining the baseline for the 20-percent cuts and for presenting the reductions it achieved in FY 2015, it counted all full-time government positions in the active Air Force and the Air Reserve Component that had a PEC ending in $98 .^{23}$ Table 2.1 shows the baseline, reductions, and new ceilings reported by the Air Force for the Section 904 Report in May 2015.

Table 2.1. Air Force Reductions in End Strength and Funding

\begin{tabular}{|c|c|c|c|c|}
\hline & \multicolumn{3}{|c|}{ End Strength } & \multirow[b]{2}{*}{ Funding } \\
\hline & Civilian & Military & Total & \\
\hline $\begin{array}{l}\text { Baseline } \\
\text { (FY } 2018 \text { column of FY } 2014 \text { PB) }\end{array}$ & 6,253 & 7,594 & 13,847 & \$854 million \\
\hline Air Force position in the FY 2015 PB & 5,463 & 5,406 & 10,869 & $\$ 678$ million \\
\hline Reduction & $\begin{array}{r}790 \\
(13 \%)\end{array}$ & $\begin{array}{l}2,188 \\
(29 \%)\end{array}$ & $\begin{array}{r}2,978 \\
(21.5 \%)\end{array}$ & $\begin{array}{l}\text { \$176 million } \\
(21 \%)\end{array}$ \\
\hline
\end{tabular}

SOURCE: DoD, 2015.

The table shows that the Air Force counted a total of 13,847 positions with PECs ending in 98 in the FY 2018 projection of the FY 2014 budget, with a funding forecast of $\$ 854$ million. $^{24}$ The Air Force's September 30, 2015, position (found in the FY 2016 column of the FY 2016 PB) showed that its total for authorizations in positions with PECs ending in 98 was only 10,869 and that funding for headquarters was $\$ 678$ million. These numbers show that, compared with FY 2018 projections, the Air Force had achieved reductions of 21.5 percent and 21 percent in authorizations and funding, respectively.

\section{Assessing the Air Force Cuts}

\section{Net Reduction in Management Headquarters Funding and Authorizations}

RAND assessed the Air Force cuts in two stages. First, because the Section 904 Report was based on net overall headquarters reductions, we analyzed Air Force documents to determine

\footnotetext{
23 AF/A1 staff member, interview with the authors, September 29, 2015.

${ }^{24}$ Recall that military personnel are not included as part of headquarters budgets. The headquarters funding thus includes only civilian salaries and "non-pay" operation and maintenance funding (such as equipment) associated with headquarters.
} 
adjustments made to the total number of authorizations identified with PECs that end in 98. Second, because some members of Congress had expressed concern about how the Air Force made and reported its reductions - for example, Senator John McCain, Chairman of the Senate Armed Services Committee, accused the Air Force of engaging in a "shell game" of moving money without reducing positions ${ }^{25}$ - we examined reductions made at the MAJCOM and HAF levels and compared them with the Air Force's initial reduction plans. The detailed analysis is in Appendix A; here, we discuss only the changes in total authorizations.

Table 2.2 compares RAND's determination of authorization and funding changes with those reported by the Air Force. ${ }^{26}$

Table 2.2. Net Change in Air Force Management Headquarters Authorizations

\begin{tabular}{|c|c|c|c|c|}
\hline & \multicolumn{2}{|c|}{ End Strength } & \multicolumn{2}{|c|}{ Funding } \\
\hline & Air Force & RAND & Air Force & RAND \\
\hline $\begin{array}{l}\text { Baseline } \\
\text { Based on FY } 2018 \text { end strength } \\
\text { of the FY } 2014 \text { PB }\end{array}$ & 13,847 & 13,847 & \$854 million & $\$ 855$ million \\
\hline $\begin{array}{l}\text { FY } 2019 \text { ceiling } \\
\text { (20\% cut from baseline) }\end{array}$ & 11,078 & 11,078 & $\$ 683$ million & $\$ 682$ million \\
\hline $\begin{array}{l}\text { Air Force Sept. } \mathbf{3 0}, \mathbf{2 0 1 5}, \\
\text { position (FY } 2016 \text { column of } \\
\text { FY } 2016 \text { PB) }\end{array}$ & 10,869 & 10,878 & & \\
\hline $\begin{array}{l}\text { Air Force Sept. 30, 2015, } \\
\text { position (FY } 2016 \text { column of FY } \\
2016 \text { PB) }\end{array}$ & & & $\$ 678$ million & $\$ 677$ million \\
\hline $\begin{array}{l}\text { Air Force "reductions" } \\
\text { credited for next round of } \\
\text { cuts }\end{array}$ & $\begin{array}{c}2,978 \\
(13,847-10,869) \\
21.5 \%\end{array}$ & $\begin{array}{c}2,969 \\
(13,847-10,878) \\
21.4 \%\end{array}$ & $20.6 \%$ & $20.8 \%$ \\
\hline
\end{tabular}

SOURCE: Air Force numbers for end strength are from the Section 904 Report (DoD, 2015). Air Force funding numbers are from U.S. Air Force, "20\% Mgmt HQ Redux, FY 2015 Review," briefing slides, 2015a, provided to RAND by the Air Force Director of Budget Operations and Personnel. RAND numbers are from an independent analysis of ABIDES data contained in the December 21, 2015, file "PB1416_ABIDES_ES_20151220.xlsx." NOTE: ABIDES data showed 7,769 military authorizations in management headquarters in FY 2018 of the FY 2014 PB. We discovered that 175 of these were erroneously "double counted" and made an appropriate correction.

The first row of Table 2.2 shows that RAND's baseline count of PEC 98 authorizations, based on the FY 2018 entry of the FY 2014 PB, matches the count determined by the Air Force, and comes very close to the Air Force's funding baseline - only a million dollars off. The FY

\footnotetext{
25 Brian Everstine, "McCain Calls for Air Force Headquarters Layoffs," Air Force Times, March 25, 2015.

${ }^{26}$ See Appendix A for details of the databases and exact data filters that were used to obtain the RAND numbers. Appendix A also has these figures broken down in more detail by category (civilian compared with military authorizations; military pay, civilian pay, and operation and maintenance non-pay).
} 
2019 "ceiling" shows the number of authorizations and the amount of funding allowed after a 20-percent cut of the baseline amounts.

The Air Force claimed in the Section 904 Report that it had achieved the 20-percent reductions by the end of FY 2015, so we next consider the Air Force budget position reported on September 30, 2015 (the FY 2016 column of the FY 2016 PB). The tiny difference (nine) between the RAND count of authorizations and the Air Force count is significant only in that it shows that the assessments are independent. ${ }^{27}$ Both counts are below the new "baseline," so RAND confirms that the Air Force achieved its 20-percent reduction in authorizations by FY 2015.

The fourth row shows the September 30, 2015, funding position; we have displayed it on a separate row from the authorizations to prevent the impression that funding reductions relate directly to the total number of authorization reductions. Only civilian pay and headquartersrelated operation and maintenance funding that is not pay-related are included in the funding amount; military pay is not, so the reductions in military authorizations did not reduce headquarters funding. Nonetheless, the RAND determination of FY 2016 funding is essentially the same as that of the Air Force, and both values are lower than the respective new funding ceilings, so the 20-percent funding cuts have been achieved. ${ }^{28}$

The word "reductions" in the final row of the table is in quotation marks for a reason: This row represents the difference between the planned levels of personnel and funding in FY 2018 and the planned levels in FY 2016, as of September 30, 2015. It does not represent the changes in total authorizations from FY 2014 to FY 2015, and the changes do not represent a 20-percent reduction from FY 2014. However, the number of "reductions" will help determine what additional changes may be necessary to satisfy the more recently announced 25-percent MHA reductions. They will be used to determine the credit the Air Force will receive for reductions already accomplished.

\section{Congressional Concerns About the Air Force's Reductions}

At least one member of Congress has expressed concern about whether the Air Force satisfied the intent of the reductions directed by Secretary Hagel, or if apparent "reductions" were merely the result of shuffling people around to new organizations. ${ }^{29} \mathrm{We}$ respond as follows to some of these concerns:

\footnotetext{
${ }^{27}$ We also note that RAND's analysis revealed the existence of an error in the ABIDES data that counted 175 authorizations twice.

${ }^{28}$ About 83 percent of funding cuts were from civilian pay. See Appendix A for details of the cuts by military and civilian authorizations.

${ }^{29}$ John M. McCain, Chairman of the Senate Armed Services Committee, letter to Deborah Lee James, Secretary of the Air Force, March 24, 2015.
} 
- Was the establishment of 25th Air Force and AFIMSC "directly contrary" to guidance of not growing subordinate headquarters? These new organizations have created efficiencies that lead to a net reduction in headquarters positions.

- Were lower-priority activities eliminated as directed? In presentations to the Air Force Council, MAJCOMs provided detailed information on activities that have been eliminated and services that have been reduced because of the reduction in headquarters authorizations. ${ }^{30}$

- Were any civilians actually removed from the payroll? Some headquarters positions that were eliminated were unfilled (some were unfilled, in fact, because of congressional restrictions imposed by the Budget Control Act); nonetheless, because they were funded positions, their elimination still results in savings. Also, in accordance with government personnel practices, people in eliminated positions are allowed to move to existing authorized positions that may be unfilled in other organizations. Finally, in situations where an "encumbered" (filled) position was eliminated, the Air Force offered incentives to leave (through the Voluntary Separation Incentive Program or the Voluntary Early Retirement Authority). Reduction-in-force actions are necessary only if vacant positions are unavailable or there are insufficient volunteers for the separation or retirement programs. Thus, even though authorizations have been eliminated and management headquarters end strengths have been reduced, the number of personnel eventually removed from the payroll will depend on how many find vacant positions and how many accept voluntary separation or retirement, and processing these actions takes time.

- Did the Air Force produce actual staff reductions that yielded savings? Planning data in ABIDES clearly show that funding reductions were planned and headquarters authorization reductions were made. ${ }^{31}$ Moving and eliminating personnel as a result of these reductions takes time.

\section{Conclusion}

The tables in this chapter and in Appendix A show that, when using a technical count of PEC 98-coded positions, the Air Force achieved the 20-percent reduction in funding and authorizations as stated in the Section 904 Report, and all MAJCOMs contributed to the reductions.

\footnotetext{
${ }^{30}$ This information was presented in Office of the Secretary of the Air Force, "Air Force Council HQ Staff Reductions Compilation," briefing slides, August 26, 2014.

31 The actual year-end position of the Air Force for FY 2015, which captures the final assigned military pay, final civilian pay, and final operation and maintenance non-pay as of September 30, 2015, shows a funding reduction of 26.1 percent. When military pay is excluded, the savings are 9.1 percent, which still falls within the goal of one-fifth of the cuts being made each year (U.S. Air Force, 2015a).
} 


\section{The Next Step: 25-Percent Cuts}

In 2015, Deputy Secretary of Defense Work directed a 25-percent reduction across all appropriation funding for major DoD headquarters activities. ${ }^{32}$ In addition, Section 346 of the FY 2016 NDAA directed the Office of the Secretary of Defense to modify its Section 904 reduction plan to achieve savings by FY 2020 that are 25 percent of the "baseline" amount. The baseline amount is the FY 2016 authorization for major DoD headquarters activities, adjusted by a credit for reductions already accomplished in accordance with the 2013 guidance for 20percent reductions.

DoD instructions define "management headquarters" as headquarters that are primarily responsible for overseeing, directing, and controlling subordinate organizations or units through developing and issuing policies and providing policy guidance; reviewing and evaluating program performance; allocating and distributing resources; or conducting mid- and long-range planning, programming, and budgeting. ${ }^{33}$ However, the same instructions indicate that "major DoD headquarters activities" (MHA) include management headquarters, combatant headquarters, and direct support.

During preparation of the Section 904 Report, it became clear that there was disagreement among organizations about what should be included in MHA. The memorandum directing the 25-percent reductions included an "activities framework" diagram to help guide the discussion about what should be included, but as of January 2016, no final decision has been made on the elements that should be counted as MHA. What has become clear, however, is that the new baseline for reductions will most likely be larger than the baseline that was used for the 20percent reductions, because the nature of the activities performed, and not the organizational location of a position, will determine if it is considered MHA. For example, as of September 2015, the Air Force expected that many positions that are currently not coded with PEC 98 will be included in the new MHA baseline, and that the baseline might increase by as many as $1,000 .^{34}$

After a decision is made about what should be included in the baseline, a second decision will be required: how the reduction of 2,978 PEC-98 positions already made by the Air Force will be credited toward the new 25-percent reductions, and whether the Air Force will be required to make more cuts. While organizations can explore approaches for further reductions, the actual number of reductions required cannot be determined until a formula is developed to account for reductions already made.

\footnotetext{
32 Robert O. Work, Deputy Secretary of Defense, "Cost Reduction Targets for Major Headquarters," memorandum, August 24, 2015.

${ }^{33}$ DoD, Major DoD Headquarters Activities, Washington, D.C., Department of Defense Instruction 5100.73, September 10, 2009.

${ }^{34}$ U.S. Air Force, “Major Headquarters Activities,” briefing slides, September 22, 2015c.
} 



\section{Chapter Three: Comparing Practices from Literature and Industry with the Services' Approach to Streamlining and Delayering}

In this chapter, we discuss sound practices for downsizing, right-sizing, or delayering headquarters organizations as identified in literature and industry. We call them sound practices because, through the course of this analysis, we discovered that there are no best practices that apply to all organizations or types of industry. Sound practices, on the other hand, can be applied across business goals and organizational structures. We first discuss sound practices identified in literature, then those used by industry, and finally how the Air Force and other services approached the 2013-mandated headquarters reductions. ${ }^{1}$

\section{Key Practices Identified in Literature}

The management literature describing organizations is vast, so we began our analysis by reviewing literature on topics that relate to delayering and streamlining organizations. We view organizational design, business process reengineering, consulting practices used to delayer organizations, and management best practices as particularly important to the topic of streamlining organizations, so we call out lessons from the literature in these areas. ${ }^{2}$ Theory and practice offer different perspectives on streamlining and organizational design. The theory tends to provide a good perspective on the elements of organizations, their purpose, and factors to consider when structuring an organization to most effectively and efficiently deliver the work product. The practice literature focuses on methods and approaches for conducting organizational change or restructuring. Table 3.1 summarizes the key points from each genre reviewed during this analysis.

\footnotetext{
${ }^{1}$ See Appendix B for our preliminary, high-level review of the delayering that was accomplished within the Air Staff and Secretariat during the management headquarters reductions taken in FY 2015.

${ }^{2}$ See Appendix $\mathrm{C}$ for an annotated bibliography of the literature reviewed during this analysis.
} 
Table 3.1. Key Focuses from Theory and Practice Literature

\begin{tabular}{ll}
\hline Genre & \multicolumn{1}{c}{ Key Focuses } \\
\hline $\begin{array}{l}\text { Academic organizational } \\
\text { design }\end{array}$ & $\begin{array}{l}\text { Organization function; importance of headquarters in shaping } \\
\text { business units; importance of developing work regulations to } \\
\text { harmonize mission accomplishment }\end{array}$ \\
$\begin{array}{l}\text { Business process } \\
\text { reengineering }\end{array}$ & $\begin{array}{l}\text { Organizations' need to focus work processes on goal achievement } \\
\text { and reduce work that is not value added }\end{array}$ \\
Management practice & $\begin{array}{l}\text { Examples of how various businesses are organized and } \\
\text { differences among industry groups; rationale for differences }\end{array}$ \\
Consulting literature & Methods for approaching reorganizations \\
Military literature & Approaches for process or organizational design \\
\hline
\end{tabular}

Our review of the literature produced many factors to consider; however, those principles all depend on maintaining focus on the organization's strategic goals. Focusing on strategic goals should help ensure that changes being considered (organizational, process, or otherwise) do not lead to an inefficient or ineffective organizational structure or to broken or inefficient processes. In fact, according to the sound practices we reviewed as part of this analysis, identifying those processes that need to be improved to achieve the organization's strategic goals should precede any organizational structure change. In practice, all elements of the DOTMLPF (doctrine, organization, training, materiel, leadership and education, personnel, and facilities) framework should be considered when reviewing and evaluating processes tied to strategic goals. ${ }^{3}$ If one or more of these elements is not addressed, the changed process may not achieve the desired results. Streamlined and effective processes that are bonded firmly to strategic goals result in a sound structure for the organization.

Several key factors, as evidenced by our analysis, need to be considered in MHA analysis and design. These factors include division of labor, design of formal reporting relationships, and design of coordinating mechanisms.

\section{Division of Labor}

Division of labor includes how work is performed, for both services and products. Important characteristics to consider in division of labor include how positions are grouped into units and what size those units should be to achieve the organization's strategic goals. The workloadmeaning the quantity of service or rate of the production cycle and units produced - dictates the size of the workforce and, to some extent, the organization and supporting components required to operate effectively. The structure and size of the various support components will vary based

\footnotetext{
3 DOTMLPF is a framework used in DoD to evaluate gaps or shortfalls in a solution space. A thorough analysis considers all of its contributing elements when evaluating a range of potential options.
} 
on the complexity of the work product and the makeup of the workforce, but on the whole, the larger the number of people in the organization, the larger the support components. ${ }^{4}$

\section{Design of Formal Reporting Relationships}

Span of control and levels of hierarchy needed to achieve the organization's strategic goals dictate design of formal reporting relationships. Span of control, which identifies the formal reporting relationships within levels of hierarchy, is typically defined as the number of employees who report to a single supervisor. Formal reporting relationships between levels of hierarchy are typically described in terms of the number of levels within an organization.

The span of control of any unit within an organization varies and depends on a number of factors. On one hand, the number of employees a single supervisor can directly manage is limited. On the other hand, complex tasks or tasks that involve any uncertainty require a narrower span of control. Unit size is therefore somewhat constrained by the need for direct supervision and the number of supervisors required. The type of work and amount of standardization possible in the work processes will determine the most efficient span of control for each supervisor and, to an extent, the echelons required above the first-line supervisor. Larger or more-diverse organizations may require more levels of management.

The levels of organization hierarchy vary across organizations, and there is no one ideal number of echelons. Larger organizations (in terms of number of employees) tend to have more levels of hierarchy, as do those with few major divisions and more automation. ${ }^{5}$ Complex or uncertain tasks also tend to have more hierarchy. When tasks, problems, and decisions are routine or repetitious, rules or procedures (standardization) may be used instead of multiple levels of hierarchy. ${ }^{6}$

\section{Design of Coordinating Mechanisms}

The design of coordinating mechanisms includes the amount of standardization involved in each unit of work, centralization of decisionmaking rights, and lateral linkages both within and outside the organization. Standardization, sometimes called formalization, is the use of rules and procedures to guide the actions of an organization's personnel. ${ }^{7}$ The more standardization in a

\footnotetext{
4 See the discussion of Henry Mintzberg's ideas in Appendix D, as well as in D. Collins, D. Young, and M. Goold, "The Size, Structure, and Performance of Corporate Headquarters," Strategic Management Journal, Vol. 28, No. 4, 2007, p. 393.

5 Peter M. Blau, "The Hierarchy of Authority in Organizations," American Journal of Sociology, Vol. 73, No. 4, 1968.

6 Richard L. Daft, Organization Theory and Design, 9th ed., Mason, Ohio: Thomson South-Western, 2007.

7 Daft, 2007; and Dan R. Dalton, William D. Todor, Michael J. Spendolini, J. Fielding Gordon, and Lyman W. Porter, “Organization Structure and Performance: A Critical Review, ” Academy of Management Review, Vol. 5, No. 1, 1980.
} 
process or organization, the less time its managers need to spend on direct supervision. In addition, the more highly trained or specialized the personnel, the less closely they may need to be supervised, ${ }^{8}$ and, thus, the more personnel each manager can manage. However, for complex tasks or tasks that involve uncertainty, standardization may be difficult to achieve. Finally, too much standardization can limit or stifle creative improvements to work processes.

In an organization with centralized decision rights, the decisionmaking authority is centralized at the highest echelon. In the most extreme case, "[a]1l decisions are made by one individual, in one brain, and then implemented through direct supervision." " On the other hand, decisions in decentralized organizations are made at lower levels of the organizational hierarchy. There is no one right amount of centralization; centralization depends on the task and the organizational hierarchy and their relative importance in achieving the organization's goals. ${ }^{10}$ Higher centralization can accelerate problem-solving, but the quality of solutions tends to be higher with greater decentralization. ${ }^{11}$ It has also been found that innovation thrives more readily in a decentralized environment. ${ }^{12}$

Lateral linkages are linkages that enable horizontal integration and reduce the need to refer decisions up the hierarchical chain of command. They are used to coordinate between functions and echelons. Lateral linkages are especially useful to help organizations operate more efficiently under conditions of uncertainty, ${ }^{13}$ to communicate information that is less quantifiable, ${ }^{14}$ and to promote knowledge-sharing more generally. ${ }^{15}$ Lack, or insufficient use, of lateral linkages may account for a lack of innovation and adaptation in dynamic environments, as well as for conflicts between different departments because of a focus on departmental goals at the expense of organizational ones. ${ }^{16}$

Although literature discusses methodologies for applying the considerations discussed above, there is no single solution for how best to apply these factors in the design of an organization.

\footnotetext{
${ }^{8}$ Henry Mintzberg, Structure in Fives: Designing Effective Organizations, Longman Higher Education, 1982, p. 67.

${ }^{9}$ Henry Mintzberg, The Structuring of Organizations: A Synthesis of the Research, 1st ed., Englewood Cliffs, N.J.: Prentice Hall, 1979, p. 182.

10 Jay R. Galbraith, Organization Design, Reading, Mass.: Addison Wesley Publishing Company, 1977.

11 J. Mihm, C. H. Loch, D. Wilkinson, and B. A. Huberman, "Hierarchical Structure and Search in Complex Organizations," Management Science, Vol. 56, No. 5, 2010.

12 Fariborz Damanpour, “Organizational Innovation: A Meta-Analysis of Effects of Determinants and Moderators," Academy of Management Journal, Vol. 34, No. 3, 1991.

13 Galbraith, 1977.

${ }^{14}$ Michael L. Tushman and David A. Nadler, "Information Processing as an Integrating Concept in Organizational Design," Academy of Management Review, Vol. 3, No. 3, 1978.

15 Annick Willem and Marc Buelens, "Knowledge Sharing in Public Sector Organizations: The Effect of Organizational Characteristics on Interdepartmental Knowledge Sharing," Journal of Public Administration Research and Theory, Vol. 17, No. 4, 2007.

${ }^{16}$ Danny Miller, “Environmental Fit Versus Internal Fit,” Organization Science, Vol. 3, No. $2,1992$.
} 
Variations in organizational size, complexity, type of work, and type of workforce all affect the solutions chosen. The basic elements of the organization will vary based on the application of these factors and the type of organization. For example, organizations with complex work products might have a larger management structure than organizations with simple, repetitive work products.

However, common throughout the literature is the idea that strategic goals should lead any process or organizational restructuring. Process reengineering should be guided by understood strategic goals and is critical to effectively structuring organization components. Evaluating an organization's processes should enable better identification of opportunities to centralize (or decentralize) decision rights, reduce redundancies, and eliminate work that is not value added. Understanding all elements of the DOTMLPF framework of an organization's processes can aid in determining costs, effectiveness, and risks of process options. The most efficient way of structuring is to ensure that processes are streamlined and efficient, decisionmaking is at the lowest level in the organization that is appropriate for the category of decisions, and leadership remains committed and thoroughly engaged. Organizational alignments that best implement these process improvements and modifications should follow process reviews and be considered last.

Next, we discuss what we learned about organizational streamlining and delayering from industry and the military services.

\section{Industry Approach to Streamlining}

As part of our analysis of sound practices, we interviewed six companies about their recent reorganization experience to gain industry insights into reorganization, streamlining, and process reengineering. Because no commercial companies directly compare with the U.S. Air Force in terms of size and scope, we targeted large Fortune 100 firms that had recently reorganized and smaller companies that had undertaken extensive reorganization, with specific focus on streamlining headquarters and support functions.

We first conducted a literature search to identify companies that were reported to have reorganized or had large reductions in workforce. We subsequently reviewed that list and targeted companies that focused their reorganization or reductions on headquarters activities or support staff. We then down-selected to companies that represented sectors or industries that were similar to major organizations within the Air Force enterprise. By contacting a range of companies differing in size and purpose across a variety of industries, we developed a broadbased sample of commercial reorganization efforts. Industries represented in our sample included consumer goods, airlines, health care, retail, financial services, and manufacturing.

We used a structured protocol to guide our discussions (see Appendix E). The protocols contained questions to identify aspects of reorganizations that might help the Air Force improve the outcomes of future reorganization efforts. We found that company reorganization approaches 
varied, and a number of different objectives guided headquarters reshaping. But even for those firms that did not undertake specific targeted management headquarters analyses, all reorganizations resulted in a change in headquarters function and size based on the line changes and reduction and realignment of staff.

The goals of the reorganizations also varied, but all interviewees established a temporary reorganization strategy team to lead their reorganization efforts. They typically had a senior executive committee creating the strategy and providing direction and oversight. Firms used different methods to reduce personnel; however, all companies focused on strategic and operational-level process review, with substantial upfront strategy planning preceding the most successful reduction efforts.

We asked all companies to describe what they would determine to be sound practices and lessons learned. Many of the examples shared contained features of the sound practices we derived from literature, including the following:

- a clear strategy and active executive leadership

- effective communication plans and change management programs

- an inclusive reorganization strategy team to lead the effort

- substantial time in upfront strategy planning.

Companies also placed special emphasis on specific targets, such as analyzing span of control and organizational layers, reducing redundancies, identifying best practices of each merged entity, and realigning into a combined entity.

\section{Military Services' Approach to Streamlining}

In this section, we outline the methods that the services used to achieve the headquarters reductions mandated in 2013 by the Secretary of Defense. Each service used a different method to achieve the reductions, and each method embodied some of the sound practices we identified above. We document both here. ${ }^{17}$

\section{Army Approach}

The Army began its headquarters reduction efforts even before the 2013 Secretary of Defense mandate. The Army was facing end-strength reductions of 40,000 military and 17,000 civilians by FY 2019, ${ }^{18}$ so it established a working group to identify the positions that should be considered part of headquarters staffs and developed business rules for reductions. The review group made recommendations resulting in reductions of headquarters positions of about 20-25

\footnotetext{
${ }^{17}$ For more detail on the Navy and Army approaches, see Appendix F.

${ }^{18}$ C. Todd Lopez, “Army to Realign Brigades, Cut 40,000 Soldiers, 17,000 Civilians,” U.S. Army News Archives, July 9, 2015.
} 
percent; these were to be implemented over the next five years, with one-fifth of the reductions taken over each year. Cuts varied by area of responsibility, with the Pacific taking approximately 14 percent of the reductions and Europe taking approximately 40 percent.

After the services received the mandated reductions from the Secretary of Defense in 2013, the Army hired a consulting group to apply a structured delayering approach to identify any additional reductions that could be achieved. This approach focuses on increasing the span of control for managers (having at least eight personnel reporting to each manager) and reducing the number of "echelons" of management between the head of an organization and the personnel doing the work (a maximum of seven layers). The structured delayering approach did not initially lead to any further personnel reductions at Army Headquarters beyond those already achieved by the Army using other approaches. ${ }^{19}$ However, the Secretary of the Army directed a more detailed review in July 2014. The goal this time was to achieve a 25-percent manning reduction in all Army two-star-level headquarters and above, including Army Headquarters and its FOAs. $^{20}$

The same consulting group was employed to develop an approach to accomplish these reductions, and the Army believes that the resulting recommendations will achieve the 25percent reductions by FY 2019. ${ }^{21}$

In DoD's February 2015 budget request, the Army states that for all Army headquarters (two-star and above), actual authorizations were reduced at least 20 percent in FY 2016, and noted that it would comply with further directed reductions by FY $2019 .^{22}$

\section{Navy Approach}

The Navy used a different approach to meet the 20-percent headquarters reduction mandated by the Secretary of Defense. It began by examining which positions should be considered headquarters functions. It found discrepancies between what was self-reported as a headquarters position and what was reported in the Program Budget Information System. The N8 (Office of the Deputy Chief of Naval Operations, Integration of Capabilities and Resources) worked with

\footnotetext{
${ }^{19}$ Delayering alone produced savings of 8 to 10 percent. Greater savings required additional actions, such as reducing the number of contractors used for staff work by about 30 percent. See U.S. Army, "HQDA Organizational Assessment: Deliverable \#1: Draft Report, Task 3.2," briefing slides, February 14, 2014.

${ }^{20}$ Raymond T Odierno, Chief of Staff of the Army, and John M. McHugh, Secretary of the Army, "Directive for Transition of Headquarters, Department of the Army to the Fiscal Year 2019 Organization Design," memorandum for Principal Officials of Headquarters, Department of the Army, June 11, 2015.

21 Odierno and McHugh's memorandum directs that the delayering recommendations be implemented (Odierno and McHugh, 2015). A U.S. Army presentation discusses the principles used in designing the approach to reductions (U.S. Army, "HQDA Delayering: Executive Summary for the Office of the Secretary of Defense," briefing slides, July 14, 2015b).

22 See Office of the Under Secretary of Defense (Comptroller), United States Department of Defense Fiscal Year 2016 Budget Request: Overview, Washington, D.C., February 2015, pp. 3-5, 8-9.
} 
subordinate headquarters to determine positions (including those coded as headquarters and those not) that should be included in the headquarters personnel count.

Once a broadened baseline of what should be considered headquarters was established, the Navy used a risk assessment to determine how the reductions would be allocated across the service. The Navy allocated a large percentage of the reduction to nondeployed or nonoperational forces as a means to balance the risk. Nondeployed or nonoperational organizations took reductions of 20 percent or more, while operational or deployed organizations only took reductions of approximately 5 percent. The Navy planned its reductions over five years. It achieved its planned reductions for FY 2016, but a new risk assessment led it to "buy back" some of the planned reductions for FY 2017.

\section{Air Force Approach}

The Air Force process for managing headquarters reductions involved several steps. First, in response to the July 2013 Future Air Force Organization memorandum (as discussed in Chapter Two and Appendix A), ${ }^{23}$ the Air Force rebaselined HAF, MAJCOMs, and NAF responsibilities to ensure that functions were not duplicated within or between management levels. The goal was to reengineer key business processes and then make the appropriate organizational changes to enable the improved processes. As previously discussed, the focus fell on several areas:

- continuing to centralize installation services using the process that began with establishing the Air Force Civil Engineer Center (and accepting AFIMSC concepts)

- improving the management of operations in cyber and ISR (streamlined management of these capabilities by creating the 25th Air Force)

- streamlining the programming, planning, budgeting, and execution process (realignment of A5/8 at Air Staff to improve strategic planning). ${ }^{24}$

The guiding principles for this plan included some of the sound practices identified in literature and by industry, ${ }^{25}$ such as identifying improved business processes that streamline information flow and eliminate work, eliminating or combining redundant organizations, and ensuring that work is done at an appropriate organizational level.

Originally, MAJCOMs were expected to achieve about 2,725 personnel reductions from the focus on reengineering these processes. However, by July 2014, the Air Force had not reached its 20 -percent reduction goals. As a next step, 1,190 remaining cuts were distributed by targeted apportionment among the MAJCOMs. HAF and the MAJCOMs handled the additional cuts in different ways.

\footnotetext{
${ }^{23}$ Fanning and Welsh, 2013.

${ }^{24}$ Fanning and Welsh, 2013.

${ }^{25}$ For details of the plan, see U.S. Air Force, 2014a.
} 
HAF was given general guidance for managing the targeted apportionment by the Assistant VCSAF, who also directed some organizational design changes. Director of Staff and Commander's Action Group positions below HAF two-letter-level organizations (such as in the Office of the Assistant Secretary of the Air Force for Acquisition, SAF/AQ) were eliminated; however, this resulted in very few reductions. Supervisory ratios of 1:10 were institutionalized in HAF, which also caused some minor reorganization. ${ }^{26}$

To drive the streamlining and reduction processes, HAF two-letter-level organizations were given specific targets to achieve. Each organization tailored its solutions to meet its unique mission needs, and a steering group reviewed and approved the final proposals. Most two-letter organizations were allowed to choose how to make cuts and some directorates analyzed process changes that would enable reductions.

Each MAJCOM used different approaches for achieving the targeted apportionment reductions. For example, AFMC's process implemented some of the sound practices discussed previously in this chapter. It began early to develop an enterprise approach for examining where to make reductions. It had a governance structure in place to oversee the reduction process, including "vector checks" with AFMC senior leaders. Within the command, AFMC allocated labor to every task it performed. It then used the mission-essential task list to target where to take reductions and developed a model to examine risks of eliminating those tasks. It used an integrated approach to make decisions across the command rather than within independent directorates.

Other MAJCOMs, on the other hand, allocated reduction goals across the staff based on current populations within each of its directorates. These MAJCOMs left reduction decisions up to the individual directorates to determine. The reductions were allocated based on mission effects within but not across directorates. In many cases, reductions were not spread uniformly within directorates. Some directorates at some MAJCOMs issued policy letters outlining work that would no longer be supported as a result of reductions. And some MAJCOMs required a higher-level review of the directorate recommendations, causing some adjustments to be made before the reductions were implemented.

\section{Summary Findings from Comparing the Air Force's Approach with Sound Practices}

When we compared the methodology and approach used by the Air Force to achieve the 2013 mandated headquarters reductions with government and industry sound practices, we found that the approach the Air Force used aligned with those identified in literature as sound practices.

\footnotetext{
${ }^{26}$ See Frank Gorenc, Assistant Vice Chief of Staff and Director of Staff of the Air Force, and Tim Beyland, Administrative Assistant to the Secretary of the Air Force, "State of the HAF-Organization Design," memorandum, May 15, 2013.
} 
Some of those processes included the formation of the AFIMSC and 25th Air Force and the transfer of some functions to the Air Force Personnel Center (AFPC); most of these changes consolidated like functions and centralized decision rights. Acquisition process improvements and the realignment of A5/8 to strengthen ties between strategic planning and Program Objective Memorandum activities are examples of improving lateral linkages, reducing redundancies, and improving coordination in processes. The Air Force adjusted its hierarchy to incorporate appropriate span-of-control practices by consolidating the Air Force Civil Engineer Center, Air Force Security Forces Center, Air Force Installation Contracting Agency, Air Force Financial Services Center, AFPC services, and Financial Management Center of Expertise under AFIMSC. The organizational design principles of process reengineering used by the Air Force resulted in approximately 60 percent of the required MHA reductions. To deal with the targeted apportionment that was used to find the additional approximately 40 percent of the required reductions, most MAJCOMs used task analyses and focused on eliminating low-value tasks; some included assessment of risks in their analyses.

\section{Air Force Materiel Command Reorganization of 2011}

While there are many examples of directed personnel reductions and many cases where the Air Force applied sound practices to business decisions, the AFMC reorganization in 2011 is a recent example that combines both — mandated personnel reductions and use of management sound practices.

Similar to the personnel reduction mandated in 2013 by Secretary Hagel, the Budget Control Act of 2011 directed cuts in defense spending that equated to 16,500 civilian authorizations in the Air Force. ${ }^{27}$ AFMC leadership used the requirement to reduce personnel as an opportunity to change the way the MAJCOM did business, implementing new processes and procedures, as well as reorganizing the command structure. ${ }^{28}$

Prior to the reorganization effort in 2011, AFMC was organized into 12 centers, each of which reported to the AFMC commander. This structure had a large span of control, with like functions spread across many centers. For example, product development and support system design functions were spread among seven centers. Depot maintenance and Air Force supply chain operations were managed in four centers. And each center had its own staff.

Using the mandated personnel reductions as a catalyst, AFMC reorganized into five centers, each focusing on one of AFMC's mission areas: product development/support-system design, operations support, research and technology development, developmental testing, and nuclear

\footnotetext{
27 Public Law 112-25, Budget Control Act of 2011, August 2, 2011.

${ }^{28}$ During the reorganization, AFMC implemented the Office of the Secretary of Defense product support business model, which provides cradle-to-grave weapon system program management.
} 
weapon support. The reorganization reduced AFMC's span of control from 12 to five centers and consolidated decision rights within mission areas.

In addition to reducing the span of control, the AFMC reorganization created three new centers (Air Force Life Cycle Management Center [AFLCMC], Air Force Sustainment Center, and Air Force Test Center), each focusing on a specific mission area; consolidated product development/support system design under one center (the AFLCMC); and integrated depot maintenance and Air Force supply chain activities under the Air Force Sustainment Center. Even while creating three new centers, with staffs, and realigning thousands of management reporting chains, the reorganization was able to reduce staffs by more than 1,000 personnel.

\section{Air Force Installation and Mission Support Center}

Like the 2011 AFMC reorganization, the 2013 mandated cuts offered an opportunity to reengineer processes and consolidate like functions. AFMC again leveraged the personnel reduction mandate and centralized installation and mission support functions under a new AFIMSC. The span of control of the AFMC increased from five to six centers, and the hierarchy under AFMC was steepened; however, installation and mission support functions are now consolidated under one center.

As with the 2011 AFMC reorganization, this consolidation of like functions created new center headquarters AFIMSC staff (about 350); realigned many organizations; resulted in hundreds of reporting changes; and centralized programming actions for key agile combat support (ACS) resources within AFIMSC. The creation of the AFIMSC is an extension of the sound practices used during the 2011 AFMC reorganization efforts.

\section{Further Streamlining Opportunities at AFIMSC Below the Headquarters Level}

It is important to note that the creation of the AFIMSC and consolidation of installation and mission support functions offer an opportunity to improve enterprisewide ACS effectiveness and efficiency below the headquarters level. Past RAND analyses have shown that the current ACS manpower mix may be unable to meet contingency planning scenario needs, especially in antiaccess, area denial environments. ${ }^{29}$ Manpower requirements are determined by functional stovepipes instead of with an ACS enterprise focus, and most are based on needs to support homestation installation operations, not contingency operations. Flex-basing and dispersed-basing concepts in anti-access, area denial scenarios only increase the ACS expeditionary requirements.

Centralized, enterprisewide programming against operationally relevant metrics for expeditionary operations offers opportunities to improve effectiveness at lower costs. For

\footnotetext{
${ }^{29}$ Patrick H. Mills, John G. Drew, John A. Ausink, Daniel M. Romano, and Rachel Costello, Balancing Agile Combat Support Manpower to Better Meet the Future Security Environment, Santa Monica, Calif.: RAND Corporation, RR-337-AF, 2014.
} 
example, the AFIMSC could reprogram ACS resources for expeditionary operations to improve effectiveness and efficiencies. A focus on expeditionary operations would require trade-offs among home-station and expeditionary requirements (such as the number of surge bases versus the number of steady-state bases). And maximizing ACS enterprise contingency capabilities while maintaining home-station capabilities would require rebalancing personnel between active and reserve, between military and civilian, and across functional areas. The creation of the AFIMSC establishes an organization that can make enterprisewide programming decisions, thus providing an opportunity to further improve ACS effectiveness and efficiency. 


\section{Chapter Four: Opportunities for Additional Savings and Staff Reductions}

As we have described, the Air Force has faced a series of reductions affecting headquarters staffing and functions for more than a decade. In 2005, Program Budget Directive 720 reduced the total active Air Force by approximately 40,000 personnel, some of whom were headquarters personnel. In 2009, RMD 802 reduced contractor funding to lower the contractor workforce to the previous FY 2000 levels. The goal was to reduce contractors but increase civilian end strength by FY 2015. Then, in 2011, RMD 703A2 called for all services to return to their FY 2010 civilian staffing levels. This decision equated to an initial reduction of 16,500 civilian operation and maintenance authorizations across the Air Force. More than 4,026 personnel, or approximately 25 percent of these reductions, were taken from management positions at headquarters, FOAs, and bases. And most recently, in 2013, the Secretary of Defense directed a 20-percent headquarters reduction, which amounts to 2,978 positions in the Air Force.

These reductions have been deep - approximately 7,000 positions across Air Force headquarters, affecting all headquarters and their operations. Process changes, realignments, and major structural changes have all been made to achieve these large cuts. For example, AFMC reorganized into its current five-center construct to reduce its span of control. 13th Air Force was absorbed into the Pacific Air Forces staff, while 3rd Air Force and 17th Air Force were absorbed into U.S. Air Forces in Europe staff (with the exception of the Air and Space Operations Center). Global Strike Command, 25th Air Force, and the AFIMSC were all created to consolidate like functions, centralize decisionmaking, and achieve economies of scale in manpower. And the MAJCOMs have eliminated lower-priority work to reduce manpower.

The Air Force is currently analyzing headquarters processes and staffing distributions in place as a result of the reductions taken to date. As part of the initial cuts taken to meet the targeted apportionment, MAJCOMs reviewed, by each organizational element, those activities they would no longer be performing and identified the risks associated with not performing those activities. Since taking the cuts, they have been conducting in-depth resource allocation reviews to determine where resources need to be reallocated among or within directorates. The Air Force is also reviewing workloads to determine the effects that cuts may have on the mission. The Air Force may need to reverse some of the cuts or realign personnel to meet its strategic goals.

As a result, there do not appear to be any obvious MHA that stand out as immediate targets for the next round of reductions. During our interviews, Air Force personnel provided anecdotal 
evidence that any easy personnel reductions have already been garnered. ${ }^{1}$ The 2013 headquarters reductions of 20 percent required elimination of headquarters functions, several of which may have negative effects on headquarters mission sets. In fact, all MAJCOMs have identified areas adversely affected by the recent personnel reductions.

However, the 20-percent reductions did result in some positive improvements, such as major process enhancements and consolidation of like functions. The creation of the AFIMSC offers the potential for significant improvement of global installation and mission support effectiveness and efficiencies through enterprise ACS posture planning. Streamlining acquisition processes should reduce staffing and eliminate redundant workload, potentially making the acquisition review process more responsive. The mandated reductions were also the catalyst for consolidating major functions at HAF and within the MAJCOMs, such as the creation of the Air Staff Office of Strategic Plans and Programs (A5/8), and the realignment of certain portions of $\mathrm{AF} / \mathrm{A} 1$ and the AFPC.

Looking to the future, core organizational design principles may offer targets of opportunity for future Air Force reductions. If the Air Force were to focus on consolidating like missions and using a matrix management approach to achieve economies of scale, several opportunities may be worth further evaluation. For example, combining the Space and Missile Systems Center and AFLCMC; consolidating support functions across headquarters organizations (e.g., a single public affairs office to service HAF and all MAJCOMs); and combining HAF staffs (e.g., combining the Manpower and Reserve Affairs office in the Secretariat [SAF/MR] with AF/A1 and the Installations, Environment, and Energy office in the Secretariat [SAF/IE] with the Logistics, Engineering, and Force Protection office of the Air Staff [AF/A4]) may all offer potential for manpower savings while adhering to sound organizational and management practices. If the Air Force were to focus on opportunities to eliminate duplication and non-value added processes - for example, consolidating the programming, planning, budgeting, and execution process at HAF while eliminating the core function lead integrator processes, or eliminating the Service Acquisition Executive and assigning its responsibilities to AFMC - it may find more opportunities for savings. Yet another potential course of action would be for the Air Force to focus on driving work out of headquarters processes by eliminating non-value added or low-value processes and products.

Whatever actions are taken in the future, HAF leadership must emphasize the use of sound principles to identify opportunities for further cuts. And no matter which principle is used to identify targets of opportunity, further analysis by the Air Force will be required. Before the next round of reductions, HAF needs to specify the strategic direction and approach to be used in the process. The continuous process improvement group in the Office of the Deputy Under Secretary

\footnotetext{
${ }^{1}$ The time frame of the analysis did not allow us to conduct an in-depth quantitative analysis of work tasks to personnel to determine whether any additional personnel savings could be achieved by realigning workload within current manning documents.
} 
of the Air Force for Management could develop a detailed approach or, if preferred, could hire an outside consultant for its view of how to approach the next round of reductions. The MAJCOM continuous process groups could facilitate the implementation of the desired approach. Whatever the approach may be, detailed process reengineering and analysis of options takes time. And there needs to be a senior leadership governance council appointed to oversee the process, consisting of the VCSAF and MAJCOM Vice Chiefs of Staff, for example. Transparency of process and strategic communications are essential to the success of any reorganization or reduction.

While there do not appear to be any immediate easy opportunities for future reductions, if the Air Force focuses on the sound practices described in Chapter Three, it could find opportunities for process reengineering, consolidation, or elimination of tasks. All will require strategic direction, time, and analyses from the Air Force. 



\section{Chapter Five: Conclusions and Recommendations}

The first part of this analysis centered on providing an independent verification that the Air Force had indeed taken reductions meeting the intent of the 2013 Secretary of Defense mandate to reduce management headquarters funding and authorizations. As shown in Chapter Two and Appendix A, we determined that the Air Force did achieve the 20-percent reductions when using a technical count of PEC 98-coded positions, as reported in the Section 904 Report. And all MAJCOMs contributed to the reductions.

The rest of the analysis focused on sound practices, methodologies used to achieve headquarters management function reductions, and opportunities for future reductions. Industry practices emphasize several key considerations that should be included in any future MHA reduction initiatives, including early and regular engagement of a broad cross-section of stakeholders, consistency of approach and methods for long-term accountability and traceability, and simple messaging to aid the acceptability of reductions.

The Air Force approach to reducing its headquarters management functions included some examples of sound practices, such as identifying improved business processes that streamline information flow and eliminate work, eliminating or combining redundant organizations, and ensuring work is done at an appropriate organizational level.

Although sound practices were employed in meeting the management headquarters reductions in the Air Force, they were not applied consistently across the Air Force. Different MAJCOMs employed different strategies with differing results.

With a requirement for additional reductions likely in the near future, the Air Force asked RAND researchers to identify the degree to which opportunities currently exist for further reductions. Throughout the course of this analysis, we found that while additional opportunities to reduce MHA may exist, no areas stand out as immediate targets. MAJCOMs have already eliminated low-priority activities and are currently addressing the residual adverse effects from those reductions. Process reengineering and other efficiencies identified during previous reduction efforts can provide targets for future MHA reductions. However, they will take time and detailed analyses from the Air Force. And any initiative to reduce or streamline Air Force functions should be based on maintaining focus on the Air Force's strategic goals to ensure that organizational, process, or other changes do not lead to inefficient or ineffective processes or organizational structures. 



\section{Appendix A: Detailed Discussion of Reductions and Data}

In this appendix, we first provide a history of the different numbers associated with the headquarters changes that the Air Force has made and reconcile the 20-percent PEC 98 reductions with the reductions that were reported to Congress in 2014. We then display the 20percent PEC 98 reductions by military and civilian authorizations. Finally, we describe the databases and data adjustments that we used to assess the Air Force's reductions.

\section{A History of Different Reduction Numbers}

\section{Reduction Timeline}

As mentioned in Chapter Two, there have been many policy directives related to headquarters reductions. Air Force responses to these directives have been captured in memoranda and press releases that contain different numbers describing the reductions made. This appendix attempts to clarify some of these differences, and Table A.1 guides that discussion.

In Chapter Two, we pointed out that in response to the 2013 Strategic Choices and Management Review, the Air Force developed a Future Air Force Organization initiative that would improve headquarters effectiveness and efficiency, as well as reduce requirements for personnel. The first column of Table A.1 shows the initiative-related reductions that were proposed in a December 2, 2013, briefing presented at a Corona conference. ${ }^{1}$ According to the briefing, the baseline for these reductions was determined using the FY 2018 forecast from the FY 2014 PB (as directed by Secretary Hagel), although we were unable to find any documentation of the process by which this was done. The goal of 3,361 end-strength reductions was about 21 percent of the baseline, a reduction slightly above what Secretary Hagel directed. The baseline value and the reductions were based on positions above wing level. Some of these positions were technically considered "management headquarters" (coded with a PEC ending in 98), but some were coded with other PECs. MAJCOMs were expected to take a net reduction of 2,725 authorizations; other organizations (among them HAF and its FOAs, the Air National Guard, and the Air Force ISR Agency) were expected to take a net reduction of 636 authorizations.

\footnotetext{
${ }^{1}$ Tillotson, 2013. "Corona" conferences are strategic planning meetings where major leaders of the Air Force gather to discuss relevant issues.
} 
Table A.1. Timeline of Headquarters Reduction Documentation

\begin{tabular}{|c|c|c|c|c|c|}
\hline & $\begin{array}{c}\text { Corona Briefing } \\
\text { December 2, } \\
2013^{\mathrm{a}}\end{array}$ & $\begin{array}{c}\text { Corona Briefing } \\
\text { December 2, } \\
2013^{\text {b }}\end{array}$ & $\begin{array}{l}\text { VCSAF Memo } \\
\text { July } 9,2014^{c}\end{array}$ & $\begin{array}{l}\text { Congressional } \\
\text { Notification } \\
\text { July } 11,2014^{d}\end{array}$ & $\begin{array}{c}\text { Section } 904 \\
\text { Report } \\
\text { May } 2015^{\mathrm{e}}\end{array}$ \\
\hline $\begin{array}{l}\text { Net MAJCOM } \\
\text { reductions }\end{array}$ & 2,725 & 3,459 & 2,725 & 2,725 & \\
\hline $\begin{array}{l}\text { Reductions in } \\
\text { other } \\
\text { organizations }\end{array}$ & 636 & & 636 & 734 & \\
\hline Total reductions & 3,361 & 3,459 & 3,361 & 3,459 & 2,978 \\
\hline Comments & $\begin{array}{l}\text { Count includes } \\
\text { positions not } \\
\text { coded with PEC } \\
98 . \text { These } \\
\text { reductions were } \\
\text { programmed. }\end{array}$ & $\begin{array}{l}\text { Count includes } \\
\text { positions coded } \\
\text { with PEC } 98 \text { and } \\
\text { some not coded } \\
\text { with PEC } 98 \text {. This } \\
\text { count assumed } \\
\text { that the creation of } \\
\text { AFIMSC would } \\
\text { allow reductions in } \\
\text { MAJCOM } \\
\text { headquarters. }\end{array}$ & $\begin{array}{l}\text { Follows the } \\
\text { programmed } \\
\text { reductions } \\
\text { described in } \\
\text { December 2, } \\
2013 \text {, briefing, but } \\
\text { does not explicitly } \\
\text { mention } \\
\text { reductions in other } \\
\text { organizations. }\end{array}$ & $\begin{array}{l}\text { Count includes } \\
\text { positions coded } \\
\text { with PEC } 98 \text { and } \\
\text { some not coded } \\
\text { with PEC } 98 \text {. }\end{array}$ & $\begin{array}{l}\text { Count includes } \\
\text { only positions } \\
\text { coded with PEC } \\
98 \text {. Comparison is } \\
\text { between FY } 2018 \\
\text { and FY } 2016 .\end{array}$ \\
\hline
\end{tabular}

a Tillotson, 2013.

b Tillotson, 2013.

c Spencer, 2014.

d U.S. Air Force Office of Legislative Liaison, 2014.

e DoD, 2015.

The December 2013 briefing included another set of numbers that appears to describe potential reductions, as shown in the second column of Table A.1. The briefing lists the total personnel in each MAJCOM that are involved in installation support, and calculates 70 percent of this number. Adding up 70 percent of the installation support for each MAJCOM results in 3,459 positions. Apparently, the point of this chart was that the establishment of the new AFIMSC would allow the MAJCOMs to give up 3,459 positions - some of which would go to a new organization, and some of which would be eliminated. These reductions include both positions coded with PEC 98 and positions coded with other PECs.

The Air Force's goal was to achieve its reductions by the end of FY 2015. A July 9, 2014, memorandum from the VCSAF to the MAJCOMs noted that steps taken up to that point had not yielded the desired cuts. The memorandum refers to the total programmed reductions of 3,361 that were presented in the December 2013 briefing (although the memo does not mention that briefing) and, as in that briefing, notes the original "debt" of 2,725 net reductions for the MAJCOMs; this is shown in the third column of Table A.1. According to the VCSAF memo, 1,190 reductions remained to be made, and it described the "targeted apportionment" reductions that MAJCOMs would be responsible for (see Table A.2). The memorandum does not explicitly 
address the reductions made by other organizations; it implies that 636 reductions were made elsewhere (e.g., HAF and its FOAs, Air National Guard, Air Force ISR Agency). ${ }^{2}$

On July 11, 2014, two days after the VCSAF memorandum was sent, the Air Force issued a formal congressional notification of the impending cuts to prepare legislators for the potential effect of reductions in their districts and states. This notification again indicates that MAJCOM reductions will total 2,725, but it states that HAF and its FOAs will take cuts of 734. As shown in the fourth column of Table A.1, the total cuts are therefore 3,459, the same as the second number that was presented in the December 2013 briefing, although the reductions are distributed in a different way.

Finally, the 20-percent reductions directed by Secretary Hagel were to be made from headquarters organizations. The reductions described in the December 2013 briefing; the July 9 , 2014, memorandum; and the July 11, 2014, congressional notification all included positions that were not technically management headquarters positions (that is, not coded with PEC 98). To report the effect of its headquarters changes as required by Section 904 of the NDAA, the Air Force restricted its attention to changes that were made to positions coded with PEC 98 and used as a baseline the authorizations that were forecasted for FY 2018 in the FY 2014 PB, as required by Secretary Hagel. As shown in Chapter Two and in the last column of Table A.1, this comparison of PEC 98 positions showed that the Air Force had "cut" 2,978 authorizations.

The reports of different numbers were thus the result of different reporting contexts and different times.

\section{MAJCOM Breakdown of Reductions}

The net reduction of authorizations from the MAJCOMs is the same in three of the cases shown in Table A.1. The congressional notification showed reductions by MAJCOM, so Table A. 2 provides a closer look at the composition of these reductions, as described by Air Force leadership.

Three types of reductions that affected the MAJCOMs are shown in the table. First, some MAJCOM personnel (A1 staff) positions were given up in anticipation of savings that would result from centralizing personnel functions at the AFPC. ${ }^{3}$ Second, as part of the creation of AFIMSC, MAJCOMs gave up 350 authorizations to establish the AFIMSC headquarters. These are shown in the table as a negative number for AFIMSC (an addition), because there was no overall reduction in headquarters authorizations as a result of this change. However, MAJCOMs also gave up an additional 923 authorizations because of efficiencies expected to be associated

\footnotetext{
2 Spencer, 2014.

${ }^{3}$ While the MAJCOMs gave up about 76 authorizations, our discussions with MAJCOM staff indicated that efficiency gains were expected to result in the AFPC receiving only 25 of those positions back, for a net reduction of 51 authorizations.
} 
with establishing the AFIMSC. ${ }^{4}$ These authorizations were not transferred to the new center. The force structure adjustment column results from changes that were not directly related to Future Air Force Organization efforts. AF/A1 anticipated that DoD budget cuts would lead to force structure cuts in the MAJCOMs; all else being equal, smaller commands should require smaller headquarters staffs, so AF/A1 distributed additional MAJCOM headquarters cuts proportionally. Notice that Air Force Global Strike Command and Air Force Space Command were actually granted more authorizations because of force structure adjustments, as shown by the negative "reductions."

Table A.2. Status of Reductions in July 2014

\begin{tabular}{|c|c|c|c|c|c|}
\hline Organization & $\begin{array}{c}\text { (1) } \\
\text { Reductions } \\
\text { Associated } \\
\text { with AFPC } \\
\text { Consolidation }\end{array}$ & $\begin{array}{c}(2) \\
\text { Reductions } \\
\text { Associated } \\
\text { with AFIMSC } \\
\text { Initiative }\end{array}$ & $\begin{array}{c}\text { (3) } \\
\text { Force } \\
\text { Structure } \\
\text { Adjustment }\end{array}$ & $\begin{array}{l}\text { (4) } \\
\text { Targeted } \\
\text { Apportionment }\end{array}$ & $\begin{array}{l}\text { (5) } \\
\text { Total HQ } \\
\text { Reductions }\end{array}$ \\
\hline $\begin{array}{l}\text { Air Force Global Strike } \\
\text { Command }\end{array}$ & 6 & 101 & -3 & 62 & 166 \\
\hline $\begin{array}{l}\text { Air Force Special Operations } \\
\text { Command }\end{array}$ & 5 & 12 & & 4 & 21 \\
\hline Air Mobility Command & 11 & 173 & 43 & 63 & 290 \\
\hline Pacific Air Forces & 7 & 145 & 32 & 53 & 237 \\
\hline U.S. Air Forces Europe & 10 & 226 & 71 & 39 & 346 \\
\hline Air Combat Command & 12 & 240 & 201 & 289 & 742 \\
\hline $\begin{array}{l}\text { Air Education and Training } \\
\text { Command }\end{array}$ & 10 & 133 & 44 & 192 & 379 \\
\hline AFMC & 10 & 136 & 17 & 201 & 364 \\
\hline AFIMSC & & -350 & & & -350 \\
\hline Air Force Space Command & 5 & 107 & -4 & 165 & 273 \\
\hline Air Force Reserve Command & & & 135 & 122 & 257 \\
\hline MAJCOM total & 76 & 923 & 536 & 1,190 & 2,725 \\
\hline HAF and other organizations & & & & & 636 \\
\hline Total & & & & & 3,361 \\
\hline \multicolumn{6}{|c|}{$\begin{array}{l}\text { SOURCE: These numbers are from Spencer, } 2014 \text {. The memo lays out only the MAJCOM reductions; it appears to } \\
\text { assume that } 636 \text { cuts were made in other organizations in order to reach the original goal of } 3,361 \text { reductions. All of } \\
\text { these numbers should be considered approximate. }\end{array}$} \\
\hline
\end{tabular}


By July 2014, reductions resulting from these three types of changes fell 1,190 short of the goal of 3,361. Because the Air Force needed to complete the reductions by the end of FY 2015, ${ }^{5}$ these 1,190 cuts were distributed among the MAJCOMs in a "targeted" way. First, the 1,190 cuts were distributed proportionately based on the size of a MAJCOM's headquarters. Then, because the Air Force wanted to lower the risk of reductions to staffs in the warfighting commands (Air Force Global Strike Command, Air Force Special Operations Command, Air Mobility Command, Pacific Air Forces, and U.S. Air Forces Europe), their new reductions were essentially cut in half, with the difference added to the reductions required of the other commands. ${ }^{6}$ These targeted reductions are shown in column 4 of Table A.2. The MAJCOMs were "empowered" to determine what workload reductions they would accept in making these additional cuts. The total reductions by individual MAJCOM, shown in the last column of Table A.2, are the same as those in the July 2014 congressional notification.

\section{Authorization Reductions at the MAJCOM Level}

As discussed in Chapter Two, ABIDES data comparing the number of PEC 98 positions in the FY 2018 forecast in the FY 2014 PB with what the Air Force planned in the FY 2016 column of the FY 2016 PB showed that the Air Force had reduced the total number of authorizations by 2,978 (RAND showed a slightly smaller reduction of 2,969). The Section 904 Report did not require the Air Force to break this reduction down by MAJCOM, but it is useful to do so to help address criticism that no actual reductions were made. Table A.3 presents this information by headquarters organization.

\footnotetext{
5 As mentioned in Chapter Two, our discussions with AF/A1 indicate that the 3,361 "wedge" was developed as part of the Strategic Choices and Management Review, and when initial Future Air Force Organization efforts fell short of the total reductions that were already programmed, remaining reductions had to be distributed among the MAJCOMs (U.S. Air Force AF/A1 staff, 2015).

${ }^{6}$ This process was described in a discussion with AF/A1 (U.S. Air Force AF/A1 staff, 2015). No documentation was provided to support it, but independent calculations by one of the authors using this approach resulted in cuts very close to those shown in the targeted apportionment column of Table A.2.
} 
Table A.3. Detailed Changes in PEC 98-Coded Authorizations

\begin{tabular}{|c|c|c|c|c|c|c|}
\hline $\begin{array}{l}\text { Headquarters } \\
\text { Organization }\end{array}$ & $\begin{array}{l}(1) \\
\text { PEC 98 End } \\
\text { Strength in } \\
\text { FY 2014 of } \\
\text { FY 2014 PB }\end{array}$ & $\begin{array}{c}(2) \\
\text { PEC 98 } \\
\text { Baseline } \\
\text { (FY 2018 of } \\
\text { FY 2014 PB) }\end{array}$ & $\begin{array}{l}(3) \\
\text { PEC 98 End } \\
\text { Strength in } \\
\text { FY } 2016 \text { of } \\
\text { FY } 2016 \text { PB }\end{array}$ & $\begin{array}{c}(4) \\
\text { PEC 98 } \\
\text { "Reduction" } \\
\text { from } \\
\text { Baseline }\end{array}$ & $\begin{array}{c}(5) \\
\text { Other } \\
\text { Changes }\end{array}$ & $\begin{array}{c}(6) \\
\text { Total } \\
\text { Reductions }\end{array}$ \\
\hline $\begin{array}{l}\text { Air Force Global Strike } \\
\text { Command }\end{array}$ & 1,013 & 971 & 808 & 163 & & 163 \\
\hline $\begin{array}{l}\text { Air Force Special } \\
\text { Operations Command }\end{array}$ & 93 & 83 & 70 & 13 & & 13 \\
\hline Air Mobility Command & 1,202 & 1,201 & 999 & 202 & 99 & 301 \\
\hline Pacific Air Forces & 978 & 948 & 528 & 420 & -189 & 231 \\
\hline U.S. Air Forces Europe & 1,106 & 875 & 438 & 437 & -91 & 346 \\
\hline Air Combat Command & 2,268 & 2,259 & 1,572 & 687 & 48 & 735 \\
\hline $\begin{array}{l}\text { Air Education and Training } \\
\text { Command }\end{array}$ & 1,119 & 1,121 & 735 & 386 & & 386 \\
\hline AFMC & 1,389 & 1,369 & 962 & 407 & -43 & 364 \\
\hline AFIMSC & & & 338 & -338 & & -338 \\
\hline Air Force Space Command & 897 & 865 & 609 & 256 & & 256 \\
\hline $\begin{array}{l}\text { Air Force Reserve } \\
\text { Command }\end{array}$ & 692 & 692 & 528 & 164 & & 164 \\
\hline Subtotal & 10,757 & 10,384 & 7,587 & 2,797 & -176 & 2,621 \\
\hline $\begin{array}{l}\text { Air Force District of } \\
\text { Washington }\end{array}$ & 54 & 48 & 0 & 48 & & 48 \\
\hline $\begin{array}{l}\text { 25th Air Force and Air } \\
\text { Force ISR Agency }\end{array}$ & 109 & 109 & 2 & 107 & & 107 \\
\hline HAF and FOAs & 3,338 & 3,271 & 3,227 & 44 & & 44 \\
\hline Other non-MAJCOM & 19 & 35 & 62 & -27 & & -27 \\
\hline Subtotal & 3,520 & 3,463 & 3,291 & 172 & & 172 \\
\hline Total & 14,277 & 13,847 & 10,878 & 2,969 & -176 & 2,793 \\
\hline
\end{tabular}

SOURCE: RAND analysis of ABIDES data contained in the file "PB1416_ABIDES_ES_20151220.xIsx."

NOTE: The "Other non-MAJCOM" category includes Air Force elements and other PEC 98 authorizations that were difficult to categorize.

The first column of the table shows the RAND count of PEC 98-coded authorizations by MAJCOM in the FY 2014 column of the FY 2014 PB. When these values are compared with the FY 2018 count forecast in the FY 2014 PB - the baseline for the 20-percent cuts shown in the second column of the table - we see that the number of authorizations decreased overall and 
decreased for the majority of MAJCOMs. In other words, the Air Force did not inflate its plans for FY 2018 to be able to claim that its FY 2016 plan showed larger cuts.

The third column of Table A.3 shows the FY 2016 Air Force plan for end strength (for PEC 98 positions) as presented in the FY 2016 column of the FY 2016 PB - where the Air Force claims it achieved its 20-percent cuts-and the fourth column compares these values with the FY 2018 baseline of column 2. Reductions are shown in column 4 as positive numbers, and increases as negative. As can be seen, every MAJCOM reduced positions that are coded with PEC 98, and the total reductions in PEC 98 positions is 2,969. However, the individual MAJCOM reductions differ from those listed in the July 9, 2014, memorandum directing the targeted apportionment cuts and in the July 2014 congressional notification. For example, Pacific Air Forces' reduction in PEC 98 positions is 420, when the congressional notification showed a reduction of only 237.

This is partially explained by the fact that reductions made as part of the Future Air Force Organization initiative and the management headquarters review included positions that were not coded with PECs ending in 98. Changes also involved recategorizing some positions.

For example, AFMC was directed to take a total of 364 cuts. The management change request submitted by AFMC as part of the management headquarters review shows a reduction of 364 positions in FY 2016. ${ }^{7}$ However, it also shows that 43 PEC 98 positions were converted to positions with different PECs. Because the ABIDES database does not allow tracking positions that are converted, RAND's analysis found the 364 reduction plus the elimination of the 43 PEC 98 positions that had been recoded, for the total of 407 for AFMC shown in column 4 of the table. Adjustments such as those made by AFMC (transfers of PEC 98 positions to other PECs, as well as changes in other PECs that were not examined to verify the 20-percent reduction) were provided by several MAJCOMs and are shown in column 5 of Table A.3. Taking these changes into account, with the exception of Air Force Reserve Command (for which we did not receive information on adjustments), the total reductions (column 5) shown in Table A.3 for the MAJCOMs are very close to the reductions shown in Table A.2 that were included in the July 2014 congressional notification.

\section{Reductions to Headquarters Air Force and Field Operating Agencies}

As seen in Table A.3, there were few PEC 98 reductions in the HAF and FOA categories when comparing FY 2018 of the FY 2014 PB with FY 2016 of the FY 2016 PB. This does not affect the fact that the Air Force achieved its 20-percent reductions overall, but in light of the original goals for reductions mentioned in Table A.1, it does require some explanation. As mentioned in Chapter Two, RAND obtained copies of memoranda that described the offices

\footnotetext{
${ }^{7}$ Spreadsheets showing MAJCOM adjustments for AFMC, Air Combat Command, Air Mobility Command, Pacific Air Forces, and U.S. Air Forces in Europe were provided to RAND by the respective MAJCOM A1 organizations.
} 
from which 735 cuts were to be made from HAF and FOA organizations. ${ }^{8}$ The chief of the manpower division in the Office of the Administrative Assistant to the Secretary of the Air Force explained in email exchanges that, while funding reductions were achieved by the end of FY 2015, authorization reductions were planned to take place from FY 2015 through FY 2019. ${ }^{9}$ He provided instructions on how to examine the UMD to check for changes in funded authorizations, and RAND determined that the document shows that organizations targeted for reductions had 705 funded authorizations in FY 2015 and 79 in FY 2019-a reduction of 626. ${ }^{10}$ He also described the reduction exercise as "dynamic" (that is, the reduction numbers fluctuated as decisions were made over the course of several months). Reduction counts were taken at different points in time and, therefore, the total reduction observed depends on the day each "snapshot" was taken. The chief of the manpower division provided a spreadsheet that showed how these reductions, plus others not reflected on the UMD, could be tracked to about $735 .^{11}$

The UMD indicates that, over this period, the number of PEC 98 positions will be reduced by about 370, and the other reductions are from other PECs. The "dynamic nature" of all manpower and budgeting databases contributes to the fact that this difference did not appear in the ABIDES analysis. ABIDES data for the FY 2014 PB are published about 18 months earlier than the endof-FY-2014 UMD, so many changes could easily have occurred in the intervening year and a half.

A comparison of planned funding in the FY 2014 PB and the FY 2016 PB shows an interesting aspect of HAF funding when compared with the MAJCOMs. The ABIDES data indicate that HAF contractor funding was almost 78 percent of all contractor funding related to PEC 98 positions in FY 2018 of the FY 2014 PB, and that 90 percent of the reductions in contractor funding observed when this is compared with FY 2016 of the FY 2016 PB came from changes made in HAF.

\section{Conclusion}

As mentioned in Chapter Two, there has been concern that some apparent reductions resulted from merely transferring authorizations from one organization to another with no change in the work associated with the authorization. Some MAJCOM authorizations were in fact transferred

\footnotetext{
${ }^{8}$ Fanning and Spencer, 2014a, which described 325 cuts, and Fanning and Spencer, 2014b, which described 409 cuts.

${ }^{9}$ Office of the Administrative Assistant to the Secretary of the Air Force staff, email correspondence with the authors, December 10, 2015.

${ }^{10}$ Specifically, we were advised to examine the September 2014 end-of-month snapshot from the Manpower Programming and Execution System historical universe and look for positions with the code "FAFOR" (for Future Air Force Organization Reduction) in the "Command Remarks 2" field of the UMD.

${ }^{11}$ The Excel spreadsheet provided was named "HQ and FOA Future AF Org Baseline and Draft Manpower Reductions to Date 04-Dec-14.xlsx."
} 
to AFPC, but expected gains in efficiency led to a net reduction in the number of authorizations. Some apparent reductions in PEC 98-coded positions found in our analysis of ABIDES data were the result of recoding positions. In the cases we found, however, either the MAJCOM did not take credit for the reduction (AFMC) or credit was appropriate because the position did not involve management headquarters activities (this was the case for about 76 positions at Air Mobility Command).

The actual numbers observed for Air Force headquarters reductions depend on the data source (ABIDES versus UMD, for example) and the date that the data were reported. The MAJCOMs were originally expected to reduce their headquarters authorizations by 2,725. Our ABIDES analysis comparing FY 2016 with FY 2018 showed MAJCOM reductions of more than 2,700 PEC 98-coded positions, and analysis of UMD data (again comparing FY 2016 with FY 2018) showed MAJCOM reductions of more than 2,500. The AF/A1 office provided us with documents showing that positions associated with these reductions were either completely eliminated or used to fund nonheadquarters positions for other Air Force priorities, such as cyber, intelligence, and weapon systems. ${ }^{12}$

MAJCOMs gave up 1,273 authorizations for the establishment of AFIMSC. As noted above, 350 of these positions were transferred to AFIMSC's headquarters; this transfer is apparent in both ABIDES and UMD data. According to interviews with MAJCOMs and AF/A1 Manpower, the remaining 923 reductions were "true" reductions - that is, they were not transferred to AFIMSC, but were either eliminated or used to fund other Air Force priorities - and this is borne out by ABIDES and UMD data.

The "steady-state" authorized end strength in AFIMSC detachments will be 275, and these billets will be sourced from efficiencies gained by realigning and integrating into AFIMSC some activities from the Air Force Civil Engineering Center, the Air Force Installation Contracting Agency, the Air Force Financial Services Center, the Air Force Security Forces Center, the services functions from the AFPC, and the Financial Management Center of Expertise from the Air Force Cost Analysis Agency. This plan is apparent when comparing FY 2015 of the September 30, 2015, UMD with FY 2014 of the September 30, 2014, UMD: These organizations lose about 275 total authorizations. ${ }^{13}$ However, UMD data and other Air Force documents show that the new MAJCOM detachments associated with AFIMSC will initially have 414 authorizations. The additional 139 authorizations (414 minus 275) will "be accommodated from

\footnotetext{
12 U.S. Air Force, "FY 15 PB Manpower Drivers," PowerPoint slides, undated (provided to RAND by AF/A1 Manpower on January 28, 2016). We also received MAJCOM examples describing the number of unfilled civilian positions that were eliminated and the number of civilians who accepted the Voluntary Separation Incentive Program or the Voluntary Early Retirement Authority as a result of the authorization reductions.

13 These authorizations appear in the FY 2015 column of the September 30, 2015, UMD. The operating locations are discussed in an August 28, 2014, memorandum (Larry O. Spencer, Vice Chief of Staff of the Air Force, and Eric K. Fanning, Under Secretary of the Air Force, "Air Force Installation and Mission Support Center (AFIMSC) Operating Locations (OLs)," memorandum to the AFMC commander, August 28, 2014).
} 
within overall Air Force authorized end strength levels for FY 15-17."14 The authorizations will be drawn down to the steady state of 275 by $2021 .^{15}$

Thus, many changes have been made in Air Force headquarters since the 2013 Strategic Choices and Management Review and the Secretary of Defense direction to reduce headquarters budgets by 20 percent. The timing and context of different reports about the effects of these changes can lead to initially confusing differences in numbers; nonetheless, analysis of ABIDES data shows that 20-percent reductions in PEC 98-coded authorizations and funding were achieved by the end of FY 2015.

\section{Breakdown of PEC 98 Reductions by Military and Civilian Authorizations}

Table A.4 summarizes the Air Force's 20-percent reductions by military, civilian, and nonpay categories.

Table A.4. Civilian and Military Breakdown of End-Strength and Funding Reductions

\begin{tabular}{|c|c|c|c|c|c|c|}
\hline & \multicolumn{2}{|c|}{$\begin{array}{c}\text { Baseline (FY } 2018 \text { of the } \\
\text { FY } 2014 \text { PB) }\end{array}$} & \multicolumn{2}{|c|}{ FY 2016 PB Submit } & \multicolumn{2}{|c|}{$\begin{array}{c}\text { Percentage } \\
\text { Change from } \\
\text { Baseline }\end{array}$} \\
\hline & Air Force & RAND & Air Force & RAND & Air Force & RAND \\
\hline \multicolumn{7}{|l|}{ End strength } \\
\hline Military authorizations & 7,594 & 7,594 & 5,406 & 5,412 & $-28.8 \%$ & $-28.7 \%$ \\
\hline Civilian authorizations & 6,253 & 6,253 & 5,463 & 5,466 & $-12.6 \%$ & $-12.6 \%$ \\
\hline Total & 13,847 & 13,847 & 10,869 & 10,878 & $-21.5 \%$ & $-21.4 \%$ \\
\hline \multicolumn{7}{|l|}{ Funding ( $\$$ thousands) } \\
\hline Military personnel pay & $\$ 1,016,577$ & $\$ 1,016,577$ & $\$ 714,606$ & $\$ 714,606$ & $-29.7 \%$ & $-29.7 \%$ \\
\hline Civilian pay & $\$ 758,711$ & $\$ 763,323$ & $\$ 616,167$ & $\$ 616,167$ & $-18.8 \%$ & $-19.3 \%$ \\
\hline $\begin{array}{l}\text { Operation and maintenance } \\
\text { non-pay }\end{array}$ & $\$ 95,560$ & $\$ 91,384$ & $\$ 61,739$ & $\$ 61,110$ & $-35.4 \%$ & $-33.1 \%$ \\
\hline Total & $\$ 1,870,848$ & $\$ 1,871,284$ & $\$ 1,392,512$ & $\$ 1,391,883$ & $-25.6 \%$ & $-25.6 \%$ \\
\hline $\begin{array}{l}\text { Total excluding military } \\
\text { personnel (\$ thousands) }\end{array}$ & $\$ 854,271$ & $\$ 854,707$ & $\$ 677,906$ & $\$ 677,277$ & $-20.6 \%$ & $-20.8 \%$ \\
\hline
\end{tabular}

The top half of the table shows the end-strength reductions. For example, the "Total" row shows the authorization baseline of 13,847, the FY 2016 numbers determined by the Air Force

\footnotetext{
${ }^{14}$ Spencer and Fanning, 2014. In addition, "AFMC is authorized to carry necessary overages and to over execute the Unit Manpower Document to establish the AFIMCS [operating locations] during this time period" (Spencer and Fanning, 2014).

${ }^{15}$ Larry O. Spencer, Vice Chief of Staff of the Air Force, "Air Force Installation and Mission Support Center (AFIMSC) Operating Locations," memorandum to the AFMC commander and AF/A1, March 30, 2015.
} 
and by RAND, and the percentage change determined by the Air Force and RAND. This part of the table shows how the reductions were distributed among military and civilian authorizations.

The bottom half of the table shows the funding reductions broken down by military personnel pay, civilian pay, and operation and maintenance non-pay, which can include contractor salaries, as well as equipment. Recall that military pay reductions do not count toward the 20-percent spending reduction goal, so the last row of Table A.4 excludes them.

\section{Description of Databases Used}

\section{Data for Confirming the 20-Percent Reduction}

The data source for verifying the 20-percent reduction in authorizations coded with PEC 98 was the ABIDES database. ABIDES is the classified database that hosts the Air Force's Force and Financial Plan and the Options Development System, which is a database for all recommended FYDP adjustments. ${ }^{16}$ RAND has access to the ABIDES database through its Military Operations Simulation Facility in Santa Monica, California.

To determine baseline personnel authorizations and funding, RAND examined the FY 2018 entry of the FY 2014 PB, looking only at positions with PEC 98 under the following criteria:

- Full-time military in the active-duty and reserve components were counted; no individual mobilization augmentees or part-time reservist positions were included.

- Direct hire civilians were counted.

- National Intelligence Program PECs and Air National Guard Readiness Center authorizations were excluded.

- An error in the ABIDES data for FY 2018 double-counted 175 positions in U.S. Air Forces in Europe and a handful of positions in other commands (confirmed by AF/A1 Manpower), which we deleted.

For funding, the following criteria were used. Military pay costs were drawn from appropriations 3500 (Military Personnel, Air Force) and 3700 (Reserve Personnel, Air Force) for PECs ending in 98F, excluding those associated with the National Intelligence Program and all positions in the Air National Guard Readiness Center.

Operation and maintenance costs - including civilian pay; contractor operation and maintenance costs; and other, non-contractor operation and maintenance costs-consisted of appropriations 3400 (Operation and Maintenance, Air Force) and 3740 (Operation and Maintenance, Air Force Reserve). Codes used in the data permit the separate identification of these three types of operation and maintenance costs. We excluded costs associated with the

\footnotetext{
${ }^{16}$ See U.S. Air Force, Manpower and Organization: Programming USAF Manpower, Washington, D.C., Air Force Instruction 38-204, April 21, 2015b.
} 
National Intelligence Program and all positions in the Air National Guard Readiness Center. Again, all data were for PEC 98 positions only.

To determine if the Air Force achieved its 20-percent reductions by the end of FY 2015, the same authorization and funding criteria were used to examine the FY 2016 entry in the FY 2016 PB.

\section{Other Analyses}

RAND's analysis also included UMD data. The UMD is a component of the Manpower Programming and Execution System, to which RAND has access. The system exists in two forms. The "high side" is classified and is used by the Air Staff to specify manpower figures in the FYDP. All locations in the continental United States are rolled up into a single "country" in the classified UMD, but overseas locations are categorized by individual country codes (Alaska, Hawaii, and other U.S. territories are classified as overseas and have individual country or state codes). As a result, there are no specific location, unit, or other position descriptions in the FYDP. The "low-side" UMD has full position details (e.g., unit, installation, Air Force specialty code, facility) that are worked out by the MAJCOMs in response to their allocated authorizations from the FYDP, including MAJCOM, resource identification code (the personnel type), PEC, Air Force specialty code, and other data elements.

These differences led to difficulties in analyzing the data. For example, because the 20percent reduction was based on FY 2018 information that was forecasted in FY 2014, the highside information allowed us to examine the distribution of PEC 98 positions by MAJCOM, but not by location, unit, installation, or Air Force specialty code. Thus, when comparing FY 2018 with the Air Force position in FY 2016, it was relatively easy to determine the overall reductions in PEC 98 authorizations, but was impossible to observe the changes in positions by unit and location.

Individual UMD spreadsheets from several MAJCOMs (AFMC, Air Combat Command, Air Mobility Command, Pacific Air Forces, and U.S. Air Forces in Europe) allowed us to study their changes and reductions more closely, but many details were difficult to track because of the timing of data releases. For example, the FY 2014 PB, estimating Air Force authorizations for FY 2014, would have been released in February or March 2013, but the end-of-year FY 2014 UMD — with the "actual" number of authorizations — was dated at the end of the fiscal year, in September 2014, almost 18 months later.

The low-side UMD was used to examine planned HAF reductions and to perform a "delayering" analysis to see whether headquarters echelons and spans of control were reduced. UMD data are unclassified but For Official Use Only because of future projections that are still subject to deliberations. The data from the high-side UMD are unclassified when summarized to the level of MAJCOM, resource identification code, and PEC, with National Intelligence Program PECs excluded. 


\section{Appendix B: Delayering in the Air Staff and Secretariat}

The Air Force asked the RAND Corporation to provide a high-level review of the delayering that was accomplished within the Air Staff and Secretariat during the management headquarters reductions taken in FY 2015. This appendix provides the results of that preliminary, high-level analysis.

\section{Examining Span of Control and Levels of Hierarchy to Assess Delayering}

To conduct the analysis, we started by reviewing how to define delayering and the methods for measuring it. We refer to some of Mintzberg's academic literature to define delayering and examine the effect it has on organizational design. Mintzberg's theories are described in more detail in Appendix D.

Mintzberg highlighted the five elements of the organization: the strategic apex, operating core, middle line, support staff, and technostructure. Delayering an organization is generally viewed to mean eliminating levels of staff that exist in middle management, the support staff, and the technostructure. This process also is sometimes referred to as flattening an organization. Eliminating staff in these areas affects the design of formal reporting relationships, which is dictated by span of control and levels of hierarchy. A flat or delayered organization is characterized by fewer levels of hierarchy, with each level having a broader span of control, as opposed to a hierarchical organization, where many levels of hierarchy have narrower spans of control. $^{1}$

For the purposes of our brief analysis, we examined changes in the span of control and levels of hierarchy within the Air Staff and Secretariat. We used the UMDs from September 2014 as the baseline and compared the span of control and levels of hierarchy with the data in the UMD from September 2015. Each organizational element in the document was assigned to a level. The offices of the Chief of Staff of the Air Force and the Secretary of the Air Force and their immediate staffs were each assigned to Level 1. Each subordinate organization was subsequently assigned a level based on their office symbol and/or description (for example, two-digit office symbols were classified as a Level 2). Where A-Staff functions had been combined (for example, A-4/7), they were viewed as a Level 2.

\footnotetext{
${ }^{1}$ For a description of the delayering approach that the Boston Consulting Group developed for the U.S. Army, see U.S. Army, 2014.
} 
To form the basis of comparison with delayering analysis performed for other services, we considered some of the principles that the Army established when it analyzed its headquarters structure. ${ }^{2}$ For the purpose of this analysis, we applied the following ground rules:

- The Secretary of the Air Force and Under Secretary of the Air Force, as well as the Chief of Staff of the Air Force and Vice Chief of Staff, were all considered a Level 1.

- Unique liaison positions (for example, reserve adviser or individual mobilization augmentees) assigned to Level 2 offices were not counted toward span of control.

- When an organization had subordinate directorates or divisions, the span of control was measured by counting the number of directorates or divisions directly below the primary organization being measured. When an organization had no subordinate levels, the span of control was the count of the number of persons in the organization being measured.

- Front office staffs - including administrative staffs, executive officers, commander's action groups, and so on - all appeared to be grouped into organizations typically referred to as "executive services" and were therefore included in the span of control counts that were a measure of subordinate directorates/division.

- When a rule for whether or not to include specific data was applied, it was applied consistently to both FY 2014 and FY 2015 data (for example, National Guard Bureau was excluded from the analysis in both years).

Given a limited time to perform the analysis, we did not review staff structures within offices to make assessments of the grade structure, same grade levels reporting to each other, or excessive numbers of senior personnel.

\section{Results of Analysis}

Our analysis revealed three key points that are explained in more detail below:

- From FY 2014 to FY 2015, one level of hierarchy was eliminated. In FY 2014, some organizations were classified as Level 5. In FY 2015, the lowest level of organization was classified as a Level $4 .^{3}$

- From FY 2014 to FY 2015, the span of control decreased from an organization count perspective.

- From FY 2014 to FY 2015, the span of control increased both from the perspective of the number of personnel in the office representing the lowest level of an organization and from the average size of all organizations with the Air Staff and Secretariat.

Figure B.1 shows the average span of control for every level of hierarchy for both FY 2014 and FY 2015. This span of control measure is the average number of subordinate organizational elements for each level that had subordinate organizational elements.

\footnotetext{
${ }^{2}$ See U.S. Army, 2015b.

${ }^{3}$ The majority of Level 5 organizations existed in AF/A3, AF/A4/7, and the Air Force Personnel Operations Agency. We excluded data from the Air Force Personnel Operations Agency, which was a FOA in FY 2014 and was subsequently realigned under $\mathrm{AF} / \mathrm{A} 1 \mathrm{X}$ as a named activity.
} 
Figure B.1. Span of Control, by Number of Subordinate Organizational Elements

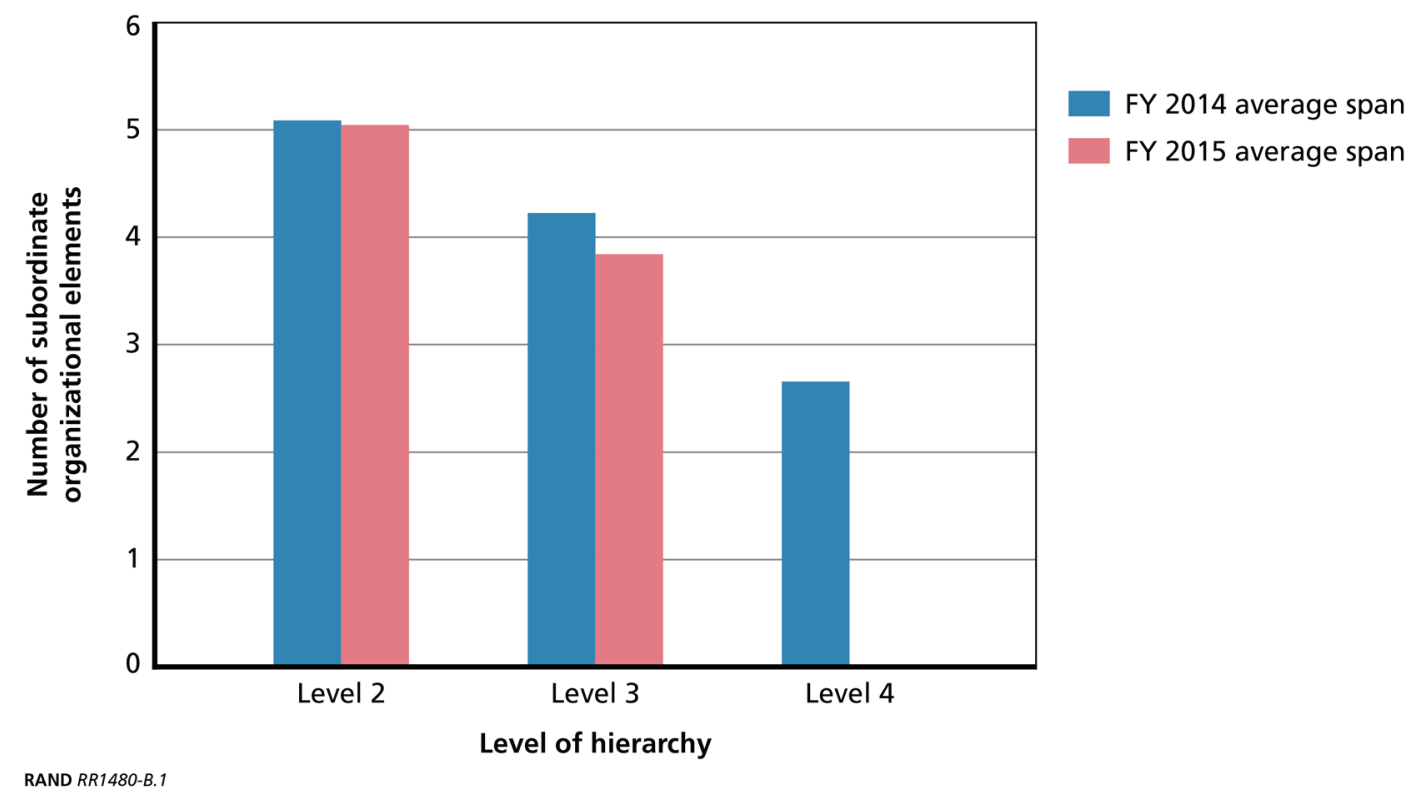

For each level within the hierarchy, the average number of subordinate organizational elements has decreased. Of particular note is that for Level 4 organizational elements, there is a complete elimination of subordinate elements from FY 2014 to FY 2015. This shows a reduction in one level of hierarchy over the two years.

Figure B.2 shows the average number of personnel in organizational elements that do not have subordinate elements; we observe that the average size of these organizations increased from FY 2014 to FY 2015-except, of course, for Level 5 organizational elements, which were eliminated. 
Figure B.2. Span of Control, by Number of Personnel in the Lowest-Level Organizational Element

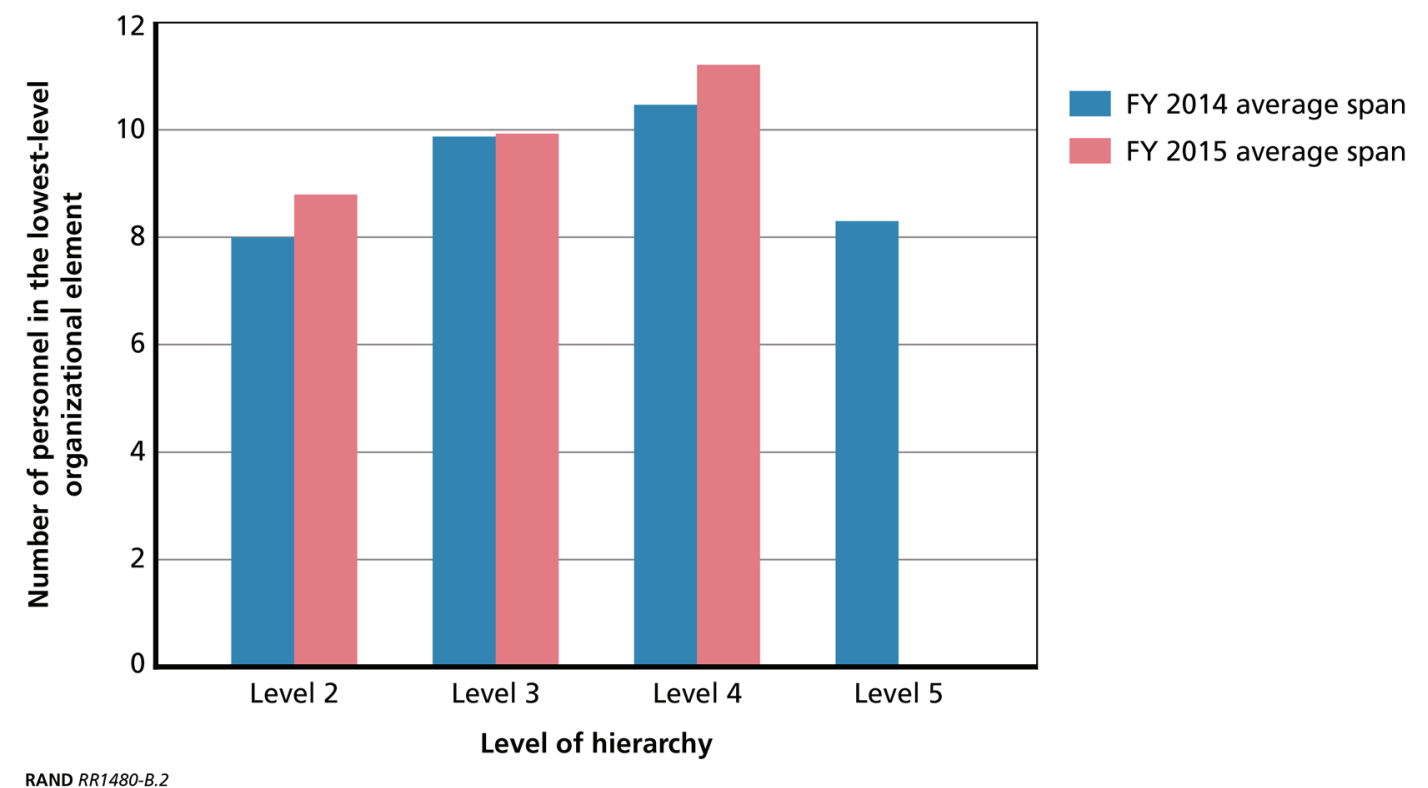

Figures B.1 and B.2 appear to suggest that there has been a consolidation of offices at each level in the hierarchy, resulting in larger staffs within those consolidated offices. The effect of this is an increase in the span of control for the leadership in the offices that exist at the lowest level within the respective Level 2 organization.

Figure B.3 amplifies those findings. The figure shows the change in the average number of personnel in each distinct organizational element at each level from FY 2014 to FY 2015, as well as the number of organizational elements at each level. With the exception of Level 3, which decreased slightly, and Level 5, which was eliminated for FY 2015, there is an increase in the average size of organizations. This includes a nearly 36-percent growth in the size of the organizational elements at Level 2 of the hierarchy, consolidation of Level 3 subordinate organizations, and a 10-percent increase in the average size of Level 4 organizations, which is likely the result of eliminating the lowest level in the hierarchy. By comparing FY 2014 (the triangles) with FY 2015 (the circles), Figure B.3 also shows how the total number of organizational elements at each level in the Air Staff and Secretariat changed during the period. The number of Level 2 elements was about the same, the number of Level 3 elements increased, and the number of Level 4 elements decreased. In FY 2014, there were 426 organizations across all five levels of hierarchy. That number was reduced to 374 in FY 2015, including the elimination of 34 organizations at Level 5. 
Figure B.3. Span of Control, by Number of Personnel and Organizations

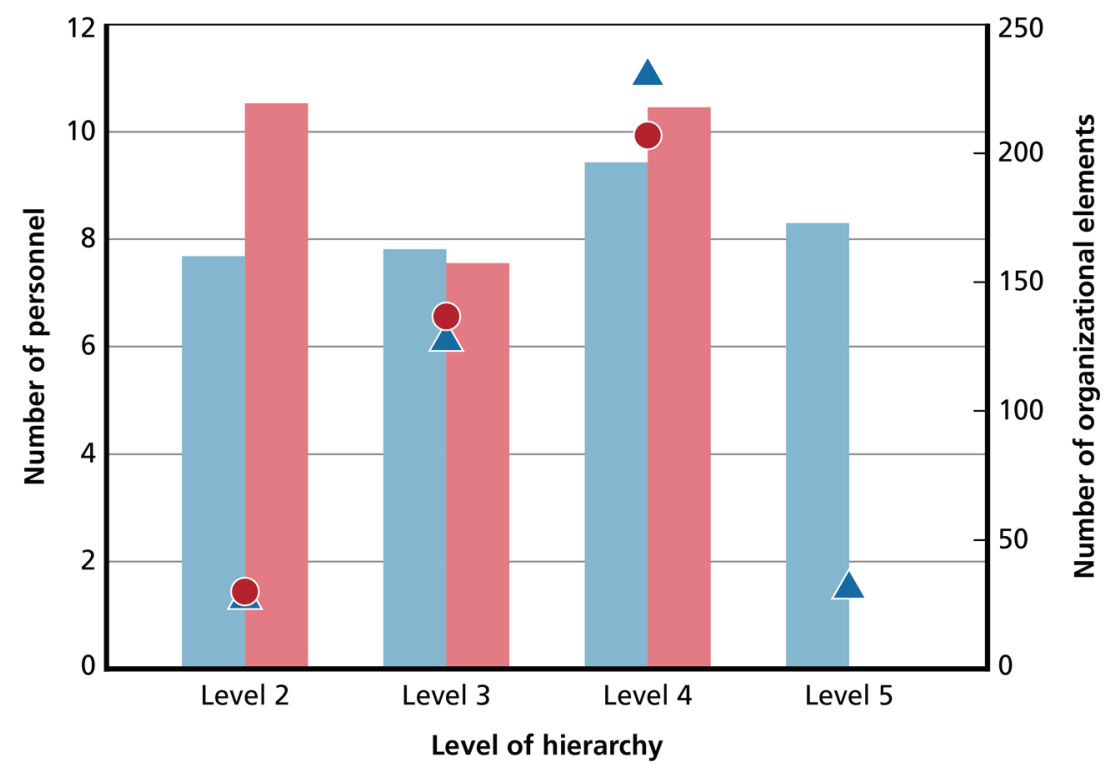

FY 2014 average span (number of personnel)

FY 2015 average span (number of personnel)

A FY 2014 span (number of organizational elements)

FY 2015 span (number of organizational elements)

RAND RR1480-B.3

Without drawing conclusions about what the appropriate span of control or levels of hierarchy should be, the Air Force's management headquarters reduction eliminated a level of hierarchy, ${ }^{4}$ reduced the overall number of organizational elements within the Air Staff and Secretariat, and increased the average span of control from a headcount perspective for the elements that remained. The headquarters reduction activities also resulted in a net decrease of 326 positions within the Air Staff and Secretariat, based on a comparison of the FY 2014 and FY 2015 UMDs. ${ }^{5}$ Finally, for Level 4 organizations, the average ratio of the number of personnel to the number of colonels increased slightly (from 10.8 to 11.4).

This is a fairly mechanical look at the hierarchical impact of headquarters changes made by the Air Force, and while there are likely benefits to delayering, additional analysis is required to assess its impact on the effectiveness and efficiency of organizational processes.

\footnotetext{
${ }^{4}$ The management headquarters reduction activities for the Air Force eliminated the fifth level of the hierarchy within the Air Staff and the Secretariat. In our review of the actions taken by the Department of the Army (see Appendix F), that service's target for levels of hierarchy was seven, with a minimum span of control of eight.

${ }^{5}$ Our count in the FY 2014 UMD is 4,284 (excluding 106 in the National Guard Bureau). Our count in the FY 2015 UMD is 3,958 (excluding 206 in the Air Force Personnel Operations Agency and 63 in the National Guard Bureau). Because these changes are based on UMD data from FY 2014 and FY 2015, the numbers differ from headquarters comparisons made earlier using ABIDES data.
} 



\section{Appendix C: Annotated Bibliography}

Our analysis of academic and management literature included a review of numerous books, reports, and articles that address theory and common practices related to organizational design and restructuring. In this appendix, we present an annotated bibliography of the most relevant literature on the topic. For each entry, we provide the source document and a synopsis of the pertinent content.

\section{Academic Literature Review}

Aronowitz, S., A. De Smet, and D. McGinty, "Getting Organizational Redesign Right," McKinsey Quarterly, June 2015.

Companies will better integrate their people, processes, and structures by following nine golden rules. The authors' research shows that 73 percent of the executives whose companies followed more than six of the nine golden rules felt that the organizational redesign had succeeded. The rules are broadly relevant for different industries, regions, and company sizes. They also hold true for redesigns prompted by different types of organizational change, including end-to-end restructurings or more-focused efforts, such as cost-cutting or improvements in governance. The authors' golden rules are: (1) Focus on the longer-term strategic aspirations (be clear about what the redesign is intended to achieve and ensure it is linked to strategy); (2) Take time to survey the scene (assess the state of the organization ahead of the redesign); (3) Be structured about selecting the right blueprint (weigh redesign criteria, challenge biases, and minimize the influence of political agendas); (4) Go beyond lines and boxes (target at least two structural-, two process-, and two people-related redesign elements); (5) Be rigorous about drafting in talent (focus on roles first, then on people); (6) Identify the necessary mind-set shifts - and change those mind-sets (identify negative mind-sets and seek to change the way people think about the reorganization); (7) Establish metrics that measure short- and long-term success (simple, clear key performance indicators are the way forward); (8) Make sure leaders communicate (top leaders explain the rationale for the change and spell out new design in their own words); and (9) Manage the traditional risks (track metrics and develop and execute riskmitigation plans).

Bryan, L., and C. Joyce, “The 21st-Century Organization,” McKinsey Quarterly, Vol. 3, 2005, pp. $24-33$.

This article focuses on the increased inefficiency of knowledge workers and reasons behind this inefficiency. The authors state that organizational designs do not do enough to increase the 
productivity of knowledge professionals. They mention that the vertical orientation of organizational structures often leads to greater inefficiency and increases the complexity of professional work. They comment on the need for a new organizational model that retains the best aspects of the traditional hierarchy while accounting for the value of innovative employees. Companies seeking to streamline line-management structures need to create effective companywide governance controls for decisions related to them.

Downs, Anthony, Inside Bureaucracy, Santa Monica, Calif., RAND Corporation, P-2963, August 1964. As of February 15, 2016:

http://www.rand.org/pubs/papers/P2963.html

Downs believed that organizational theory must abandon its presently excessive generality if it wishes to produce testable propositions that are helpful to grapple with real-world organizations. He provides a work on bureaucratic decisionmaking within the literature of the time, which was beginning to provide a general framework for a more general approach to bureaucracy. According to the author, such decisionmaking was not yet focused on that new structure with sufficient precision to allow for making forecasts of bureau behavior possible. In this paper, the author attempts "to present a theory of bureaucratic decisionmaking aimed at achieving such predictability. Bureaucrats are not simply people who work for bureaus. Any person who works for a large organization receives an income from that organization, which constitutes the major part of his/her income; is promoted on the basis of performance; and produces outputs that cannot be evaluated on a market." His central hypothesis is that different types of officials pursue different goals, all described in detail. He then defines the operating condition of the environment in which his theory (and the officials) operate, the inherent hierarchical structure of bureaus, and why it must be so. He discusses the problems of communications and control in bureau hierarchies and of information and directive distortion, as well as how to limit effects of both types. He follows with the dynamics of bureaus - their lifecycle, including aging, accelerator, and decelerator effects - and discusses why bureaus seek expansion. He closes with practical applications on his theory linking internal elements to aspects of bureau functions and their external environments. His end game is to use the internal structural elements of a bureau to forecast its external actions, or use its external environment and the nature of its functions to forecast its likely internal structure and behavior, or do some combination of both.

Galbraith, Jay R., "Organization Design Challenges Resulting From Big Data," Journal of Organizational Design, Vol. 3, No. 1, 2014, pp. 2-13.

In this article, the author discusses firms that are at the leading edge of developing a big data analytics capability. "Firms that are currently enjoying the most success in this area are able to use big data not only to improve their existing businesses but to create new businesses as well. 
Putting a strategic emphasis on big data requires adding an analytics capability to the existing organization. This transformation process results in power shifting to analytics experts and in decisions being made in real time." Before an organization can make real-time decisions, it must get data scientists and analytics experts embedded into the decision process. The author presents "two arguments for the development of a semi-independent unit for these science and analytic types. Operating independently, it can control its own activities while proving itself to established units. As a new unit, it is fragile, will undergo trial and error until it discovers its success formula, and needs independence, nurturing, and developmental help from higher management. The second argument is that it is not just new, it is very different. A separate unit can operate at its own and faster pace than if embedded in other organizational units." A digital unit is described for commercial enterprises. It consists of community management, social media, mobile specialists, website management, hardware engineering, and a software function. Supply chain management is the final function to be accelerated by big data. At Procter \& Gamble, a "control tower" consists of a cross-functional team meeting in a "decision sphere." Procter \& Gamble has 42 of them located throughout the company, and their military parallel is a command and control center. Analytics capabilities are used to determine how to reroute deliveries when required to meet commitments to its customers. The boldest challenge is the need to create information and decision processes to support the structure and strategy of the organization. The organization must harness its information infrastructure to combine its various databases. Then, in order to execute real-time decision processes, the organization needs the people who are skilled in digital tools and work effectively in teams. Finally, the author states that firms now making decisions in real time can be instructive for organizations as they reshape because the organizational, managerial, and cultural changes required by a big data analytics capability are considerable.

Groth, Lars, Future Organizational Design: The Scope for the IT-Based Enterprise, electronic edition, John Wiley \& Sons, Ltd., 1999.

A Mintzberg disciple, Groth extends Mintzberg's view of organizations and proposes new forms of organizations because of advancements in information technology (IT). Computerbased systems create a new level of sophistication and complexity in organizations. The structure and functioning of new organizations is a combination of living patterns carried out in real time by members and programmed patterns implemented in computer-based systems affecting and influencing the live actions of their users. Conscious modeling, a normal part of systems design, is increasingly a prerequisite for organizational design. New structural configurations, made possible because of IT, offer great promise to industry and government. One such projection is that the flexible bureaucracy represents the natural evolutionary path for the machine bureaucracy (Mintzberg), or what Groth terms "the modern organization." The key to the transformation of this classic modern organization is the IT-based transition from inflexible to 
flexible standardization, combined with much more-efficient internal coordination. Groth provides an extensive historical review of individual capacity and organization before the computer. In his section on "extending the space of constructible organizations," his theme of "comprehension and control" is about how IT is used to improve understanding and control of both work and the organization, with implications for organizational structure and the way organizations can be run. For example, IT makes it possible to centralize command in large organizations with great geographical spread to a much larger degree than before, and it allows central management to extend its direct reach of supervision to a much greater depth in the organization. Using Mintzberg's definition of decentralization as necessitating transfer of decisionmaking and power, Groth discusses how IT can extend the possibilities for genuine decentralization in several ways, by information availability, despecialization, and increasing the depth of control. In discussing new configurations based on Mintzberg's configurations, Groth's discussions on "perfecting the machine bureaucracy" and "the rise of the flexible bureaucracy" provide valuable guidelines for reorganization within today's major bureaucratic organizations, such as the military. Consideration of Groth's concept of meta-organizations, whose purpose is to automate coordination of processes across the member organizations, is also important and has applicability to coordination between service branches in the U.S. military. He seeks to increase our understanding of the potential of conceptual modeling, and point the way to how much models can form the basis for really comprehensive computer-based systems - and thus allow organizations to achieve new levels of integration and coordination. His view is also that "evolving model-driven organizations should have a pattern manager, and one of the duties of his office would be to continuously maintain and update the conceptual model of the organization and its problem domain."

Jones, Marc T., "Globalization and Organization Restructuring: A Strategic Perspective," Thunderbird International Business Review, Vol. 33, No. 3, 2002, pp. 325-351.

According to Jones, "The new market opportunities, competitive threats, and diffusion of business models associated with globalization have been key drivers of organizational restructuring over the past decade. Companies have responded to these developments in a variety of ways, with the objective of improving their cost and/or revenue structures through reorganizing their vertical, horizontal, and spatial boundaries and governance mechanisms. Major forms of restructuring at the business level have included labor intensification, investment in new technologies, downsizing and reengineering, the formation of strategic alliances and networks, spatial reconfiguration, and a shift from international and multinational to global and transnational strategies. To be most effective, any type of restructuring must be clearly and explicitly aligned with a firm's business-level strategy in order to maximize the efficient and effective allocation of resources in pursuit of competitive advantage." The author provides a useful procedural logic of a boundaries-based analysis based on historical boundaries that can be 
applied to Air Force activities in today's global reach operating environment. He discusses how such factors as costs for reconfiguring organization boundaries are sometimes prohibitive or undoable because of internal barriers to change, constrain the boundary alignments, and will fail to be aligned (fit) with their current environments. He also addresses the restructuring process in some detail, including downsizing and reengineering "since they are most often implemented in tandem." The primary normative theme of this article is the importance of properly relating organizational restructuring to a firm's overall strategy. Jones provides insights into simple and complex global strategies, their implementation through reorganization, and how to lead that process.

Karlöf, Bengt, and Fredrick Helin Lövingsson, Reorganization, New York: Springer, trans.

Michael Parsley, February 2007.

This book was intended to fill a gap of providing a practical guide for anyone faced with organizing a business. The authors, through experience as consultants and businessmen, as well as through study, developed a sense of what is important in shaping or redesigning an organization, and thus the focus is on organizational design - that is, questions of structure. The authors emphasize, though, that it is impossible not to look at aspects of infrastructure, such as culture, power, leadership, control, and communication. They cover the main streams of thought in organization theory from 1920 to the present day: machinery, social systems, decision systems, political arenas, open systems, dynamic systems, cultures, and networks (both network organization and virtual organizations). In addressing the work of Henry Mintzberg, they say, "Mintzberg is an important theorist and his ideas have had much influence in academic circles, but we cannot say that his 'contours' have been much of practical use in organization work. We have included them here because they can be useful in categorizing different types of organizations." This overview of organizational theory, fundamental organizational models, an organization's anatomy, physiology and psychology, organization and management, aspects of organizing, tools and conceptual models, and reorganization step by step is a useful guide and reminder of the correct considerations for one charged with reorganizing. And the book is perhaps best used to evaluate if people charged with reorganizing are aware of the various aspects of reorganization work and the tools available to deal with it for their specific structure, culture, goals, systems, processes, and so on.

Lemieux, Victoria, “Applying Mintzberg's Theories on Organizational Configuration to Archival Appraisal," Archivaria, Vol. 1, No. 46, January 1998. As of January 15, 2016: http://journals.sfu.ca/archivar/index.php/archivaria/article/view/12675/13842

This article applies Henry Mintzberg's theories on organizational configuration to archival appraisal as a means of demonstrating how organizational theory can inform archival theory. The article presents a number of record-keeping and archival appraisal hypotheses based on 
Mintzberg's theories. It then compares these hypotheses with appraisal case studies by Helen Samuels and JoAnne Yates as a means of verifying the validity of the hypotheses. Finally, a methodology is presented for applying Mintzberg's theories to conduct appraisals. The article concludes that Mintzberg's theories, and the record-keeping and appraisal hypotheses derived from them, provide archivists with a faster and more precise means of identifying sites of archivally significant records than existing appraisal theories and strategies. It further concludes that, given the utility of Mintzberg's theories for archival appraisal, organizational theory offers great potential for informing archival theory.

Mintzberg, Henry, “Organization Design: Fashion or Fit?” Harvard Business Review, January 1981, pp. 103-116.

In this seminal work, Mintzberg argues "that the characteristics of organizations fall into natural clusters or configurations." He proposes that "specifically, five clear configurations emerge that are distinct in their structures, the situations in which they are found, and even in the periods of history in which they first developed." The five structural configurations are: simple structure (entrepreneurial), machine bureaucracy, professional bureaucracy, divisionalized form, and adhocracy (innovative). In this article, Mintzberg writes briefly on deriving the configurations from five component parts having to do with how work is divided, and in later works (e.g., Mintzberg, 1982), he further suggested that "organizations can be differentiated along three basic dimensions: (1) the key part of the organization, that is, the part of the organization that plays the major role in determining its success or failure; (2) the prime coordinating mechanism, that is, the major method the organization uses to coordinate its activities; and (3) the type of decentralization used, that is, the extent to which the organization involves subordinates in the decision-making process." Using the three basic dimensions, he further suggested (in Henry Mintzberg, Tracking Strategies: Towards a General Theory of Strategy Formation, New York: Oxford University Press, 2008) that the strategy an organization adopts and the extent to which it practices that strategy result in the five structural configurations first described in this paper. There is no one "right" organizational structure, so it is important to understand how structure relates to the variety of attributes in a company. Typically, government agencies are the machine bureaucracy form. The machine organization has a tight vertical structure. Functional lines go all the way to the top, allowing top managers to maintain centralized control. The key part of the government organization is the technostructure-for example, analysts and engineers who design systems concerned with planning and control of work. The prime coordinating mechanism is standardization of work performed, and the type of decentralization is vertical (or the distribution of power down the chain of command) or shared authority between superordinates and subordinates in any organization. These machine forms can be very efficient, and they rely heavily on economies of scale for their success. However, the formalization leads to specialization, and pretty soon, functional units can have conflicting goals 
that can be inconsistent with overall corporate objectives. While structure, consistency, and longevity are strengths, limited openness to new perspectives and inefficiencies resulting from bureaucratic processes are common deficiencies. Mintzberg suggests that an organization cannot be all things to all people and that it should do what it does well and suffer the consequences. He writes, "Be an efficient machine bureaucracy where that is appropriate and do not pretend to be highly adaptive. Or create some new configuration to suit your own needs." He concludes by stating that the main point is not which configuration is chosen or appropriate. It is most important to achieve a configuration.

Mintzberg, Henry, “The Fall and Rise of Strategic Planning," Harvard Business Review, January-February 1994, pp. 107-114.

In this excerpt from one of his books, Mintzberg asserts that the label "strategy planning" has been applied to all kinds of activities, such as going off to an informal retreat in the mountains to talk about strategy, but the event quickly leads to formalized mission statements and assessments of corporate strengths and weaknesses. Strategic thinking, in contrast, is about synthesis. It involves intuition and creativity. "The outcome of strategic thinking is an integrated perspective of the enterprise, a not-too-precisely articulated vision of direction, such as the vision ... that three-dimensional visual computing is the way to make computers easier to use. ... Formal planning, by its very analytical nature, always will be dependent on the preservation and rearrangement of established categories, the existing levels of strategy (corporate business, functional), the established types of products (defined as 'strategic business units'), overlaid on the current units of structure (divisions, departments, etc.). But real strategic change requires not merely rearranging the established categories, but inventing new ones." Mintzberg proceeds by distinguishing between strategic planning and strategy-making, which he states are not the same. Overall, he challenges the widespread assumption that strategic planning, strategic thinking, and strategy-making are all synonymous, at least in best practice. "The evidence of strategic planning's failure seems to exist everywhere, and nowhere is it clearer than in the most structured, most hierarchical organization of all — the government," although applying more so to public policymaking than to defense or military department strategy-making. The value of the book is not so much the debunking of strategic planning as practiced, but rather a forceful exposition of what a valid theory of strategic planning must entail.

Mintzberg, Henry, and Joseph Lampel, "Reflecting on the Strategy Process," Sloan Management Review, Spring 1999, pp. 21-28.

In the first part of this article, the authors briefly review the evolution of strategy formulation in terms of ten "schools." They ask whether these perspectives represent fundamentally different processes of strategy-making or different parts of the same process. In both cases, the answer is yes. Mintzberg and Lampel strive to show how some recent work tends to cut across these 
historical perspectives. Their historical survey of strategy literature suggests that it has been characterized by ten major schools since its inception in the 1960s, three prescriptive (or "ought") and seven descriptive (or "is"). The authors discuss the ten schools and then ask whether they represent different processes or different parts of the same process, stating that dealing with all the resultant complexity of a "yes" answer to the latter may seem overwhelming, but the fault may lie in the process itself. They write, "Strategy formulation is judgmental designing, intuitive visioning, and emergent learning; it is about transformation as well as perpetuation; it must involve individual cognition and social interaction; cooperative as well as conflictive; it has to include analyzing before and after programming as well as negotiating during; and all this must be in response to a demanding environment. Try to omit any of this and watch what happens?" The authors' advice is that we need better practice, not neater theory, advise concerning ourselves with "process and content, statistics and dynamics, constraint and inspiration, the cognitive and the collective, the planned and the learned, the economic and the political." More attention must be given to strategy formulation as a whole.

Porter, Michael E., "What Is Strategy?" Harvard Business Review, November-December 1996, pp. 61-78.

The author states that positioning — once the heart of strategy — is rejected as too static for dynamic markets and changing technologies. He argues that the root of the problem is the failure to distinguish between operational effectiveness and strategy. His main tenets are as follows: operational effectiveness is not strategy, strategy rests on unique activities, a sustainable strategic position requires trade-offs, fit drives both competitive advantage and sustainability, and strategy renders choices about what not to do as important as what to do. He concludes discussing how to reconnect with strategy.

Slinger, Giles, and Rupert Morrison, "Will Organization Design Be Affected by Big Data?" Journal of Organizational Design, Vol. 3, No. 3, 2014, pp. 17-26.

According to the authors, "Computing power and analytical methods allow us to create, collate, and analyze more data than ever before. When datasets are unusually large in volume, velocity, and variety, they are referred to as 'big data.' Some observers have suggested that in order to cope with big data, (a) organizational structures will need to change and (b) the processes used to design organizations will be different. In this article, [the authors] differentiate big data from relatively slow-moving, linked people data. [They argue that] big data will change organizational structures as organizations pursue the opportunities presented by big data. The processes by which organizations are designed, however, will be relatively unaffected by big data. Instead, organization design processes will be more affected by the complex links found in people data." The authors conclude that "the process of organization design is fundamentally driven by the bundled, reflexive, and linked nature of people data. People data are multiple- 
aspect with many-to-many links. Successful organization design in the future will make use of all the traditional tools, but it can avoid having to build enormous data warehouses. Instead, it will supplement the existing databases with graphing, visualization, and linking tools and methods that at last will let us treat organizations properly as systems."

Tripp, Robert S., and Larry B. Rainey, “A Cybernetic Approach for the Design and Development of Management Information and Control Systems (MICS): An Illustration Within the Air Force Logistics Command (AFLC)," Cybernetica, Vol. 26, No. 4, 1983.

"This paper demonstrates how a cybernetic model of the organization can be used to guide MICS [management information and control systems] design and development activities, to diagnose potential problems in existing MICSs, and serve to guide MICS development activities. For illustrative purposes, a case study of AFLC [the Air Force Logistics Command] is used to demonstrate how the cybernetic organization model can be made operational in the 'real world.' The paper shows how this methodology can be used as a road map for integrating and guiding several MICS initiatives which are under way to make AFLC more responsive in meeting potential wartime scenarios. This paper is organized into sections which describe AFLC mission responsibilities, identify some current AFLC MICS problems, describe AFLC's recognition of these problems, describe and use a cybernetic MICS model to diagnose current problems, and develop some observations, which can be used to guide current and future MICS design and development efforts."

Tripp, Robert S., and Larry B. Rainey, "Cybernetics: A Theoretical Foundation for Developing Logistics Information and Control Systems," Logistics Spectrum, Summer 1985, pp. 32-38.

According to Tripp and Rainey, "The successful operation of logistics activities depends on the correct flow and timing of information passing between decision makers and those charged with executing logistics functions. As an example, within [AFLC], managers use literally hundreds of logistics information and control systems (LICS) to direct various activities to get 'the right part to the right place at the right time.' Yet, despite the importance of information in logistics operations, no theory has been presented to guide the development, implementation, and modification of the system." This paper discusses how the application of cybernetics can provide the underlying theory needed to establish a sound development and integration strategy for the logistics information and control system. "Cybernetic models of the organization are based upon the central and autonomic nervous system in living organisms. As a result, the cybernetic approach conceptualizes an information system as a model of an organization ... that can be constructed and tested." The authors then describe an organization system model that can be used to provide a coherent picture of the total organization identifying logical relationships and the channels of communications through which flows the life blood of the organizationinformation. This model can unify understanding of organization behavior and provide corporate 
focus for command and control. In addition, the authors state that this model can provide management with a tool for integrating management activities in contracting, supply, transportation, maintenance, and so on. Adoption of cybernetic concepts would provide a meaningful theoretical basis for formulating development and integration strategy for logistics information and control systems.

Tripp, Robert S., Larry B. Rainey, and John M. Pearson, “The Use of Cybernetics in Organizational Design and Development: An Illustration Within Air Force Logistics Command (AFLC)," Cybernetics and Systems: An International Journal, Vol. 14, 1983, pp. 293-314.

This paper shows "how cybernetic concepts can be used to guide organizational design and development activities." It demonstrates "how a cybernetic model of a viable organization can be used to diagnose potential problems in existing organizations and serve to guide organizational development activities. For illustrative purposes, a case study of AFLC is used to demonstrate how the cybernetic organization model can be made operational in the 'real world.' The paper shows how this methodology can be used as a road map for integrating and guiding several initiatives which are under way to make AFLC more responsive in meeting potential wartime scenarios." The paper's sections describe AFLC mission responsibilities and organization, identify current major problems, describe and use a cybernetic organizational model to diagnose causes of current problems, and develop some observations that can be used to guide future organizational design and development efforts, particularly future organizational and management information and control system design efforts.

\section{Management Practice Literature Review}

Booz Allen Hamilton, "Attacking Overhead Costs from Both Sides: Optimizing the Supply and

Demand for G\&A Services," 2003. As of February 15, 2016:

http://www.strategyand.pwc.com/media/file/128544.pdf

In this article, Booz Allen Hamilton explains that, "over the past decade, most global 500 companies have implemented several waves of restructuring programs to cut general and administrative costs, including business process reengineering, shared services, enterprise resource planning, and strategic outsourcing. While these traditional initiatives have often been effective in improving the bottom line and enhancing shareholder value, they have largely run their course." This article highlights how companies may consider how to wring additional and significant savings from their overhead functions by aligning supply with demand to achieve a value-based equilibrium in their general and administrative cost structure. Managing demand is a careful, systematic, and business-specific assessment of what services are needed at what level of performance and why, measuring their criticality to determine the need for excellence versus 
adequacy. This Booz Allen approach is aimed at discovering the supply-demand "sweet spot" by "disaggregating" overhead services from both a supply and demand perspective. Disaggregating supply services involves by breaking them up into their component activities and then reassembling them by inherent nature, frequency of use, and the channel through which accessed (on-site or call centers). Demand-side disaggregation is done by sorting into categories of "must have," "want to have," "smart to have," and "nice to have" services based on why customers (users) need them, where accessed, and how applied to support decisions, operations, and processes. The article then looks more closely at fit-for-purpose solutions, or "the happy medium between one-size-fits-all and custom-tailored service offerings." An illustration of information technology desktop services is employed that details this restructuring. Booz Allen claims that "as companies make difficult, critical and clear supply-demand affordability trade-offs," structural cost reductions of up to 40 percent are achievable.

Booz Allen Hamilton, "Management Spans and Layers: Streamlining the Out-of-Shape Organization," 2009. As of February 15, 2016:

http://docplayer.net/7123943-Management-spans-and-layers-streamlining-the-out-of-shapeorganization.html

In this article, Booz Allen Hamilton states, "In an environment of ever-escalating efficiency, effectiveness, and performance requirements, public sector organizations need to be fit and flexible to prosper. Too many they say, however, are burdened with a cumbersome organizational structure." The "hourglass organization"-characterized by a wider span at the top, narrow spans at the middle, and widest spans at the entry level—often results in bureaucratic build-up, bottleneck decisionmaking, and a general lack of innovation. These organizations need to look beyond organizational charts and job descriptions to the underlying "Mission DNA," which consists of the building blocks of decision rights, motivators, information, and structure. Eliminating lines and boxes on an org chart only masks symptoms of dysfunction. The root causes of organizational dysfunction are defined as "lack of accountability, sub-optimizing silos, and micro-managers and must be addressed in any restructuring effort." There is no single best method of removing layers. Some start at the top with an agency commissioning an audit or issuing instructions to flatten layers. Others "bubble up" from below by engaging the entire organization in interviews and workouts to address root causes. This article concludes by stating that "whichever is adopted, it is wise to remember the six tenets of genetic reengineering as they apply to Mission DNA:" (1) Note that not all spans are created equally; (2) Create crossfunctional teams with process owners around key processes; (3) Design fulfilling career paths and staffing strategies; (4) De-program micro-managers; (5) Institutionalize communications vehicles; and (6) Coach the change agents. Details of each are provided in the article, which is a good overview for public-sector organizations that seek to be fit and flexible and wish to achieve greater efficiency. 
Booz Allen Hamilton and the Partnership for Public Service, Making Smart Cuts: Lessons from the 1990s Budget Front, Washington, D.C., September 2011. As of February 15, 2016: http://www.boozallen.com/content/dam/boozallen/media/file/SmartCuts_11.pdf

The report outlines eight strategies most often used during the previous budget-cutting era, and shares insights on the advantages and disadvantages of each. The strategies are as follows:

1. Across-the-board cuts, which reduce budgets, programs, or functions by an equal percentage, are easy for leaders to implement since they apply to all alike, but they ignore differences in priority, performance, or efficiency.

2. Programmatic cuts, which reduce programs or functions according to relative importance or efficiency, may allow agencies to protect those programs that are the highest priority or achieving the best results, but they require difficult decisions that may be opposed by affected stakeholders.

3. Decreasing administrative costs, which can reduce overhead, may lead over time to a weakening of managerial capacity or critical support functions, such as human resources and financial management.

4. Personnel reductions, which can contribute to major cost-savings through attrition, forced layoffs, or both, can also create severe skills imbalances, degrade morale, and "hollow out" organizational limits.

5. Consolidating or centralizing functions, which can lead to greater efficiency, may degrade responsiveness or citizen and customer service.

6. Reengineering, which can improve service quality and speed, may require significant upfront resources, particularly if technology is employed, as is often recommended.

7. Investing in information technology, which can significantly increase productivity and efficiency, requires significant initial investment and may result in unanticipated implementation costs.

8. Outsourcing, which assigns functions or tasks to external organizations, ideally at a lower cost, requires oversight by skilled government personnel and may not achieve expected savings.

The report concludes with general recommendations or lessons learned taken from government documents, Government Accountability Office studies, interviews, and so on.

Cameron, K. S., S. J. Freeman, and A. K. Mishra, "Best Practices in White-Collar Downsizing: Managing Contradictions," Executive, Vol. 5, No. 3, 1991, pp. 57-73.

This article notes that between 1978 and 1986, at the same time that production workers were declining in number and real output was rising, white-collar productivity decreased and the number of workers increased by 21 percent. Thus, downsizing - that is, eliminating functions and redesigning systems and policies to contain costs — was becoming common. More than 85 percent of the Fortune 1000 firms downsized their white-collar workforce between 1987 and 
1991. The authors sought to identify the downsizing strategies that were associated with the most effective organizational outcomes, as well as their consequences. Firms in the automotive industry were selected because extensive downsizing was occurring. Six general strategies highlight best practices among firms downsizing effectively. According to the authors, the most successful downsizing strategies (1) were implemented by command from the top down, but also initiated from the bottom up; (2) were short term and across the board, but also long term and selective in emphasis; (3) involved paying attention to both those employees who lost their jobs and those who did not; (4) were surgical and targeted inside the firm, but also generalized and included the firm's external network; (5) resulted in small, semi-autonomous organizations, but also resulted in large integrated organizations; and (6) emphasized downsizing as a means to an end, but also as a targeted end. The second of those strategies includes a discussion of looking at three other downsizing strategies: workforce reduction, organization redesign, and systemic. The most successful firms implemented all three types - that is, they implemented both short term (workforce reduction) and long term (redesign and systemic change) practices (strategies) as they downsized. The six "best practice" strategies are detailed, and reading the article is both useful and necessary to gain a proper understanding of them, learn their consequences, and see why seemingly contradictory practices can be simultaneously implemented and should be considered. The authors contend that "the apparent contradiction in these strategies is actually the best explanation of the difference between effective and ineffective firms." Top managers in the effective firms were actively pursuing strategies that included a duality, adopting a bifurcated, both/and approach, and only in the most effectively downsizing firms were these processes not defined as contradictory. The authors contend that past assumptions bound too narrowly the research questions being investigated and change strategies (one or the other) being pursued. We note also that these authors' recommendations to broaden the nature of organizational dynamics are apparent in the more current literature (e.g., Mintzberg).

Collis, David, David Young, and Michael Goold, "The Size, Structure, and Performance of Corporate Headquarters," Strategic Management Journal, Vol. 28, 2007, pp. 383-405.

This study of 600 companies details "corporate headquarters" definitions and basic roles, and identifies determinants (or "roles," theories," and "critical variables") that determine the size of headquarters. Determinants include the size of a corporation, governance systems, and the corporate strategy and corporate portfolio, as well as the influence of both on organizational policies. Of interest to us in the context of our assignment to review literature for this effort is that corporate strategy, primarily through its influence on the degree of intervention in business units (reporting organizations), does affect the mix of activities undertaken at headquarters. Policies on the involvement of headquarters in functional decisions of business units result in variations in both the functions performed at headquarters and their size. The authors find continuing interest in headquarters design to be expected. There was a wide range of satisfaction 
with headquarters performance, with many managers expressing significant dissatisfaction. These frequent reviews of headquarters design are in practice no more than cost-cutting exercises. This research shows that this approach is dangerous because simply reducing headquarters is no guarantee of improved performance. The authors caution against a "one-sizefits-all" approach and state that benchmarking can be valuable, provided it can be done with firms (organizations) pursuing similar corporate strategies. Looking at value-added tasks in order to design staffs that are fit for purpose is crucial, but then as today, a single set of best practices for corporations, and particularly military "bureaucracies," is not revealed in this analysis. Rather, it indicates that senior executives need to decide precisely how a given corporate strategy adds value to the businesses in their portfolio and determine what policies and staffs are needed to exploit those specific sources of value.

\section{De Smet, Aaron, and D. McGinty, "The Secrets of Successful Organizational Redesigns," McKinsey Quarterly, 2014.}

As De Smet and McGinty note, "Organizational redesigns are an everyday fact of corporate life, yet three-quarters of redesign efforts fail both to meet objectives and to improve company performance. These are among the key findings from McKinsey's most recent survey on largescale organizational change, one of which asked executives how their companies develop, communicate, and implement large-scale changes to their organizational structure and reporting lines. Overall, their responses suggest that redesign outcomes depend more on how organizations go about the effort than on why they pursued the effort in the first place or what specific changes they made. According to respondents with redesign experience, the companies where leaders aligned on objectives, identified necessary mind-set changes, used clear criteria for the new organizational design, and rigorously planned and communicated the changes were the most likely to end up with a successful effort." Executives were asked about the five phases of a redesign: aligning on objectives, developing a blueprint for the new structure, formulating a detailed organizational design, communicating and planning for changes, and implementing those changes. Respondents who report successful overall outcomes are much likelier than average to say each of their redesign phases went well. Among the key characteristics that link to outcomes is alignment on objectives, regardless of what they are, which suggests that a redesign's success begins long before day one. Of the efforts in which respondents say that their leaders were slightly or not at all aligned on the redesign's strategic objectives, just 1 percent report successful outcomes, compared with 49 percent who say that their leaders were fully aligned. Still, even the successful redesigns faced obstacles. Employee distraction and resistance and the feeling that there was too much emphasis on the organizational chart instead of how the work would change were among the obstacles. The survey found that where senior leaders developed their own narratives to support the change story, success was more than four times more likely. The lessons included that organizations should align on what matters from the 
beginning, mind behaviors and mind-sets, and invest in rigorous processes of decisionmaking rather than on ad hoc processes or those based on views of a select few individuals. Using clear processes is a greater predictor of success, too, so rigor and clear criteria should be included in redesigns.

Goold, M., and D. Young, "When Lean Isn't Mean," Harvard Business Review, Vol. 83, No. 4, 2005, pp. 16-18. As of February 15, 2016:

http://search.ebscohost.com/login.aspx?direct=true\&db=bth\&AN=16572441\&site=ehost-live

The authors assert that "most executives believe that corporations with large headquarters are bureaucratic, out of touch with customers, and slow to make decisions - and so, perform poorly. That's why they slash headquarters staff whenever they try to cut costs or improve performance. But do lean headquarters really perform better?" Their study looked at the headquarters of 600 companies around the world, with a wide range of headquarters sizes and composition. Using financial performance measurements, they found that companies that reported above-average profitability had headquarters that were, on average, 20 percent larger than the headquarters of companies of similar size. They found that, largely, the companies with large staffs improved performance by increasing value that more than paid for their costs. The applicability here is that corporate centers add value in different ways, and this is likely as true for bureaucratic staff functions, provided they are linked to organizational objectives (strategies) and can be measured using performance standards. The authors' lesson: "Don't reflexively cut staffs. Focus instead on matching headquarters' size and roles with corporate strategy."

McKinley, William, Carol M. Sanchez, and Allen G. Schick, "Organizational Downsizing:

Constraining, Cloning, Learning," Academy of Management Executive, Vol. 9, No. 3, 1995, pp. $32-42$.

McKinley, Sanchez, and Schick write, "While downsizing rages through the U.S. economy, there is a great deal of uncertainty about its bottom-line effects. This uncertainty raises questions about why corporations have been so eager to engage in downsizing." In this article, the authors propose an answer to these questions: "Three social forces, which we call constraining, cloning and learning, frequently provide a major impetus for downsizing. We describe these forces, and point out conditions that lead to the adoption of downsizing without due regard for its mixed consequences." They suggest "methods to improve executives' downsizing decision routines . . . methods that should enhance the chances of achieving intended benefits." Constraining forces pressure organizations to conform to institutional rules that define legitimate structures and management activities. Cloning forces pressure organizations to mimic the actions of the most prestigious, visible members of their industry. Learning forces emerge through the management practices taught in universities or professional associations through the corporate world. For the military, constraints are nearly always imposed by external forces (political, hierarchical), and 
are more social in nature for corporations (conforming to "leanness"). Cloning behavior spreads through imitation and applies to other management techniques: total quality management, process reengineering, and worker empowerment. A third social force that helps spread standard management practices is found in the curricula of U.S. business schools. When combined with decisions to outsource in a manufacturing environment, trending on what is popular among these schools' curricula (such as methods of cost accounting) can encourage progressive downsizing of production.

Messenboeck, Reinhard, "Downsizing Support Functions," Parts I and II, interview for Knowledge at Wharton, Boston Consulting Group, September 2014. As of February 15, 2016:

http://d1c25a6gwz7q5e.cloudfront.net/reports/2014-09-23-Right-sizing-Support-FunctionsPart-I.pdf (Part I) and http://d1c25a6gwz7q5e.cloudfront.net/reports/2014-09-30-Rightsizing-Support-Functions-Part-II.pdf (Part II)

According to Messenboeck, support functions often reside "close to the decision makers." A board typically controls an organization through support functions, such as human resources, finance, and the budget process. They are the "brain functions and nervous system of an organization." This interview provides a look at where support functions stumble and how typical savings of 25 percent to 30 percent can be wrung out with the right approach. Support functions differ across industries and create inefficiencies by adding things (e.g., reports, resources); organizations need to have discussions about priorities and using resources best. "What's needed is a feedback loop between those who create a service and those on the receiving end, and who actually live with it. This is only fixed by thinking differently about the amount of services provided and interactions and having discussions free of what's happened in the past," and thereby "radically transform the support functions, and . . . indirectly the rest of the organization. This requires foremost that people understand and agree in senior leadership about aims. Is the aim only support functions or the whole business? This is about scope and speed, and the senior leadership must align on so that when things roll, they can compare and adjust according to principles laid out at the beginning. Set targets, and set detailed plans to work on these targets. And the key is not to make changes, but to arrive at the goal. It's a rigorous management process of making sure it happens. Last but not least, foster a different kind of thinking, and then have continuous discussion around the best use of resources between unitsthe ones who produce and the ones who take it; also on the budgeting level; also quarterly to make best use of enterprise resources. To observe inefficiency, do this: Measure how many resources are attached to an activity. Look at the organizational structure; how spread out is it or how deep? Next, what is delivered, how long does something take? Lastly, look at internal quality of service; what's the feedback about services in terms of quality, level of service, and timing? Successful downsizing efforts are characterized by two elements. One is an open arena 
to discuss core issues on a senior level even if an organization has a hierarchical decision process. Number two is to bring it down one level deeper or two or three levels, where people in various functions interact. Get them to align on what they want to achieve, rather than on what they're doing."

Nicol, Ron, "Shaping Up: The Delayered Look," Perspectives, Boston Consulting Group, 2004.

The author states that many organizations are still out of shape, have too many layers, and have spans of control that are too narrow. He defines layers as the hierarchy of reporting relationships, levels as pay grades, and spans as the number of direct reports. The companies out of shape may have tried belt-tightening methods, such as across-the-board layoffs, but that does little to fix an organization's structure. Process redesign is a lengthy approach that often does not question whether something really should exist. Value-based cost reductions, focused on process activities, often miss big opportunities and do not improve decisionmaking or responsiveness. Focusing exclusively on delayering at the management level speeds up both information flows and decisionmaking. The author recommends first conducting a detailed analysis of the layers, levels, and spans, and a before-and-after snapshot is illustrated. Then, an assessment of excess structure can determine if delayering is the correct approach. A commitment to a fact-based and transparent approach is required. There is no such thing as a covert reorganization. Treat employees like adults and be clear about the what, the why, and the how of the delayering process. The author then lists some principles, as examples, that must be established to guide the delayering process. They must be backed with an iron will. "Delayering is an honest, effective, and empowering way of reducing costs while speeding up decisionmaking. Delayering's success rests on two hypotheses. The first is that increased spans of control force managers to do their jobs differently. The second hypothesis is that breaking down hierarchy sets the stage for formation of networks that cut across processes and functions, and these networks, properly engaged and motivated, are the key to superior performance." As Nicol concludes, "Flattening the pyramid is just the first step, arguably the toughest one, toward leaving a legacy of organizational readiness and agility."

Nutt, Paul C., and Michael F. Hogan, "Downsizing Guidelines Found in a Success Story," Performance and Management Review, Vol. 32, No. 1, September 2008, pp. 103-131.

This article reports a study testing two theories of downsizing and compares the actions recommended with those taken in a highly regarded state agency, the Ohio Department of Mental Health. The agency selected for study experienced considerable success, allowing focus on exemplary actions rather than failed ones. The study looked for actions that were essential to successful downsizing from 1990 to 2004, and then explored the extent to which the Ohio Department of Mental Health's downsizing actions correspond with two prominent downsizing theories: managed de-development and the dirty-dozen (undesirable outcomes) avoidance. A de- 
development process protects core competencies, and this article spells out that process. Another approach to downsizing is based on avoiding a series of undesirable outcomes that studies find invariably accompany downsizing — a "dirty dozen." The authors discuss a prescription to avoid these outcomes and the possibility that the steps may differ for private- and public-sector organizations. This study identified Ohio's downsizing initiatives and matched actions with recommendations in the theories, which are both discussed in detail and summarized in chart form in this paper. The comparison suggests that both downsizing approaches have merit. Shifting the organization to a lower order of organized complexity, taking steps to preserve core competencies, finding and implementing a new identity, and establishing a slow pace of change were crucial to the successes achieved. The authors note limitations in generalizability and urge attempts to replicate their findings. These methods are both "real-world" and in use enough to warrant consideration, particularly for service-providing segments of governmental organizations that are subject to frequent downsizing.

Toma, A., F. Roghé, B. Noakes, R. Strack, J. Kilmann, and R. Dicke, "Flipping the Odds for Successful Reorganization-Organization of the Future: Designed to Win," Perspectives, Boston Consulting Group, 2012. As of February 15, 2016:

https://www.bcgperspectives.com/content/articles/change_management_organization_design _flipping_the_odds_for_successful_reorganization/

This article states that reorganizations have become a fact of business life, yet as common as they have become, even more common is their high failure rate. The study attempts to pinpoint the organizational capabilities that matter most in financial performance, the metric used in the study to measure success of the reorganization. The authors cross-analyze quantitative data with executives' reports on their perceptions of performance. Among the successful organizations, salient patterns emerged that distinguished their efforts from those of failed counterparts. The study distilled six factors as most critical to achieving success: (1) Synchronize design with strategy; (2) Clarify roles and responsibilities; (3) Deploy the right leaders and the right capabilities; (4) Design layer by layer, not just top down; (5) De-risk execution; and (6) Don't wait for a crisis to reorganize. The most important capability proved to be execution - applying a step-by-step approach to implementation. Disciplined execution involves rigorous processes, appropriate governance structures, and an array of support tools, but most importantly, it requires a transparent system of early warnings with clear accountability. Fully 88 percent of study respondents whose organizations had any five or all six of these elements reported overall success with their reorganization. The authors conclude "that reorganization should not be viewed as an ad hoc endeavor, but rather as part of the continuous process of transformation - of constant improvement, innovation, and adaptation." 
Tomasko, Robert M., "Reducing the Girth of Corporate Headquarters Staff," Management Review, Vol. 73, No. 1, 1984, pp. 26-39.

This article briefly discusses advantages of downsizing headquarters staff, beginning with describing the distinction between "staff" and "line" generally credited to the military. Anticipated benefits have costs, which are listed. The author lists two issues most frequently raised when headquarters staff cutbacks are considered: "How do I know where and how many to cut?" and "How will I get the job done when they are gone?" The norms or standard approaches described here include targeted budget reductions, which are primarily a matter of force-fitting an estimated payroll savings to a mandated target. "A more thorough analysis involves an examination of the company's indicators of strategic performance. These target objectives, usually quantifiable, are arrayed with the chain of other performance indicators that the business must produce to meet the targets." Staff groups that are most critical to the achievement of strategic results are identified. These are strengthened and the others reduced. Other approaches include polling line managers to rank order staff groups in terms of their contribution to the specific line (customer) operation. Weighted ranking scores are determined and used as guides to plan cutbacks. A variation on this determines the payroll costs associated with major activities, and these activity costs are compared with manager's priorities; for example, expensive but low-priority activities (and staff groups) are targets for reduction. Many other options are available, and not all work equally well. The authors do suggest that more needs to be considered in downsizing staffs than just eliminating jobs. This article provides a surface review of all options that may instill interest in more investigation into a specific technique. It also discusses the role of strategic planning and illustrates options for performing this function among or within staff organizations. Finally, it addresses retraining and redeployment of individuals in downsized staffs to achieve the loyalty and heightened morale that can result, coupled with the flexibility and faster decisionmaking possible from staff downsizing. A reader will find it more of a valuable downsizing review than a planning guide for a downsizing effort.

Tomasko, Robert M., "Restructuring: Getting It Right," Management Review, Vol. 81, No. 4, 1992, pp. 10-15.

In this article, the author investigates the issue of downsizing in the United States, stages to the successful revival of a business, comparison between cost cutting and people cutting, and reasons that positive gains from organization restructuring had been so difficult to realize. The main point of value in this report is that the author states that too often, companies - and their management consultants - develop elaborate organizational solutions when they might have been better advised to reconsider the nature of the problem. That is, what is the work that really needs to happen? And how? And where? And by whom? Tomasko reconfirms Mintzberg's theory that no one organizational design is right for every business, for there is too much 
variation in missions, strategies, and capabilities. This is likely translatable to divisions within machine or professional bureaucracies. He states that it is not so much the specification of a new, innovative configuration that must be adopted, but outlining the path that each can follow to invent its unique organizational form. Tomasko discusses why positive gains have been so hard to realize and emphasizes that attention is focused too much on eliminating unnecessary jobs, and too little on cutting unnecessary work, or too much on outplacing people, and not enough on outplacing work. He quotes a review of several hundred companies that downsized to find that less than half of them took steps to identify and rid themselves of low-value work. Tomasko presents a three-fold strategy for reorganizing that must be done in an orderly sequence, consisting first of resizing, or adjusting the organization's equivalent of the architect's "site" to fit the demands of the future mission (including constraints facing it). Then comes redesigning building blocks and arranging them most favorably (to achieve dominance); this step is necessary, but not sufficient, to reshape an organization. Finally, an organization must rethink the basics of how the work is to be managed, including direction, control, information flows, use of teams, career paths, people-flow management, and rewards and mechanisms for decisionmaking. 


\section{Appendix D: Findings from Literature}

Our review of the academic literature on organizational design and streamlining revealed many factors that address such design. The academic literature, along with the management literature and industry practices, highlights that organizational structure change should be preceded by process improvement guided by strategic goals. The derived organizational structure that best implements streamlined and effective processes, which are bonded firmly to strategic goals, is generally viewed as the best and most suitable structure for both private- and publicsector organizations. This appendix describes insights gained from both academic and management literature.

\section{From Academic Literature, We Derive Key Factors to Consider in the Design and Analysis of Major Headquarters Activities}

Key principles underlying the fundamentals of organizational design and structure have not changed significantly over the years. Henry Mintzberg offers some of the most recent comprehensive insights on the elements of an organization and how they vary based on the makeup of the workforce, the type of work, and the work product being delivered. As a result, we used Mintzberg's research as the starting point for how to view organizational design. Several Mintzberg disciples expound further on his work, but neither they nor he goes as far as defining the optimal organizational design. In fact, they suggest there is no optimal organizational design. Instead, they offer a view of the factors that should be considered when designing an organizational structure. We identified several key insights from the literature and discuss them in more detail below:

- Organizations generally consist of five components, the design of which will vary based on the type of work product, the makeup of the workforce, the external factors affecting the work product, and other factors. ${ }^{1}$

- Staff type activities (embodied in two of the five organization components) are important to shaping the regulations that govern workflow, managing the work production, and harmonizing the entire organization to mission accomplishment. ${ }^{2}$

\footnotetext{
${ }^{1}$ See Mintzberg, 1982, p. 325. Mintzberg refers to these and other factors as design parameters, which influence overall structure of the organization and its five components.

${ }^{2}$ Mintzberg, 1982, pp. 323-324.
} 
- Four primary elements should be considered when settling on an organization structure: division of labor, design of formal reporting relationships, design of additional coordinating mechanisms, and design of personnel management systems. ${ }^{3}$

Components of an Organization and Their Design Relative to the Type of Work and Organization

Mintzberg argues that there are five basic components to an organization. We highlight the different components of the organization to point out those that are considered management headquarters elements and the importance of those elements in the context of the work product. Those components, depicted in Figure D.1, include the following:

- Strategic apex: the most senior leadership in the organization

- Operating core: the people that accomplish the work of the organization

- Middle line: the people that exist between the strategic apex and the operating core and manage the operating core

- Support staff: the staff personnel that provide service necessary to the organization but not directly tied to the work product

- Technostructure: the staff personnel that perform analysis and design the regulations and systems that govern and control the work flow. ${ }^{4}$

Figure D.1. Mintzberg's Elements of an Organization

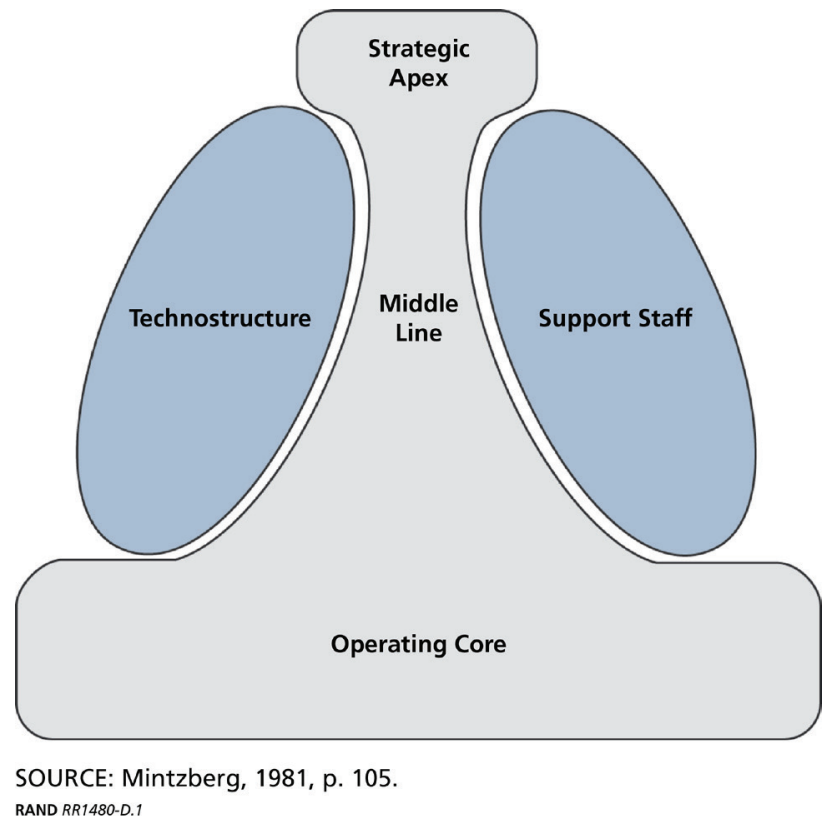

${ }^{3}$ Don Snyder, Bernard Fox, Kristin F. Lynch, Raymond E. Conley, John A. Ausink, Laura Werber, William Shelton, Sarah A. Nowak, Michael R. Thirtle, and Albert A. Robert, Assessment of the Air Force Materiel Command Reorganization: Report to Congress, Santa Monica, Calif.: RAND Corporation, RR-389-AF, 2013, p. 25.

${ }^{4}$ Henry Mintzberg, “Organization Design: Fashion or Fit?” Harvard Business Review, January 1981, p. 104. 
In the context of the mandated 20-percent reductions, the strategic apex, support staff, and technostructure would be considered management headquarters.

In addition to decomposing the structure of an organization into five components, Mintzberg describes five types of structures, each with different purposes and associated sizes of the five components. The different structures are as follows:

- Simple structure: This is basically a large unit with a few top managers and a group of operators who do the basic work. An example would be an entrepreneurial company.

- Machine bureaucracy: Most common among large, mature, mass-production companies (such as automobile manufacturers), this structure develops a bureaucracy that designs and maintains systems of standardization of processes for generally lower-skilled workers.

- Professional bureaucracy: More common among hospitals and universities, this structure is appropriate when trained professionals perform the organization's tasks, and so the bureaucracy tends to rely on standardization of skills rather than processes.

- Adhocracy: A fluid structure in which "power is constantly shifting, and coordination and control are by mutual adjustment through the informal communication and interaction of competent experts." Mintzberg thinks this structure is appropriate for the aerospace industry, think tanks, and film-making.

- Divisionalized form: This is less an integrated organization than a "set of independent entities joined together by a loose administrative overlay." An organization "divisionalizes" when its products are diversified.

Mintzberg highlights that the size and structure of the various components will vary based on the type of organization. He points out that no one specific design of the five components fits every organization, but when an organization is classified as one of the five basic structures, the size of the various components will generally conform to the design he describes for each type. For example, a professional organization with a highly trained staff at the operating core typically requires a smaller technostructure to manage and guide its work product. ${ }^{7}$ Conversely, a machine bureaucracy with a less professional, perhaps blue-collar, workforce relies heavily on a larger technostructure to manage product quality, workflow scheduling, and adherence to standards. ${ }^{8}$ Mintzberg comments that the divisionalized form provides for some degree of autonomy within the divisions, guided by performance measures established by the technostructure at the headquarters. ${ }^{9}$

In extending this concept to the Air Force, it is useful to think of the Air Force as a collection of different types of organizations or enterprises working together under the Air Force

\footnotetext{
${ }^{5}$ Mintzberg, 1981, p. 111.

${ }^{6}$ Mintzberg, 1981, p. 110.

${ }^{7}$ Mintzberg, 1981, p. 109.

${ }^{8}$ Mintzberg, 1981, p. 108.

${ }^{9}$ Mintzberg, 1981, p. 110.
} 
divisionalized form. For example, the operation commands within the Air Force might be classified as machine bureaucracies, or perhaps as divisionalized forms within the corporate Air Force divisionalized form. With its current center structure, AFMC might be viewed as a divisionalized form containing a mix of professional bureaucracies (AFLCMC) and machine bureaucracies (Air Force Sustainment Center, Air Force Nuclear Weapons Center, Air Force Test Center), and adhocracies (Air Force Research Laboratory). We make this point to suggest that when considering the appropriate size of the management headquarters, one size does not work for all, and careful consideration should be given to the type of work being performed by each MAJCOM, the Air Staff, and the Air Force Secretariat. Figure D.2 presents Mintzberg's notion of a divisionalized form (that is, the Air Force), modified to reflect a divisionalized form comprising different types of subordinate organizations (that is, MAJCOMs) within it. ${ }^{10}$ Again, the point is that no single structure is appropriate for the various types of MAJCOMs within the Air Force. However, as we learn from management literature and discuss below, the process for determining the most appropriate organizational design is important. Chapter Three discussed how the Air Force used sound practices in implementing the five-center construct within AFMC. The design of this construct follows the notion of the higher-level MAJCOM (AFMC) representing a mix of machine and professional bureaucracies.

Figure D.2. A Divisionalized Form Comprising Different Types of Subordinate Divisions

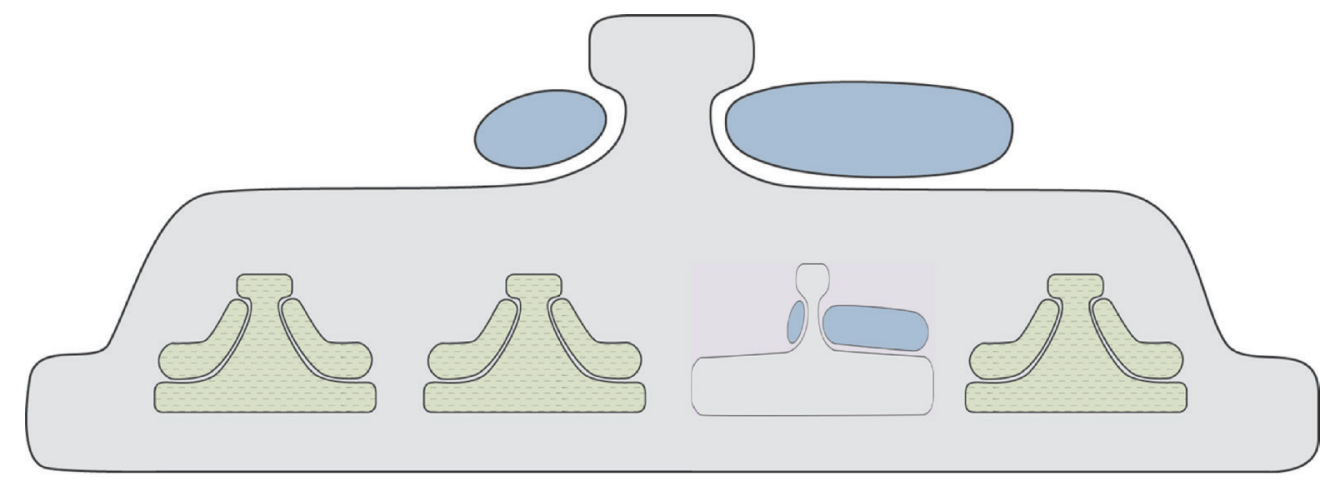

SOURCE: Mintzberg, 1981.

RAND RR1480-D.2

\section{Elements to Consider for Designing an Organizational Structure}

The academic literature highlighted several key factors that need to be considered in designing an organization. The factors that were relevant to management headquarters reductions were division of labor, design of formal reporting relationships, and design of coordinating mechanisms.

\footnotetext{
${ }^{10}$ Mintzberg suggests that a machine bureaucracy is the type of structure that works well within a divisional form; however, he offers that the divisions can be any one of the five basic structures he presents.
} 
Division of labor is how the work gets performed, for both services and products. These work activities influence how work units are grouped and organized to achieve the organization's strategy and derived strategic goals. Likewise, the quantity of service or rate of the production cycle and units produced dictates the size of the workforce, its organization, and the supporting components required to effectively operate. The structure and size of the various support components (i.e., the technostructure and support staff) will vary based on the complexity of the work product and the makeup of the workforce, but on the whole, the larger the number of people in the organization, the larger the support components. According to research in the Strategic Management Journal, "The absolute size of the corporation is a key determinant of the size of corporate headquarters. Regardless of whether policy variables are included or not, the number of employees is a highly significant determinant of the proportion of staff employed in corporate headquarters." 11

The span of control (the number of people reporting to individual managers) dictates the design of formal reporting relationships and levels of hierarchy needed to ensure that span of control is neither too large nor too small. There are limits to the number of people a single supervisor can directly manage. Unit size, therefore, is somewhat constrained by the need for direct supervision and the number of supervisors required. The type of work and amount of standardization possible in the work processes will determine the most efficient span of control for each manager and, to an extent, the echelons required above the first-line supervisor.

The design of coordinating mechanisms is another factor that must be addressed when considering organizational design. Design of coordinating mechanisms includes the amount of standardization involved with each unit of work, centralization of decisionmaking rights, and lateral linkages, both within and outside the organization. ${ }^{12}$ With respect to the relationship between span of control and coordinating mechanisms, Mintzberg highlights that as the coordination in a unit is increased through the systems of standardization designed by the technostructure, the less time its manager needs to spend on the direct supervision of each employee, and thus the greater the number of employees that can report to him. ${ }^{13}$ Mintzberg also addresses span of control as it relates to the standardization of skills of the employees within the unit. He highlights that the more highly trained the employees, the less supervision they require, which also allows for a larger work unit. ${ }^{14}$

When we consider Mintzberg's view on the design of coordinating mechanisms in the context of the management headquarters reduction, we can again conclude that no single structure for management headquarters in the Air Force can be applied across the board, in large

\footnotetext{
${ }^{11}$ Collins, Young, and Goold, 2007, p. 293.

12 Snyder et.al., 2013, p. 25.

${ }^{13}$ Mintzberg, 1982, p. 67.

${ }^{14}$ Mintzberg, 1982, p. 67.
} 
part because of the differences in the roles, responsibilities, and work force makeup for different MAJCOMs. ${ }^{15}$

\section{From Management Literature, We Learn the Importance of Taking a Process-Based Approach in Applying Organizational Design Considerations}

As mentioned above, the academic literature describes the factors to consider when structuring an organization to efficiently produce the desired work product. What we gain from the management literature are ideas on how to approach applying the organizational design considerations.

There is no single solution for how to apply these factors in the design of an organization. Variations in organizational size, complexity, type of work, and type of workforce all affect the solutions chosen. What is important is the role that corporate strategy and process reengineering play in determining corporate structure. Collins, Young, and Goold make this point in the following excerpt:

It is apparent that in the design of corporate headquarters, "one size fits all" is a flawed approach. Benchmarking can be valuable, but only if it is with firms that are pursuing similar corporate strategies.

Our research does not reveal a single set of best practices to which all corporations should aspire. Rather, it indicates that senior executives need to decide precisely how their corporate strategy adds value to the businesses in their portfolio and determine what policies and staffs are needed to exploit those specific sources of value.

Each corporate function should then be reviewed to assess its role in adding value, with the ground rule that activities that lack an added-value rationale should be curtailed. ... The end result should be a headquarters that delivers on the added-value components of the chosen corporate strategy, but which may well bear little resemblance to other superficially similar companies that follow different strategies. ${ }^{16}$

Process reengineering guided by commonly understood strategic goals is critical to effectively structuring organizational components. Studying the organization's processes enables better identification of opportunities to centralize decisionmaking, reduce redundancies, and

\footnotetext{
${ }^{15}$ Mintzberg's discussion on organizational design highlights the factors that have to be considered when making the structure of the organization operate effectively and efficiently to produce the work product. Even within two organizations designed on a professional bureaucracy structure, the design of coordinating mechanisms and lateral linkages, unit size and span of control, and liaison devices may all still vary. One organization might operate using more-formalized liaison devices (e.g., structured teams), while another may use less-formalized devices (e.g., matrixed functions).

${ }^{16}$ Collins, Young, and Goold, 2007, p. 402.
} 
eliminate work that is not value added. The most efficient way of structuring is to ensure that processes are streamlined and efficient, decisionmaking is at the lowest level in the organization that is appropriate for the category of decisions, and leadership remains committed and thoroughly engaged. R. M. Tomasko thinks that organizational alignments should follow process reviews that best implement these process improvements and modifications:

The real issue is not so much the specification of a new, innovative configuration each company must adopt, but outlining a path each business can follow to invent its unique organizational form. The exact shape may be less important than the process used to discover it. ${ }^{17}$

With respect to the directed 20-percent management headquarters reduction, the following are our takeaways from management literature:

- Define the organization's strategy and set goals in line with that strategy. The leadership of the organization is responsible for defining the strategy, and this activity is one of the main responsibilities of any organization's headquarters. When taking on an effort to reengineer the organizational structure and processes, it is necessary to define the strategy behind that effort as establishing measurable goals.

- Look at the processes in the organization from top to bottom and use talented, knowledgeable people chartered to do a process review. The process review should be clearly anchored to the strategy being followed.

- When considering process reengineering, garner insights from employees at every level. No one knows the process better than the people performing their part of the established process. Dictating process change from the top down not only may risk breaking a critical process but also may engender workforce resentment, hostility, and apathy toward this and any future process reviews.

- During process review, look into the where, what, how, and why of decisionmaking. Through benchmarking other similar organizations, a comparison can be analyzed to determine the appropriate level at which decisions can and should be made. The standard rule of thumb with organizations is that the lower the decisions are made, the flatter the organization can be. Authorities for levels of decisionmaking should be examined to see whether it is appropriate to lower the echelon in which decisions are made. This step is very applicable to delayering actions. Increasing speed, decreasing internal friction, motivating people, and bettering performance are all expected outcomes of driving decisionmaking lower in the organization.

- Build in measurable performance factors that relate to the strategy and established goals. Failure to measure properly limits the ability to determine whether changes are achieving the desired effects or whether additional adjustments are needed.

- Remember that no defined size or structure is an absolute when it comes to headquarters design.

\footnotetext{
${ }^{17}$ R. M. Tomasko, “Restructuring: Getting It Right,” Management Review, Vol. 81, No. 4, 1992.
} 



\section{Appendix E: Findings from Industry}

In addition to reviewing academic and management literature, RAND was asked to compare the methodology and approach used by the Air Force with government and industry best practices. As a part of our comparison, we interviewed six companies, many considered worldclass firms, regarding their recent reorganization experience. This section summarizes our interview process and findings.

There are no commercial companies that are directly comparable to the United States Air Force in terms of size and scope. With that in mind, we primarily targeted for interviews large Fortune 100 firms based on recently published reports that they had reorganized their enterprises. In addition, we contacted smaller companies that had undertaken extensive reorganization with specific focus on streamlining headquarters and support functions against their direct line and "customer-facing" units. Given the very short time frame for this study, we selected companies based on recent reorganization experience, size, and availability.

In order to identify which organizations to contact, we first conducted a literature search to identify companies that were reported to have reorganized or had large reductions in workforce. We subsequently reviewed that list and targeted companies that focused their reorganization or reductions on headquarters activities or support staff. We then down-selected to companies that represented sectors or industries that were similar to major organizations within the Air Force enterprise. By contacting a range of companies across a variety of industries, as well as companies differing in size and purpose, we developed a broad-based sample of how commercial organizations approach a reorganization effort. Industries represented in our sample included consumer goods, airlines, health care, retail, financial services, and manufacturing.

To guide our discussions with companies, we developed a structured protocol, which is included at the end of this appendix. The protocol began with a brief summary of the purpose of the interviews and a guarantee of confidentiality. Specific questions were developed to identify aspects of reorganizations that might help the Air Force improve the outcomes of future reorganizations. We sent the protocol to prospective interviewees prior to speaking with them.

We found that company reorganization approaches varied, with some commonalities. Headquarters reshaping was guided by many different objectives. For some, their corporate strategy had changed and they wanted to reposition the company for future direction or growth (for example, shifting regional focus) or for changing requirements (for example, different skills needs). Others sought process improvements and new technology investments. Even for those firms that did not undertake specific targeted management headquarters analyses, all reorganizations resulted in a change in headquarters function and size based on the line changes and reduction or realignment of staff. 
Some companies reorganized after bankruptcy or mergers, in which case the reorganization process was defined by regulators, such as the conservator or court that directed the bankruptcy process. Others created a "burning platform" - that is, a situation where employees realized they had to change and change fast or the company would face serious problems, declare bankruptcy, or go out of business. The burning platform for change in the companies interviewed ranged from bankruptcy and mergers to changes in governmental regulation and other customer-driven needs. The final structure was often a result as opposed to an upfront plan of reorganization efforts. The new operational architectures were focused on enhancing support planning, execution, and monitoring processes.

The goals of the reorganizations also varied. Some companies sought to reduce duplication of effort and other redundancies. Others sought to eliminate or reduce non- or low-value-added layers of bureaucracy, management (for example, redefine spans of control), or processes. Some companies sought more agility and speed to adapt to a rapidly changing commercial environment, and some sought to eliminate support overhead costs. Some companies wanted to clarify roles and responsibilities or more clearly delineate processes. Others sought to realign corporate efforts to new or changing customer needs. Some companies focused on reducing labor costs as the main success criterion for the reorganization.

One of the companies we interviewed called out a specific focus on headquarters versus line and support unit reduction for reorganization targeting. The organizational metric used in that case was the Operating Expense Ratio, which compares income to the costs to operate a particular business unit. The required operational activities were matched against the cost to execute those activities. As with most organizations, labor costs (specifically burdened rates that include salary/wages and benefits) made up the bulk of costs. They were looking for opportunities to rebalance the resources to support operations in the new merged environment while improving effectiveness, reducing costs, and eliminating redundancies. They used the preexisting Operating Expense Ratio rates in the two merging entities as a baseline while targeting the industry standard as the metric of success for the combined organization.

All interviewees established a temporary reorganization strategy team to lead their reorganization effort. They typically had a senior executive committee creating the strategy and providing direction and oversight. The committee usually included senior leaders of the affected functions, units, or work-streams being reorganized. Support teams then conducted execution of the reorganization with oversight by the executive committee.

Firms used different methods to reduce personnel; however, all companies focused on strategic and operational-level process review. Some tailored reduction methods to specific functions (for example, technology insertion, process reengineering). To determine the current organizational state and judge success after the reorganization, several of the companies used an evaluation methodology and historical standards for span of control and organizational layers. Using such historical archives, they evaluated current organizational structure as a baseline. A major focus of the cost-cutting effort was realigning the appropriate number of direct reports to 
managers and reconfiguring business units to ensure that the spans of control and departmental layers followed industry best practices. Although industry standards were targeted, internal mitigating factors were considered to customize the final organizational structure to ensure that business needs continued to be met.

The majority of companies interviewed used outside consulting firms, with varying levels of satisfaction, to advise and help them with reorganization. The primary reason for using external firms was the in-depth knowledge that the consulting firm brought to the table while also freeing up the internal executives to continue running the business during the reorganization process.

Many of the respondents did not use any specific methods from formal organizational design theories. The consulting firms generally brought in their own proprietary methods that were probably derived from organizational design theory and modified based on the firm's past practices and historical findings.

Our interviews found that substantial up-front strategy planning preceded the most successful reduction efforts. The time spent on up-front planning and strategy development was found to be at least partially dependent on the reason for the reorganization. The strategic and up-front planning ranged from about three months to one-half of the entire reorganization process time.

Those reorganizations that were mergers emphasized reducing redundancies, identifying best practices of each entity to preserve, and realigning into a successful combined entity. Those that were bankruptcies emphasized labor cost (that is, headcount) reduction and business process realignment. Those that were market-driven reorganizations emphasized customer-driven global reposturing and new business processes and appeared to enable the most flexibility in reorganization methods. All indicated that, without careful planning, reorganizations could lead to disruptions in performance and productivity.

One firm interviewed paid special attention to targeting personnel to keep (key personnel) and those to leave (for example, poor performers and those close to retirement). They stated that providing good communication and incentive packages allowed them to achieve most of the reductions through voluntary severance and retirement. Employee satisfaction, a measure of reorganization success measured annually, was rated higher after the reorganization.

When asked what they would do differently during their next reorganization, some said that inadequate up-front strategy planning led to midstream regrouping. One said that missing top leadership resulted in failure of the reorganization. If consultants are used, one interviewee said to make sure to have a strategic plan to guide the engagement, while another recommended bringing the consultants in earlier in the process. Another firm said that rushed workforce communications resulted in conflicting messages that had to be deconflicted. Another said that poorly planned voluntary exits led to unexpected and excessive loss. Several identified the need for targeted incentives to prevent key personnel loss during the reorganization. One firm identified insufficient training for new processes. Lastly, some companies underestimated the organizational "pain" associated with the reductions. 
All of the companies were asked to describe "lessons learned" and what they would determine to be "best practices." We outline the results in Tables E.1 and E.2, respectively.

Table E.1. Interviewee Lessons Learned

\begin{tabular}{lll}
\hline Category & \multicolumn{1}{c}{ Issue } & \multicolumn{1}{c}{ Effect } \\
\hline Leadership & Missing top leadership & Failure of the reorganization \\
Strategy & Inadequate up-front strategy & Midstream regrouping \\
& Using consultants & $\begin{array}{l}\text { Necessity to develop a strategic plan and bring } \\
\text { consultants in early }\end{array}$ \\
& Poorly planned voluntary exits & Excessive loss \\
& Use targeted incentives & Prevention of key personnel losses \\
Rommunication & Rushed communications & Conflicting messages \\
Execution & Insufficient training for new & Failure of the new process and/or new talent \\
& Undecesses & \\
& associated with the reductions & $\begin{array}{l}\text { Decreased workforce morale, possible negative } \\
\text { corporate reputation, and increased resistance for } \\
\text { future organizational change }\end{array}$
\end{tabular}

Table E.2. Interviewee Common Practices

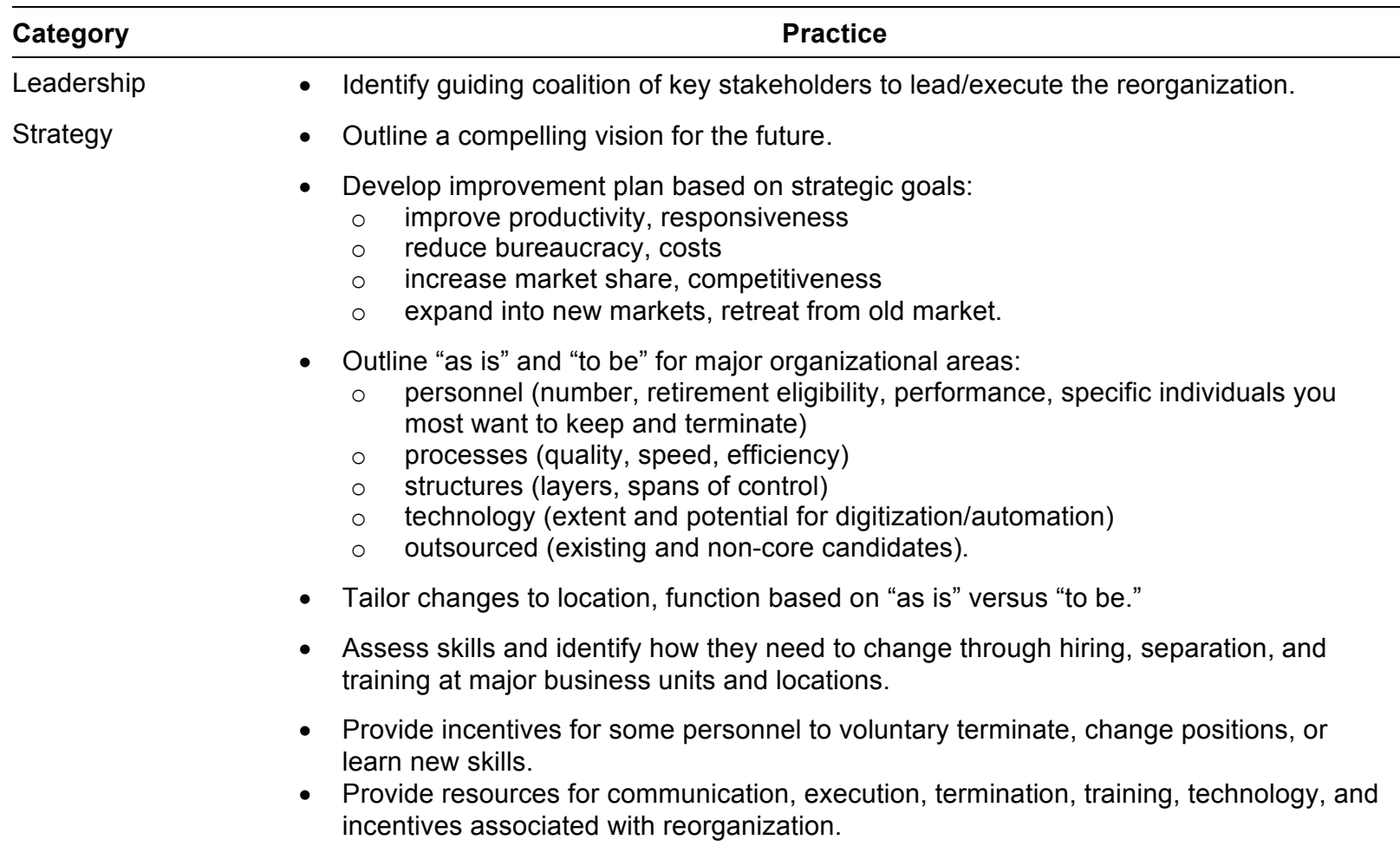


Table E.2-Continued

\begin{tabular}{ll}
\hline Communication & Develop a case for reorganization that helps personnel see and believe in the change. \\
- & $\begin{array}{l}\text { Provide sustained communication of the case for change and the vision of the future } \\
\text { and what it means for personnel. }\end{array}$ \\
Execution & Execute the reorganization plan in phases. \\
- & Monitor implementation of each phase and adjust plans as feedback is obtained on \\
results, based on agreed-to metrics for success.
\end{tabular}

\section{Interview Protocol for Commercial Companies}

The U.S. Congress has mandated personnel cuts in DoD headquarters. The Deputy Chief Management Officer of the Secretary of the Air Force (also the Director of Business Transformation) has asked RAND to help the Air Force identify ways to effectively and efficiently target and reduce headquarters personnel without adversely affecting mission and execution.

The purpose of this interview is to obtain your knowledge and perspective on ways to identify headquarters positions to eliminate without adversely affecting mission and execution. In this regard, we are interested in your experiences with planning and executing headquarters personnel reductions.

Your participation in these interviews is voluntary. The Air Force knows that we are interviewing commercial companies but not which ones we interview, and we will not identify or link responses to specific firms or individuals. Rather, we plan to synthesize our findings from themes that run across interviews.

\section{Background}

Please tell us about your current position and experience.

\section{Experience with Reorganization and Downsizing}

1. Please describe your company's recent experience with reorganization and downsizing.

a. Has it had multiple efforts? If yes, how many?

i. Where was each effort focused?

ii. Did each effort lead to more or fewer personnel?

iii. How were personnel changes distributed after each effort between

- headquarters and operational units?

- management/overhead and operations?

b. What was the motivation and purpose of each effort? What were the goals?

i. Were efforts driven by changes in strategy?

c. How was each effort organized and led?

i. What key stakeholders were involved and what were their roles? 
d. How much time was spent on advanced planning of each effort?

e. How were specific organizations, processes, or positions identified for improvement?

i. What, if any, organizational approaches were used (for example, lean, reengineering)?

f. Were external consultants used to support the effort? If so, what were their roles and levels of effort?

g. How was progress and success measured?

h. Did you identify other areas for future reorganization or downsizing during the process? If so,

i. What kinds of additional improvements did you find?

ii. Why didn't you do them at the time?

\section{Lessons Learned}

2. What would your company do differently to improve outcomes if it reorganized or downsized again? 


\section{Appendix F: Navy and Army Approaches to Reductions}

Time constraints did not allow a detailed analysis of the approaches used by other organizations to achieve the 20-percent headquarters reductions, but the Section 904 Report, a review of some service memoranda, and brief interviews with personnel involved with the reductions provided some useful background for the Navy and Army.

\section{Navy}

Shortly after Secretary Hagel directed the 20-percent cuts, the Navy began examining authorizations that were supposed to be counted as management headquarters activities - those with PECs ending in 98. Every Navy headquarters organization has what is called a budget submitting office, and discrepancies were discovered between what the offices self-reported and what was reported in the Navy's Program Budget Information System. As very general examples, some geographic commands reported that they had no PEC 98 positions at all; some system commands - which are responsible for the design, construction, and maintenance of military systems - with tens of thousands of personnel reported having very few management positions.

As a result, the programming division of the Office of Naval Operations (N-80) started asking more questions of the commands about who they considered to be in headquarters positions, and, after considerable debate with budget submitting offices and resource sponsors, developed a "broadened" baseline of headquarters personnel that included authorizations that were not coded with PEC 98.

Ultimately, as described in the Section 904 Report, the Navy "shifted the burden" of reductions to nondeployed/nonoperational forces as a means to balance the risk of making the headquarters reductions. Fleet Forces Command, U.S. Pacific Fleet, and Navy Component Command headquarters were allocated 5-percent cuts. The Office of Naval Operations, Naval Sea Systems Command, Naval Air Systems Command, Space and Naval Warfare Systems Command, Bureau of Naval Personnel, Naval Supply Systems Command, Naval Facilities Engineering Command, Reserve Forces, Naval Education and Training Command, and Naval Research Headquarters took 20-percent cuts. Because the system commands have larger budgets, the Navy was able to achieve the 20-percent funding reduction despite the different percentages applied. ${ }^{1}$

\footnotetext{
${ }^{1}$ Information up to this point in this section is from a November 17, 2015, telephone discussion with a subjectmatter expert in the Office of Naval Operations, Programming division. The comment about different percentages being applied to different organizations is also in the Section 904 Report (DoD, 2015). Recall that cuts in military
} 
This approach caused "additional pressure to be placed on other staffs to compensate for the protection of the fleets," but Navy savings were expected to be \$33 million in FY 2015, and totaling \$873 million across FYs 2015-2019. The reduction in staff size included military, civilian, and contractor personnel; flexibility was allowed for how each headquarters applied reductions, as long as targets were met. ${ }^{2}$

Unlike the Air Force, the Navy planned its reductions over a five-year period. It achieved its planned reductions for FY 2016, but a new risk assessment led it to "buy back" some of the planned reductions for FY 2017.

\section{Army}

Well before the Secretary of Defense's 20-percent reduction mandate, the Secretary of the Army and the Chief of Staff of the Army had established a working group to determine the positions that should be considered part of headquarters staffs and to study ways to reduce staff sizes. As was the case with the Air Force and the Navy, it was discovered that some positions that are not technically part of headquarters were coded as being so, and vice versa. For example, several years ago, the Army funded 400 positions for its Sexual Harassment/Assault Response and Prevention Program. Two of them went into the headquarters Army Chief of Chaplains office. They had been mistakenly recorded as headquarters positions even though they did not perform a headquarters function. ${ }^{3}$

Army analysis of headquarters positions took about a year; it started before the July 2013 memo directing the 20-percent reductions, and finished after it was released. During this period, the Army Chief of Staff had been looking at cuts in lower-level organizations (led by two-star staff), as well as higher headquarters. Internally, they made cuts in U.S. Army Forces Command. However, the Army did not try to take credit for cuts it did not feel should be counted for the 20percent reductions. Corps-level organizations have warfighting functions, so cuts there would not be claimed as part of the 20-percent cuts.

The review group made suggestions to the Chief of Staff; most cuts were in the range of 20 to 25 percent, and the plan was to take them over five years (one-fifth of the cuts per year), as

\footnotetext{
personnel do not contribute to dollar savings. The comment implies that there were some military-only staffs that were cut by 5 percent, while other organizations that included civilian and contractor authorizations were reduced by 20 percent or more in order to achieve the overall 20-percent funding reduction.

2 See Barry Bruner, Director of Programming, "Navy FY 2015 Budget: Stewardship," memorandum, March 18, 2014. The savings described in this memorandum are lower than what is stated a year later in the Section 904 Report, where the Navy indicated that it will save \$1.149 billion over the FYDP, but given the time between the documents, differences are to be expected.

${ }^{3}$ Unless otherwise noted, this discussion is based on Department of the Army Headquarters, Office of the Deputy Chief of Staff for Personnel staff, interview with the authors, November 18, 2015.
} 
allowed by Secretary Hagel's direction. The cuts varied by area of responsibility; in the Pacific, cuts were about 14 percent, and in Europe, they were about 40 percent.

According to subject-matter experts in the Office of the Deputy Chief of Staff for Personnel (G-1), there was no "affirmative" approach to making the cuts beyond taking advantage of natural attrition. While reductions applied to authorizations, the impact on people would depend on managerial decisions. As people leave, managers in headquarters staffs will make the decision about whether they should be replaced. This approach is aided by the fact that the Army will reduce its force structure by 40,000 military and 17,000 civilians by FY 2019. In the Section 904 Report, the Army said that, compared with the baseline of FY 2018 in the FY 2014 PB, it achieved FY 2015 reductions of 400 civilian full-time equivalents, 275 military authorizations, and $\$ 44$ million.

The Army hired a consulting group after it had determined its initial 20-percent cuts, and the group used a delayering approach to explore the possibility of making further cuts. This approach focuses on increasing the span of control of managers (having a minimum of eight people reporting to them) and reducing the number of "echelons" of management between the head of an organization and the people doing the work (a maximum of seven layers). According to G-1, this approach alone did not enable further reductions - at least at the Department of the Army Headquarters level. ${ }^{5}$

However, after the initial reductions were programmed, the Secretary of the Army directed in July 2014 that a more detailed review be conducted to optimize the size, roles, functions, missions, and organizational structure of headquarters in order to support Army missions within budget constraints and end strengths. ${ }^{6}$ A memorandum issued in June 2015 indicated that the review established a goal to achieve a 25-percent manning reduction in all Army two-star-level headquarters and above, including Headquarters, Department of the Army and its FOAs. However, the baseline for the 25 -percent reduction was not specified. ${ }^{7}$

The same consulting group was employed to develop an approach to accomplish these reductions, and the Army believes that the resulting recommendations will achieve the 25percent reductions by FY 2019. ${ }^{8}$

\footnotetext{
${ }^{4}$ Lopez, 2015.

${ }^{5}$ Delayering alone produced savings of 8 to 10 percent. Greater savings required additional actions, such as reducing the number of contractors used for staff work by about 30 percent. See U.S. Army, 2014.

6 John M. McHugh, Secretary of the Army, "Comprehensive Review of Headquarters, Department of the Army (HQDA)," memorandum to Principal Officials of Headquarters, Department of the Army, July 17, 2014.

7 Odierno and McHugh, 2015. An Army briefing indicates that the baseline for the 25-percent reduction was FY 2015 (U.S. Army, "HQDA Delayering: Executive Summary for United States Air Force,” briefing slides, June 19, 2015a).

${ }^{8}$ Odierno and McHugh (2015) directs that the delayering recommendations be implemented. The U.S. Army briefing discusses the principles used in designing the approach to reductions (U.S. Army, 2015a).
} 
In DoD's February 2015 budget request, the Army asserted that for all Army headquarters (two-star and above), actual authorizations were reduced at least 20 percent in FY 2016, and noted that it would comply with further directed reductions by FY 2019. ${ }^{9}$

${ }^{9}$ Office of the Under Secretary of Defense (Comptroller), 2015, pp. 3-5 and 8-9. 


\section{References}

Blau, Peter M., "The Hierarchy of Authority in Organizations," American Journal of Sociology, Vol. 73, No. 4, 1968.

Bruner, Barry, Director of Programming, "Navy FY 2015 Budget: Stewardship,” memorandum, March 18, 2014. As of December 31, 2015:

http://navylive.dodlive.mil/2014/03/18/navy-fy15-budget-stewardship/

Carter, Ashton B., Deputy Secretary of Defense, “20\% Headquarters Reductions,” memorandum, July 31, 2013.

Collins, D., D. Young, and M. Goold, “The Size, Structure, and Performance of Corporate Headquarters," Strategic Management Journal, Vol. 28, No. 4, 2007, pp. 383-405.

Daft, Richard L., Organization Theory and Design, 9th ed., Mason, Ohio: Thomson SouthWestern, 2007.

Dalton, Dan R., William D. Todor, Michael J. Spendolini, J. Fielding Gordon, and Lyman W. Porter, "Organization Structure and Performance: A Critical Review, " Academy of Management Review, Vol. 5, No. 1, 1980.

Damanpour, Fariborz, "Organizational Innovation: A Meta-Analysis of Effects of Determinants and Moderators," Academy of Management Journal, Vol. 34, No. 3, 1991, pp. 555-590.

DoD_See U.S. Department of Defense.

Everstine, Brian, "McCain Calls for Air Force Headquarters Layoffs," Air Force Times, March 25, 2015. As of November 12, 2015:

http://www.airforcetimes.com/story/military/pentagon/2015/03/25/mccain-letter-james-airforce-headquarters-cuts/70426300/

Fanning, Eric K., Under Secretary of the Air Force, "Staff Reduction, Your Apr 23, 2013 Memo," memorandum for the Deputy Secretary of Defense, May 3, 2013.

— "Future Air Force Organization: Implementation of HAF Decisions," memorandum to all MAJCOMs, FOAs, and DRUs, October 3, 2014.

Fanning, Eric K., Under Secretary of the Air Force, and Larry O. Spencer, Vice Chief of Staff of the Air Force, "Future Air Force Organization: Headquarters Air Force (HAF)," memorandum, April 11, 2014a.

- "Future Air Force Organization: Headquarters Air Force (HAF) Round 2," memorandum, July 16, 2014 b. 
Fanning, Eric K., Acting Secretary of the Air Force, and Mark Welsh, Chief of Staff of the Air Force, "Future Air Force Organization," memorandum to Larry O. Spencer, Vice Chief of Staff of the Air Force, July 23, 2013.

Galbraith, Jay R., Organization Design, Reading, Mass.: Addison Wesley Publishing Company, 1977.

Gorenc, Frank, Assistant Vice Chief of Staff and Director of Staff of the Air Force, and Tim Beyland, Administrative Assistant to the Secretary of the Air Force, "State of the HAFOrganization Design,” memorandum, May 15, 2013.

Hagel, Chuck, Secretary of Defense, "Statement on Strategic Choices and Management Review," July 31, 2013. As of December 13, 2015: http://www.realcleardefense.com/articles/2013/07/31/statement_on_strategic_choices_and_m anagement_review_106730.html

Haux, Hailey, "SAF/US(M) Becomes SAF/MG," Secretary of the Air Force Public Affairs Command Information, December 4, 2015. As of January 16, 2016 : http://www.af.mil/News/ArticleDisplay/tabid/223/Article/632642/safusm-becomessafmg.aspx

Lopez, C. Todd, "Army to Realign Brigades, Cut 40,000 Soldiers, 17,000 Civilians," U.S. Army News Archives, July 9, 2015. As of January 12, 2016:

http://www.army.mil/article/151992/Army_to_realign_brigades_cut_40_000_Soldiers_17 _000_civilians/

McCain, John M., Chairman of the Senate Armed Services Committee, letter to Deborah Lee James, Secretary of the Air Force, March 24, 2015.

McHugh, John M., Secretary of the Army, "Comprehensive Review of Headquarters, Department of the Army (HQDA)," memorandum to Principal Officials of Headquarters, Department of the Army, July 17, 2014.

Mihm, J., C. H. Loch, D. Wilkinson, and B. A. Huberman, "Hierarchical Structure and Search in Complex Organizations," Management Science, Vol. 56, No. 5, 2010, pp. 831-848.

Miller, Danny, "Environmental Fit Versus Internal Fit," Organization Science, Vol. 3, No. 2, 1992, pp. 159-178.

Mills, Patrick H., John G. Drew, John A. Ausink, Daniel M. Romano, and Rachel Costello, Balancing Agile Combat Support Manpower to Better Meet the Future Security Environment, Santa Monica, Calif.: RAND Corporation, RR-337-AF, 2014. As of February 15, 2016 : http://www.rand.org/pubs/research_reports/RR337.html

Mintzberg, Henry, The Structuring of Organizations: A Synthesis of the Research, 1st ed., Englewood Cliffs, N.J.: Prentice Hall, 1979. 
__ " “Organization Design: Fashion or Fit?" Harvard Business Review, 1981, pp. 103-116.

, Structure in Fives: Designing Effective Organizations, Longman Higher Education, 1982.

, Tracking Strategies: Towards a General Theory of Strategy Formation, New York: Oxford University Press, 2008.

Odierno, Raymond T., Chief of Staff of the Army, and John M. McHugh, Secretary of the Army, "Directive for Transition of Headquarters, Department of the Army to the Fiscal Year 2019 Organization Design," memorandum for Principal Officials of Headquarters, Department of the Army, June 11, 2015.

Office of the Administrative Assistant to the Secretary of the Air Force staff, email correspondence with the authors, December 10, 2015.

Office of the Secretary of the Air Force, "Air Force Council HQ Staff Reductions Compilation," briefing slides, August 26, 2014.

Office of the Under Secretary of Defense (Comptroller), United States Department of Defense Fiscal Year 2016 Budget Request: Overview, Washington, D.C., February 2015. As of January 7, 2016: http://comptroller.defense.gov/Portals/45/Documents/defbudget/fy2016/FY2016_Budget_Re quest_Overview_Book.pdf

Public Law 112-25, Budget Control Act of 2011, August 2, 2011.

Public Law 116-33, National Defense Authorization Act for Fiscal Year 2014, Section 904, paragraph a. As of December 7, 2015: http://www.gpo.gov/fdsys/pkg/PLAW-113publ66/html/PLAW-113publ66.htm

Snyder, Don, Bernard Fox, Kristin F. Lynch, Raymond E. Conley, John A. Ausink, Laura Werber, William L. Shelton, Sarah Nowak, Michael R. Thirtle, and Albert A. Robbert, Assessment of the Air Force Materiel Command Reorganization: Report for Congress, Santa Monica, Calif:: RAND Corporation, RR-389-AF, 2013. As of February 15, 2016: http://www.rand.org/pubs/research_reports/RR389.html

Spencer, Larry O., Vice Chief of Staff of the Air Force, "MAJCOM FY 2015 PB Headquarters Staff Billet Reduction," memorandum, July 6, 2014.

_- "Air Force Installation and Mission Support Center (AFIMSC) Operating Locations," memorandum to the AFMC commander and AF/A1, March 30, 2015.

Spencer, Larry O., Vice Chief of Staff of the Air Force, and Eric K. Fanning, Under Secretary of the Air Force, "Air Force Installation and Mission Support Center (AFIMSC) Operating Locations (OLs)," memorandum to the AFMC commander, August 28, 2014. 
Tillotson, David, Future Air Force Organizational Structure Status Update, briefing slides, Air Force Deputy Chief Management Officer, December 2, 2013.

Tomasko, R. M., "Restructuring: Getting It Right," Management Review, Vol. 81, No. 4, 1992.

Tushman, Michael L., and David A. Nadler, "Information Processing as an Integrating Concept in Organizational Design," Academy of Management Review, Vol. 3, No. 3, 1978, pp. 613624.

U.S. Air Force, "FY 15 PB Manpower Drivers," PowerPoint slides, undated.

- Air Force Management Headquarters and Headquarters Support Activities,

Washington, D.C., Air Force Instruction 38-202, March 1, 1995.

- Future Air Force Organization, background paper prepared for a leadership forum with the Office of the Under Secretary of the Air Force, Management, April 10, 2014a.

- Planning, Programming, Budgeting and Execution: Process and Organization

Whitepaper, draft, May 6, 2014b, not available to the general public.

—_, "20 Percent Mgmt HQ Redux, FY 2015 Review,” briefing slides, 2015a.

_-, Manpower and Organization: Programming USAF Manpower, Washington, D.C., Air Force Instruction 38-204, April 21, $2015 \mathrm{~b}$.

—_, "Major Headquarters Activities," briefing slides, September 22, 2015c.

U.S. Air Force AF/A1 staff, email correspondence with the authors, November 6, 2015.

U.S. Air Force Office of Legislative Liaison, "Management Headquarters Review Congressional Notification," memorandum, July 11, 2014, not available to the general public.

U.S. Army, "HQDA Organizational Assessment: Deliverable \#1: Draft Report, Task 3.2," briefing slides, February 14, 2014.

__ ,HQDA Delayering: Executive Summary for United States Air Force," briefing slides, June 19, 2015a.

—_, "HQDA Delayering: Executive Summary for the Office of the Secretary of Defense," briefing slides, July 14, 2015 b.

U.S. Department of Defense, Major DoD Headquarters Activities, Washington, D.C., Department of Defense Instruction 5100.73, September 10, 2009.

__ , “Air Force Changes Headquarters Manning, Organization,” DoD News, July 14, 2014. As of November 10, 2015:

http://www.defense.gov/News-Article-View/Article/602869

_- Plan for Streamlining DoD Management Headquarters: Section 904 Initial and Status Report to Congress, Washington, D.C., May 14, 2015. 
U.S. Government Accountability Office, DoD Needs to Better Oversee In-Sourcing Data and Align In-Sourcing Efforts with Strategic Workforce Plans, Washington, D.C., GAO-12-319, February 2012.

Willem, Annick, and Marc Buelens, "Knowledge Sharing in Public Sector Organizations: The Effect of Organizational Characteristics on Interdepartmental Knowledge Sharing," Journal of Public Administration Research and Theory, Vol. 17, No. 4, 2007, pp. 581-606.

Work, Robert O., Deputy Secretary of Defense, "Cost Reduction Targets for Major Headquarters," memorandum, August 24, 2015. 
RAND PROJECT AIR FORCE

\section{www.rand.org}

ISBN-10 0-8330-9428-9

ISBN-13 978-0-8330-9428-5

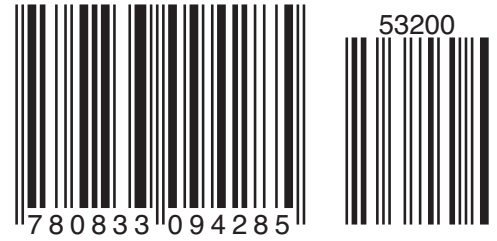

RR-1480-AF 